\title{
Setting the Conditions of Embodied Meaning-Making in Film: The Role of Film Style and Acting
}

The most powerful conveyor of meaning is the immediate impact of perceptual form.

The goal of this chapter is to examine how the building blocks of conceptual metaphor, as discussed in the previous chapter, can be manifested at the visual level of moving pictures. First, we lay out the two challenges that are inherent to the examination of this question, namely: (1) the challenge of demonstrating how image schemas may be imposed onto the iconic and representational level of films and (2) the challenge of demonstrating how moving pictures, in a non-verbal and metonymical way, may give rise to target domains to which these image schemas might be extended metaphorically. To each of these challenges the two subsequent parts of this chapter will propose an answer. The answer to the first challenge will be sought in the notion of film style. Using many examples taken from the films of Kubrick, we will show how film, through the application of various cinematic devices, may structure the reality in front of the camera in such a way as to elicit the ostensive appearance of image schemas. The answer to the second question will be sought in the notion of acting. Through an analysis of some of the performances in Kubrick's films, we will demonstrate how actors, through their body language, are able to convey the concepts of mental causation metonymically. It is only once we have successfully dealt with both challenges that we will be able to show, in the next chapter, how the films of Kubrick resort to these image schemas in order to flesh out the structure of mental causation visually.

\section{Image schemas and target domains: A twofold challenge}

In the previous chapter we used linguistic expressions for the purpose of showing how the conceptual structure of mental causation is embodied through the mechanism of metaphor. In these expressions it was not difficult 
to identify the two elements that make up the "a is b" relationship of metaphor. For instance, in a sentence such as "I'm in love," one can directly and unambiguously recognize the image schema and the target domain that are responsible for creating the metaphor. We arbitrarily use the words "in" and "love" to refer to the concepts of containment and love, because we have learnt to do so. Our shared knowledge about the code makes it easy for the communicator to represent them and easy for the reader to interpret them. However, if it is our goal to examine how the films of Kubrick communicate stories of mental causation visually and non-verbally, then, we have to examine how both elements can be elicited in moving pictures, not sentences. Moving pictures, however, do not share the arbitrary nature of language. As we already saw in the introduction, pictures, as opposed to words, bear a relationship to reality that is based on resemblance rather than on arbitrary convention, that is, they are iconic rather than symbolic. This, in turn, raised the question as to how the embodied conceptual nature of metaphor can be reconciled with the iconic nature of pictures. Given the two-fold nature of metaphor, any attempt to address this challenge amounts to answering two sub-questions: (1) How can moving pictures instantiate image schemas? and (2) How can moving pictures give rise, in a non-verbal way, to the conceptual target domains to which these image schemas can be extended metaphorically?

It is not hard to see how the second question may be resolved on an intuitive basis. As we saw in the previous chapter, abstract target domains may not only be accessed through metaphor, but also through metonymy. Metonymies, as opposed to metaphors, operate through source vehicles that refer to perceptually rich entities in the concrete world. As such they can also be represented pictorially. Let us recall, for example, the source vehicles that were used to address the target domains inherent to the structure of mental causation. They included concrete concepts such as eyes, facial expressions and bodily behavior. It is in the search for the means to represent these concepts, then, that acting quickly comes to the forefront as it is through the bodily performance of the actor or actress, that we may assume that viewers get access to the target domains of mental causation. Assessing this claim, will be the aim of the third section of this chapter in which we shall draw upon insights from cognitive theorists of acting to assess the relationship between performance and concepts.

The first question, by contrast, poses more of a challenge. As we know from the previous chapter, image schemas, as opposed to the source vehicles of metonymies, do not refer to concrete entities in the physical world, but to abstract gestalt structures of sensory-motor experience. The visual reality that is not yet rendered pictorially on-screen, however, is not abstract, but concrete. This, in turn, raises the question as to how film may organize this reality in such a way as to allow for the ostensive appearance of unifying schematic patterns that are salient in our everyday experience?

It is in the search for an answer to this question that we may turn to Rudolf Arnheim's gestalt approach to static art works such as paintings, drawings and sculptures. ${ }^{2}$ Challenging the dominance of the linguistic view of meaning and the dualistic habit of separating the intuitive from the cognitive, Arnheim put forward the view that images of art (the domain of perception) offer more than merely illustrations of events or things. Like words, they are capable of giving form to concepts (the domain of thought). This assumption has led the author to identify and advance his famous concept of "visual thinking." At the core of this concept lies the following line of reasoning: 
(1) Thinking calls for images.

(2) Images contain thought.

(3) The visual arts consist of images.

(4) Therefore, the visual arts are a homeground of visual thinking. ${ }^{3}$

To trace visual thinking in images, Arnheim argued, "one must look for well-structured shapes and relations" because it is through these patterns, which underlie the perception of form, that the specifiable themes or concepts of the work are spelled out. ${ }^{4}$ To see how the structural skeleton of a work's composition may reflect the work's content, let us consider two paintings that the author discusses in his work: Jan Vermeer's Woman Holding a Balance (aka Woman Weighing Gold) and Paul Cézanne's portrait of his wife, Mme. Cézanne in a Yellow Chair (see figure 3.1). ${ }^{5}$

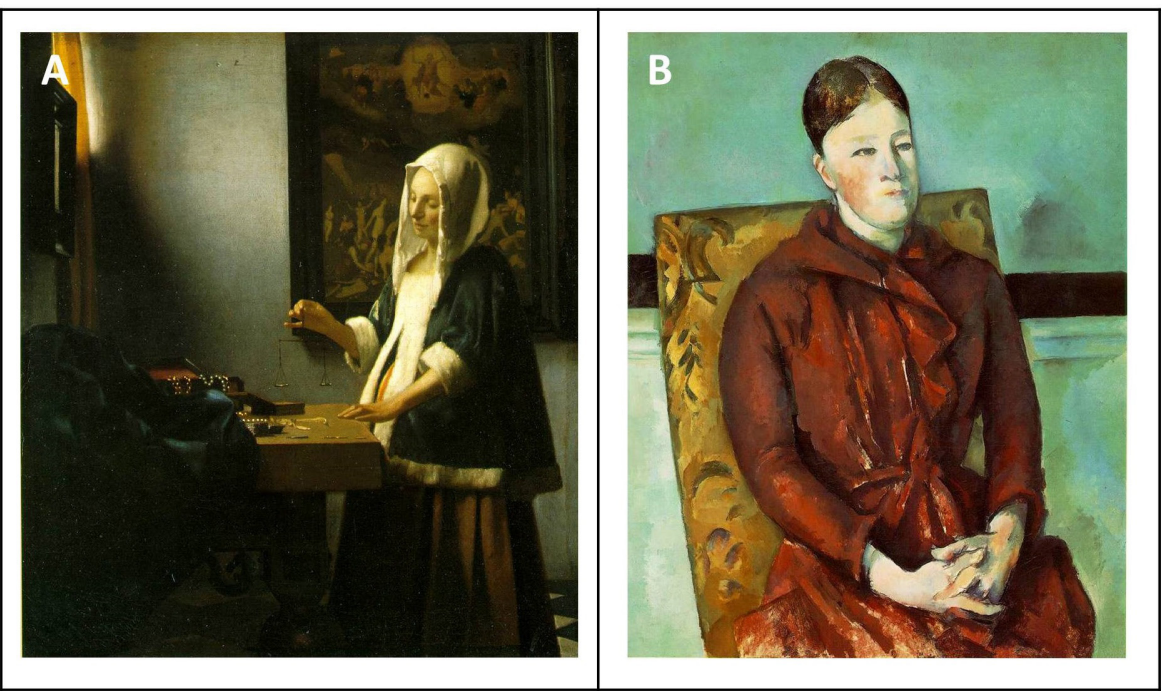

Figure 3.1. A, Jan Vermeer's Woman Holding a Balance (ca. 1664), Courtesy National Gallery of Art, Washington, and B, Paul Cézanne’s Mme. Cézanne in a Yellow Chair (1888-90), Courtesy Art Institute, Chicago.

The first painting depicts a young woman who holds an empty pair of scales in her right hand while she stands before a painting of the Last Judgment of which its content contrasts with the valuable, golden objects lying on the table in front her. It is an allegory that invites the viewer to contemplate about the importance of resisting the temptations of the world and living modestly in order to find salvation. As Arnheim argues, this intellectual theme is expressed visually by the descending dark, rigidly vertical ledge of the frame in the very center of Vermeer's composition which takes hold of the woman's hand thus suspending its movement. ${ }^{6}$ As he writes, "by this device the worldly scene of the foreground is arrested, while a light from above, stronger than the mundane glitter of the jewelry, causes the woman's eyes to close." 
The second painting shows a seated, middle-aged woman who, despite its stability and external tranquility, nevertheless is loaded with energy and strong potential activity. As Arnheim so eloquently describes, this subtle blend of serenity and vigor, of firmness and disembodied freedom, which constitutes the theme of the painting, is achieved by various stylistic choices of the artist. ${ }^{7}$ First, there is the upright format of the picture which reinforces the upright character of the figure, the chair and the head, thus creating a scale of increasing slimness running from the background over the chair to the figure in the foreground. This vertical quality, however, is counterpointed by the dark band on the wall which divides the background into two horizontal rectangles. Yet, the balance is restored again by the fact that the lower rectangle is taller than the upper one. At the same time, the pattern of dark rectangles is counteracted by the oval figures formed by the shoulders and arms, on the one hand, and the bright face, on the other hand. This dominant rightward movement is also enhanced by the way the figure is asymmetrically placed in relation to the chair. The fact that the figure is occupying mainly the right half of the chair, with the head being drawn toward the upper border of the frame, adds much to the painting's overall effect of lightness and suspension in space.

With examples such as these Arnheim attempted to show that works of art are more than illustrations of particular events. Through their structural conceptions they embody the meaning that the artist, consciously or unconsciously, intended to convey. It is here then, in Arnheim's emphasis on "hidden skeletal structures," that we may observe a close resemblance to Lakoff and Johnson's concept of an "image schema," as discussed in the previous chapter. This is acknowledged by Johnson himself who, in his own work, draws significantly on Arnheim's analysis of balance in the visual arts to develop his own conception of the image schema of BALANCE. ${ }^{8}$ Hence, if visual works of art are capable of representing meaning through hidden structural patterns (or, as in our case, image schemas), as Arnheim illustrates so vividly, then we might assume that moving pictures are equally capable of expressing conceptual content by means of film form. In this way, we would be able to overcome the challenge posed by iconic images. Before exploring this hypothesis further in the next section, it should be stressed that Arnheim himself was rather sceptical about bringing his model for analysing compositional patterns in static media to film analysis. Arnheim believed that film was more restricted than other arts. ${ }^{9}$ As to the reason why, he refers to the fundamental difference in viewing experience that exists between viewing static media such as a painting and viewing mobile media such as a film. In The Power of the Center he states this problem as follows:

\footnotetext{
Depending on the film viewer's attitude, the experience of watching a film is much less or much more self-centered than that of looking at a painting. Either he finds himself comfortably seated with the screen as his frame of vision, imposing an immobile structure upon the passing action of the film, or he is captured by the plot so completely that he moves along with it. ... A painting never belongs as much to the viewer as does the framed film screen, which is an instrument of his vision.... Visual composition reveals itself more readily in the quiet detachment from time, found in the immobile works of painting or sculpture. ${ }^{10}$
}

There is no doubt a certain truth in what Arnheim here writes. Narrative cinema deals with a rapid flow of images and an emphasis on character engagement that at first sight seems to impede the kind of absorbed contemplation that characterizes our visual experience of a painting's composition. Arnheim believed that when we are engaged in a filmic experience, we can only "react to the brutal signals of immediate satisfaction." ${ }^{11}$ In such a setting our eyes 
and ears are prevented from perceiving structures, which are critical for perceiving meaning (given the dependence of the latter on the former). However, as Scott Higgins recently has pointed out, the gap between the two modes of viewing may be smaller than Arnheim's words above seem to suggest. In his own anthology devoted to bridging Arnheim's body of thought to film scholarship, he comments on this as follows:

\begin{abstract}
Classical continuity privileges attentional patterns used to follow individuals through space; that is, we tend to watch characters rather than compositions. Yet, some filmmakers overly compose their frame and drive attention around it in a way more tune with Arnheim's aesthetic observation. Moreover, where directors do not offer an invitation to contemplate a long take, they can build patterns from shot to shot, or from camera movement to camera movement, in a manner functionally equivalent to a grand compositional scheme. ${ }^{12}$
\end{abstract}

The author finds support for his claim in the work of the American film director Vincente Minnelli whose color design, he argues, "rewards both practically and compositionally oriented viewing, both contemplation and sensual engagement." 13 In the next section, we will follow Higgin's approach by equally bringing Arnheim's way of thinking to the domain of film studies. Using many examples as taken from Kubrick's oeuvre, we will show how his films, through their visual style, impose several dynamic image schematic structures onto the visual reality.

\title{
2. Image schemas and a film's visual style
}

To structure our discussion, we will first say a few words about form. Among the scholars who have studied the concept most extensively are David Bordwell and Kristin Thompson. ${ }^{14}$ In their seminal introduction to the analysis of cinema both authors broadly refer to film form as "the overall system of relations that we can perceive among the elements in the whole film." ${ }^{15}$ Pivotal to this definition is the perceptual condition, that is, there has to be a person perceptually experiencing the film in order for the concept of film form to come into existence. Without the perceiver, a film is merely a lifeless object, patterns of light and darkness projected on a screen. Moreover, in order for this perceiver to perceive the overall system of a film, the film itself has to possess a quality. It has to prompt the viewer to see the orderly relations among the parts of the film, for in the absence of it, the viewer will not be able to exercise his or her gift for bringing order to chaos and for constructing wholes out of parts. This, in turn, begs the question of principles. By which principles of film does film help create the relationships among the parts? Bordwell and Thompson answer this question by emphasizing the significance of two interacting systems of film: the formal system and the stylistic system. ${ }^{16}$

The formal system refers to the discursive function that determines the organization of a film's images and sound. We already discussed one type of formal system in the first chapter of this book, namely narrative form. Although this type appears to be the most common one typically associated with fictional, live-action cinema it is not the only one. In addition, the authors identify four other systems: two types of form that are often used in documentaries (categorical and rhetorical form) and two types of forms that are characteristic of experimental films (abstract and associational form). Although these categories may be mapped onto genres, they are not mutually exclusive, meaning that an individual film or a genre may incorporate many types of filmic organization. 
The stylistic system refers to the "unified, developed, and significant use of particular technical choices." ${ }^{17}$ Here, the authors identify four areas of cinematic techniques: two techniques of the shot (mise-en-scene and cinematography), the technique that relates shot to shot, editing, and the relation of sound to film images. The film's stylistic system cannot be studied in isolation from the film's overall form. The pattern that emerges from the film's style, may be designed to serve one of the formal systems. For instance, techniques can function to facilitate the purpose of narrative form, that is, to advance the cause-effect chain.

It is through the second system of film style, then, that we will now argue that films are capable of structuring the spatial and visible world in such a way as to elicit image schemas. Given that this chapter is about visual images, the emphasis will be on those cinematic techniques that have a visual effect on the viewer (e.g., cinematography, mise-enscene and editing). The discussion will be structured in three parts. First, we consider the role of image schemas in our visual perception of a static shot. A static shot is here defined as a shot that does not evoke the visual effect of moving objects on-screen (i.e., static mise-en-scene) nor the visual effect of a mobile frame as elicited by camera movement. Consequently, this part will be significantly indebted to Arnheim's pre-existing work on structural patterns in static visual art, as briefly discussed above. Here, the emphasis will be on the cinematic technique of framing. Second, we consider the role of image schemas in our visual perception of a dynamic shot. A dynamic shot is here defined as a shot that does consider either one or both of the two effects above. Hence, the primary focus of this part will be on the cinematic techniques of fixed-frame movement and mobile framing. Third and last, we consider the role of image schemas in our visual perception of relations among shots. This part can be linked to the cinematic technique of editing. Each of the techniques under discussion will be illuminated through various examples taken from Kubrick's oeuvre.

\subsection{The static shot}

\subsubsection{The CONTAINER image schema}

In his Wittgensteinian-inspired book Projecting a Camera, film theorist Edward Branigan has argued that the concept of a "frame" is a polysemous word meaning that it is a word that has "distinct, though related, meanings, or at least meanings that are fairly close." 18 To illustrate this, he identifies no fewer than fifteen different, though related, ways of employing the word "frame" in the critical discourse about film. ${ }^{19}$ Here, we adopt the first way which is probably the most commonly accepted definition of a frame as experienced by the film viewer:

\footnotetext{
The frame is the real edge of an image on the screen that has resulted from limits imposed on celluloid inside a physical camera and projector so that, for example, a projected image can be said to be "in frame" or "out of frame" on the screen. A spectator, however, is not really seeing an actual edge. The edge of an image onscreen is not the edge of an individual exposed frame from inside a film camera but, at least, a composite edge that is made up of a number of exposed frames, because in watching a film a spectator does not see each individual frame halted on the screen as if a series of slides were being shown. ${ }^{20}$
}

Regardless of the polysemy of the word frame, there seems to be a general structure underlying all ways of reasoning about frames. It is clear from our language about frames, as evidenced by the expressions "in frame" and "out of frame" in the quotation above, that the structure inherent to our perception of the filmic frame is that of the 
CONTAINER image schema. ${ }^{21}$ Evidence of this congruence can be found in the way the inferences true of bounded regions, as already discussed in chapter 2, also hold for frames (see table 3.1).

Table 3.1 The frame as container.

\begin{tabular}{ll}
\hline Inferences true of bounded regions & Inferences true offrames \\
\hline $\begin{array}{l}\text { If you're in a bounded region, you're not out of } \\
\text { that bounded region. }\end{array}$ & $\begin{array}{l}\text { If you're in a frame, you're not out of that } \\
\text { frame. }\end{array}$ \\
$\begin{array}{ll}\text { If you're out of a bounded region, you're not in } \\
\text { that bounded region. }\end{array}$ & $\begin{array}{l}\text { If you're out of a frame you're not in that } \\
\text { frame. }\end{array}$ \\
$\begin{array}{ll}\text { If you're deep in a bounded region, you are far } \\
\text { from being out of that bounded region. }\end{array}$ & $\begin{array}{l}\text { If you're deep in a frame, you are far from } \\
\text { being out of that frame. }\end{array}$ \\
$\begin{array}{ll}\text { If you are on the edge of a bounded region, then } \\
\text { you're close to being in that bounded region. }\end{array}$ & $\begin{array}{l}\text { If you are on the edge of a frame, then you are } \\
\text { close the in that frame. }\end{array}$ \\
\hline
\end{tabular}

But what do these inferences mean? What does it mean to say that something is "in a frame" or something is "out of a frame"? To answer these seemingly basic questions is to take a look at the nature of the image projected on the screen (henceforth, the film image). A film image is essentially a two-dimensional image with a creation of an illusion of depth on it. This definition suggests the existence of three orientational axes. The word "two-dimensional" suggests a horizontal axis X (a LEFT-RIGHT schema) and a vertical axis Y (a TOP-DOwn schema), whereas the word "depth" suggests an illusionary depth axis Z (a FRONT-BACK schema). From this conception of a film image, we may draw six zones of off-screen space. Following Noël Burch, these can be identified as: (1) the space left of the frame, (2) the space right of the frame, (3) the space above the frame, (4) the space below the frame, (5) the space behind the set and (6) the space behind and near the camera (see figure 3.2). ${ }^{22}$ Together they comprise what Bordwell and Thompson describe as the "six areas blocked from being visible on the screen but still part of the space of the scene."23

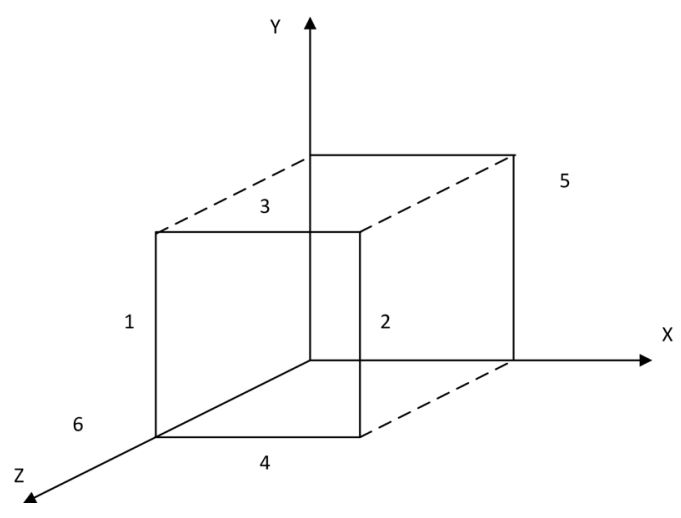

Figure 3.2. The six zones of off-screen space (after Burch). 
Inherent to these six zones are three different boundaries: (1) the boundary of the frame, (2) the boundary of the set and (3) the boundary of the camera.

The first boundary provides us with the criteria for defining the "inside" and the "outside" of a frame. Something is inside the frame if it is present within the four edges of the frame. By contrast, something is outside the frame if it lies outside these edges, that is, if it is excluded from the inside space of the frame. Naturally, it is only the inside of the frame that is also on-screen. ${ }^{24}$ This assertion is self-evident from the spatial logic built into the CONTAINER schema:

- Given two containers, the film frame, $\mathrm{A}$, and the screen, $\mathrm{B}$, and an object, $\mathrm{X}$, if $\mathrm{A}$ is in $\mathrm{B}$ and $\mathrm{X}$ is in $\mathrm{A}$, then $\mathrm{X}$ is in $\mathrm{B}$ (i.e., $\mathrm{X}$ is on-screen).

Underlying this spatial logic is a static conception of the CONTAINER schema of which its visual diagram (figure 3.3) is similar to the figure discussed earlier in chapter 2 (see figure 2.2). It is a "static" diagram because there is no movement ("an arrow") linked to either one or both of the two central figures (i.e., the containers and/or the visual object).

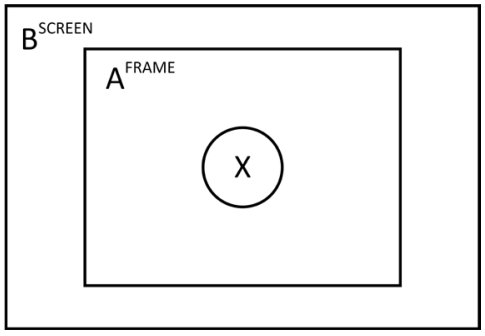

Figure 3.3. The static conception of the CONTAINER schema as applied to the filmic terms, frame and screen.

The amount of space in the screen that is occupied by the inside of the frame depends on the aspect ratio, that is, the relationship of the frame's width to its height. ${ }^{25}$ In the original ratio known as Academy ratio, the frame was 1.33 or 1.37 as wide as it was high, later the width was normalized at 1.66 times the height for the European film market and 1.85 times the height for US and Asian markets. Table 3.2 gives you an idea of the aspect ratios of Kubrick's films. It compares the original aspect ratios of their theatrical releases with the aspect ratios of today's DVD and Blu-ray versions (the versions used for capturing the screenshots for this book are marked in italics).

Table 3.2 The aspect ratios of Kubrick's films

\begin{tabular}{llllll}
\hline Year & Film & Gauge & Theatrical ratio & DVD ratio & Blu-ray ratio \\
\hline 1953 & Fear and Desire & $35 \mathrm{~mm}$ & $1.33: 1$ & $1.33: 1$ & $1.37: 1$ \\
1955 & Killer's Kiss & $35 \mathrm{~mm}$ & $1.33: 1$ & $1.33: 1$ & $1.37: 1$ \\
1956 & The Killing & $35 \mathrm{~mm}$ & $1.33: 1$ & $1.33: 1$ & $1.66: 1$ \\
\hline
\end{tabular}




\begin{tabular}{|c|c|c|c|c|c|}
\hline 1957 & Paths of Glory & $35 \mathrm{~mm}$ & $1.66: 1$ & $1.33: 1$ & $1.66: 1$ \\
\hline 1960 & Spartacus & $70 \mathrm{~mm}$ & $2.21: 1$ & $2.20: 1$ & $1.85: 1 / 2.21: 1$ \\
\hline 1962 & Lolita & $35 \mathrm{~mm}$ & $1.66: 1$ & $1.66: 1$ & $1.66: 1$ \\
\hline 1964 & Dr. Strangelove & $35 \mathrm{~mm}$ & $1.66: 1$ & $1.66: 1$ & 1.66:1/1.78:1 \\
\hline 1968 & 2001: A Space Odyssey & $70 \mathrm{~mm}$ & $2.20: 1$ & $2.20: 1$ & $2.20: 1$ \\
\hline 1971 & A Clockwork Orange & $35 \mathrm{~mm}$ & $1.66: 1$ & $1.66: 1$ & 1.66 .1 \\
\hline 1975 & Barry Lyndon & $35 \mathrm{~mm}$ & $1.66: 1$ & $1.59: 1 / 1.66: 1$ & 1.66:1/1.78:1 \\
\hline 1980 & The Shining & $35 \mathrm{~mm}$ & $1.66: 1$ & $1.33: 1$ & $1.78: 1$ \\
\hline 1987 & Full Metal Jacket & $35 \mathrm{~mm}$ & $1.85: 1$ & $1.33: 1$ & $1.78: 1$ \\
\hline 1999 & Eyes Wide Shut & $35 \mathrm{~mm}$ & $1.85: 1$ & $1.33: 1$ & $1.78: 1$ \\
\hline
\end{tabular}

As this table indicates, most of Kubrick's films were shot in the Academy ratio. ${ }^{26}$ The two exceptions are Spartacus and 2001 which were both shot in wider aspect ratios (2.21 times the height for the $70 \mathrm{~mm}$ release prints). Unfortunately, as many home theatre fans of Kubrick have remarked, some of today's DVD versions, especially those versions of his later films, do not represent the aspect ratios in which they were screened. ${ }^{27}$

The second boundary refers to the boundary between what is part of the set of the film (i.e., the scenery and props as arranged for shooting a film) and what is not (e.g., wooden supports holding up the walls, the lighting stands, electrical cords, camera men). Naturally, in narrative cinema this boundary should be preserved in order for a viewer to perceive the story as real and not as artificial. Consequently, this entails that a revelation of the outside space of the set should be avoided at any cost, unless it is the filmmaker's intention to do so, for otherwise the shot would call attention to the fictional nature of the film. Given that what we see on-screen depends on what is in frame, it follows that the inside of the frame should always overlap with the inside of the set. The boundary of the film set may be located outside the filmic frame, yet its content should at all time be the content of the filmic frame. An inclusion of the space beyond the set within the frame would reveal the scenery as artificial. Again, we may draw on the logic of the CONTAINER schema to infer these conclusions:

- Given two containers, the film frame, A, and the set, B, if the whole inside of A is in B, then the fictional nature of the film will be preserved.

- Given two containers, the film frame, A, and the set, B, if a part of the outside of B is in A, then the fictional nature of the film will be revealed.

Disregarding the container of the screen, we may illustrate and diagram this distinctive logic as in figure 3.4 ( $A$ and $B$, respectively). Naturally, making-of documentaries or behind-the-scenes are good means to expose the fictional nature of the film. Figure $3.4 \mathrm{~B}$ shows a look behind the scenes of The Shining as it was shot by Kubrick's daughter Vivian. ${ }^{28}$ 


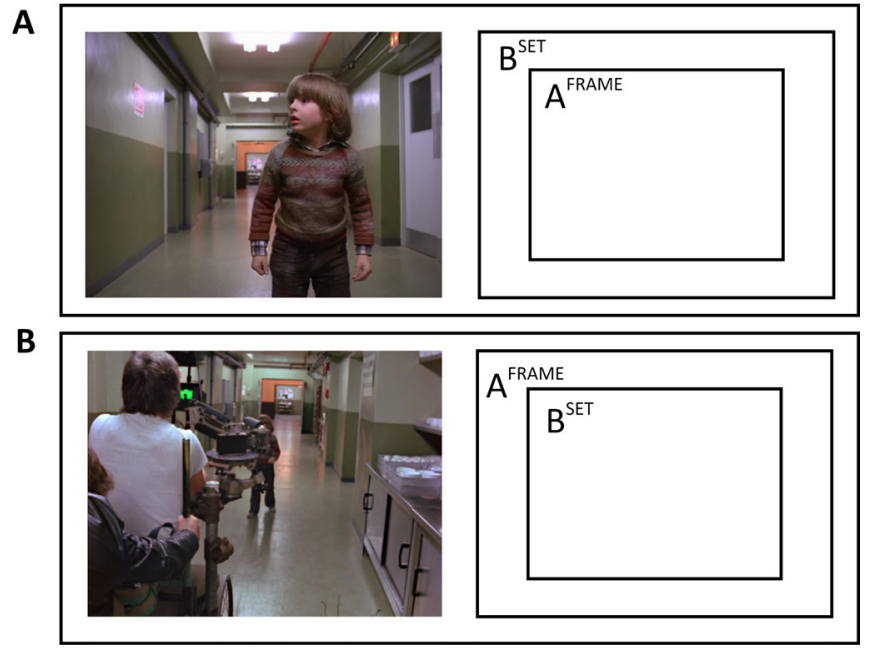

Figure 3.4. $A$, preserving fictional reality versus $B$, revealing fictional artificiality.

Moreover, given that the scenery is made up of the same material that inhabits our visible world, it follows that the scenery itself may give rise to physical instantiations of the conTAINER schema (e.g., rooms, objects). A film may restrict such instantiations as when the scenery does not contain bounded regions (e.g. shots of endless dark matter of the universe as it is the case in 2001), but it rarely may abandon them completely. If the setting consists of a bounded region, this bounded region may open up to the viewer. A character may open a window, thus revealing to the viewer a glimpse of the space outside the room. In such a case, the revealed space, although still termed the "outside" relative to the visible inside of the room, becomes, in turn, part of the visible inside space of the film set and the film frame. Again, this simply follows from the logic of the conTAINER schema:

- Given three containers, the film frame, A, the film set, B, an unspecified bounded region, C, and an object, $\mathrm{X}$, if $\mathrm{A}$ is in $\mathrm{B}$ and $\mathrm{C}$ is in $\mathrm{A}$ and $\mathrm{X}$ is in $\mathrm{C}$, then $\mathrm{X}$ is both in $\mathrm{A}$ and $\mathrm{B}$.

Figure 3.5 shows a striking filmic manifestation of this logic. Taken from Killer's Kiss, it shows the character of Gloria (X), standing in her apartment, as she is hooked in the mirror image of Davey's apartment (C). This visual containment is emphasized even more by the presence of the framework of the window of her apartment inside the mirror image. She is literally caught in a series of frames. Here, we may already give an impression of the next chapter as this "lack of freedom to move" might be extended metaphorically to the conceptual and narrative level of the film, that is, to Gloria's intense emotional state of mind which overpowers her to the extent that she is no longer in control of her free actions. 


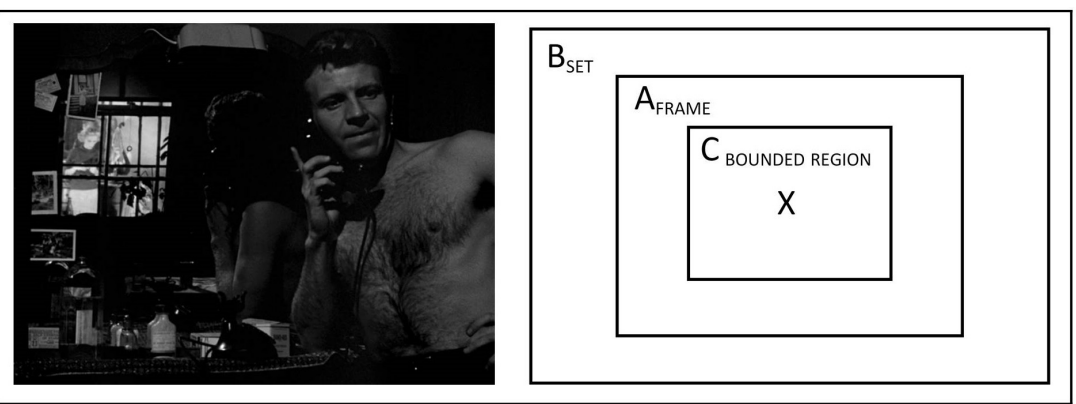

Figure 3.5. Frame-within-frame configuration in Killer's Kiss.

The third boundary may be considered as a somewhat awkward boundary because of its causal relationship with the material inside the boundary of the frame (i.e., the scene that is filmed). That is, the inside visual content of the filmic frame would not have occurred without the application of the camera. This has an important implication for our interpretation of the sixth zone of off-screen space. It entails that this zone can never be recorded. Just as our eyes cannot see the space in the back of our heads, so the camera can never record the space behind itself. Sometimes, however, a film may draw attention to this boundary as when, for example, the camera apparatus is treated as a physical entity within the off-screen space that objects within the frame may collide with. Two examples of such contact are illustrated in figure 3.6. In the first series of images $(A-C)$, taken from Killer's Kiss, we see the character of Vincent Rapallo throwing a glass at two grinning figures reflected in the glass of a picture. Because the camera, however, is located at the position of these figures, it looks as if the camera lens is shattered. In the second iconic series of images $(D-F)$, taken from The Shining, we see a river of blood approaching and eventually splattering the static camera lens, thereby blurring our vision. Underlying both examples is a dynamic pattern of containment that will be later identified in this chapter as the image schema of APPROACHING.

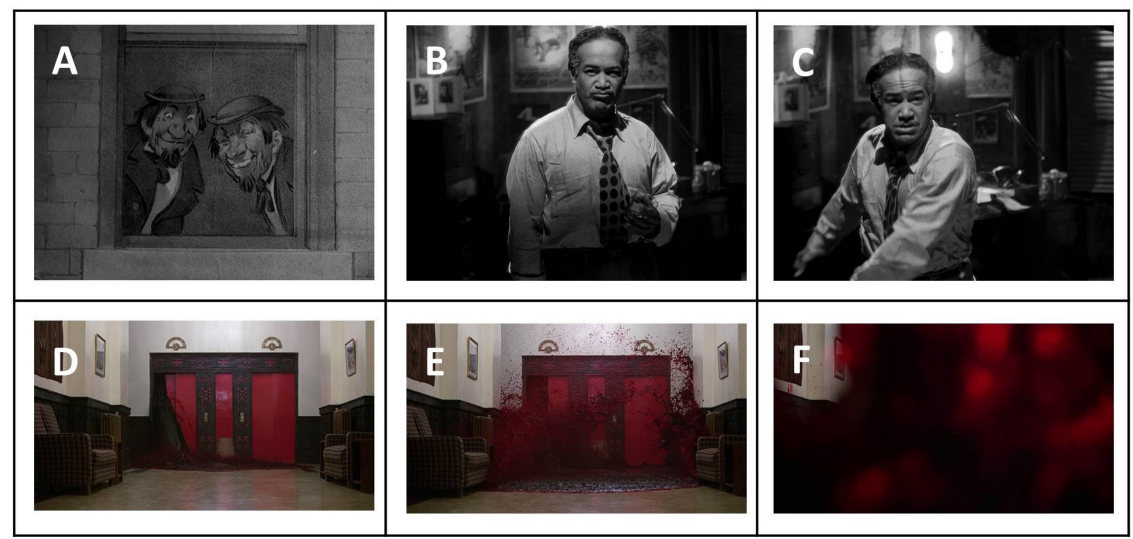

Figure 3.6. Drawing attention to the boundary of the camera in A-C, Killer's Kiss and D-F, The Shining. 


\subsubsection{The BaLANCE image schema}

Having shown how the inferential logic of the CONTAINER schema is inherent to the filmic frame, we are now in a position to identify the workings of another schema that involves the way the container of the filmic frame, in turn, relates to its visual content. To start off our discussion of this schema, let us return to the visual representation of the logic of the CONTAINER image schema, as diagrammed in figure 3.3. As we know from the previous chapter, diagrams such as this can be misleading for image schemas are not diagrams on a page, nor are they tied to particular images. We use these figures simply as a means to reason about them. However, by providing a pictorial representation of what essentially is not an image, the picture itself becomes part of our perceptual experience (i.e., it becomes an object of visual perception). As such we may rely on other image schemas of our embodied experience in the world to conceptualize our experience of seeing it. Such a projection occurs when we take a look at figure 3.3 from above in which our perception of the object in the centre of the container (a location that was not specified by the logic of the schema) may best be understood and verbalized in terms of the image schema of BALANCE, visual balance that is, not physical balance. As Johnson has stressed, the use of balance here is metaphorical in the sense that we project structure from one domain (our bodily experience of physical balance) onto another domain of a different kind (spatial organization in visual perception). ${ }^{29}$

Given this observation, then, one might even go further and explore, as Arnheim did, the effects of replacing the object on a viewer's experience of visual balance or lack of visual balance. ${ }^{30}$ Through various informal explorations he found out that, notwithstanding the location of the object within the canvas, it will be affected by the "forces" of an underlying "hidden structure." He refers to this structure as the "structural skeleton of the square." 1 Within this skeleton the centre establishes itself through the crossing of four main structural lines: the central vertical and horizontal axes and the two diagonals (see figure 3.7).

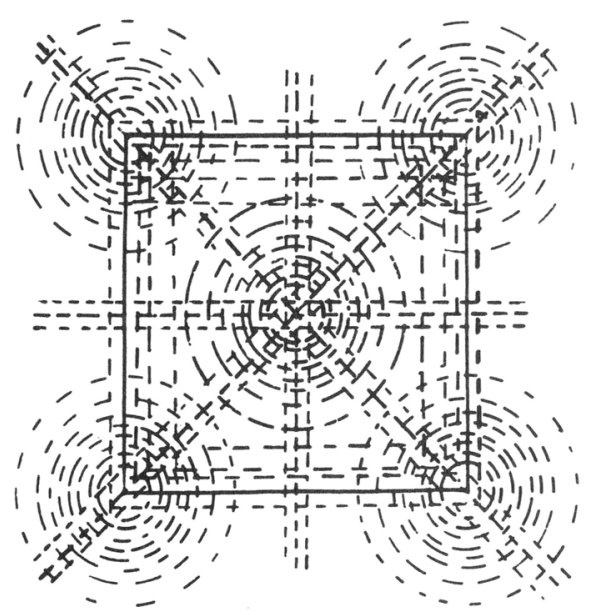

Figure 3.7. The structural skeleton of the square. Art and Visual Perception: A Psychology of the Creative Eye, by Rudolf Arnheim, (c) 2004 by the Regents of the University of California. Published by the University of California Press. 
As to how to interpret this structure, Arnheim gives the following explanation (what he terms the disk is the object in our discussion):

Wherever the disk is located, it will be affected by the forces of all the hidden structural factors. The relative strength and distance of these factors will determine their effect in the total configuration. At the center all the forces balance one another, and therefore the central position makes for rest. Another comparatively restful position can be found, for example, by moving the disk along a diagonal. The point of balance seems to lie somewhat closer to the corner of the square than to the center, which may mean that the center is stronger than the corner and that this preponderance has to be offset by greater distance, as though corner and center were two magnets of unequal power. In general, any location that coincides with a feature of the structural skeleton introduces an element of stability, which of course may be counteracted by other forces. ${ }^{32}$

Following Johnson, there are two important points to be made about Arnheim's structural skeleton. ${ }^{33}$ First, it is important to emphasize that this hidden structure only exists in relation to the viewer of the image. That is, balance does not exist objectively in the frame. The object seen "is only balanced in our acts of perception." However, as Johnson points out, since all spectators more or less are equipped with the same perceptual tools, "it will usually make perfectly good sense to speak of the balance being in the perceived object." It is precisely for this reason then that Johnson considers balance to be an image schema because it operates as a recurring structure or pattern of perceptual activity that is instantiated in a number of different bodily and perceptual experiences. For Johnson, then, the prototypical image schema of BALANCE may be represented by an axis or a point in relation to which some force vectors are symmetrically or proportionally arranged.

The second key point that Johnson makes, is that Arnheim, when talking about "force," "tensions" and "hidden structures," is not actually talking about gravitational or physical forces of the sort that we discussed in the previous chapter (i.e., forces that act upon bodies). Instead, he is talking about what Johnson calls "psychological or perceptual forces." ${ }^{4}$ In other words, he uses the terms "forces" and "weights" metaphorically in order to structure and understand our experience of perceiving balance in visual configurations. Consider, for example, the metaphorical elaboration of the concept of "weight." In its literal and physical sense weight refers to the strength of the gravitational force pulling objects downward. By contrast, the elements in two-dimensional pictures such as film images, do not have mass and, therefore, do not have any physical weight. As Arnheim writes, "there are no known physical forces that would tend to push an eccentrically placed patch of printer's ink in the direction of the center of the square." ${ }^{35}$ Yet, we use the concept of weight in a very genuine way to make sense of our experience of perceiving these images (i.e., to express the "force" that an element inside the frame exerts to attract the eye). As Johnson writes, "we have some complex metaphorical (but very real) experience of visual weight and force." ${ }^{36}$ As to the question which factors influence visual weight the most and thus determine our experience of visual balance, Arnheim distinguishes between several factors, some of which are listed as in table 3.3. ${ }^{37}$ 
Table 3.3 List of factors that influence force and weight relations (after Arnheim).

\begin{tabular}{|c|c|}
\hline Factor & Observation \\
\hline Location & $\begin{array}{l}\text { A "strong" position on the structural framework can support more weight than one lying } \\
\text { off-centre or away from the central vertical or horizontal. }\end{array}$ \\
\hline Spatial depth & The greater the depth an area of the visual field reaches, the greater the weight it carries. \\
\hline Size & Other factors being equal, the larger object will be the heavier. \\
\hline Color & Red is heavier than blue, and bright colors are heavier than dark ones. \\
\hline Intrinsic interest & $\begin{array}{l}\text { The very tininess of an object may exert a fascination that compensates the slight weight it } \\
\text { would otherwise have. }\end{array}$ \\
\hline Isolation & $\begin{array}{l}\text { An isolated object is heavier than an object of similar appearance surrounded by other } \\
\text { objects. }\end{array}$ \\
\hline Shape & The regular shape of simple geometrical figures makes them look heavier. \\
\hline Knowledge & $\begin{array}{l}\text { No knowledge on the part of the observer will make a bundle of cotton look lighter than a } \\
\text { lump of lead of similar appearance. }\end{array}$ \\
\hline
\end{tabular}

As this table shows, the location of the object inside of the frame is only one aspect of many aspects that have to be taken into consideration when assessing the overall balance of a visual work of art. Naturally, a discussion of each of these aspects would take several chapters on their own. There is, however, one aspect that is worth emphasizing here as it will be revealed later on to play an important role in the non-verbal communication of stories of mental causation. This is the aspect of the size of the object. In film studies, this aspect is related to the distance of framing. ${ }^{38}$ The distance of framing, also known as shot scale, refers to the apparent distance between the camera and the mise-en-scene elements inside the container of the frame. Film scholars usually measure this distance in relation to the human subject. This gives rise to a typology of shot sizes that alternates between an extreme close-up (a view of a portion of the subject) and an extreme long shot (a view of the whole subject as well as his surroundings). The greater the distance, the smaller the object and the "emptier" the frame, and vice versa, the shorter the distance, the bigger the object and the "fuller" the frame. Here one may notice the dynamic interaction of the EMPTY-FULL image schema with the NEAR-FAR image schema. ${ }^{39}$ Naturally, this image schematic interaction also influences the visual weight of an object. In the absence of any counterbalancing effect, the object that is nearer and thus larger will have more weight than an object that is farther and thus smaller.

How does visual balance relate to visual symmetry, that other concept often associated with it? Especially in the light of the prevalence of symmetrical compositions in the work of Stanley Kubrick such a question is worth raising. ${ }^{40}$ Unquestionably, both concepts are closely related suggesting, quite misleadingly, that balance is symmetry, of the form exemplified by Johnson: 
Any $\mathrm{X}$ is balanced when it is symmetrical, that is, where there are equal elements, with equal weights, in equal locations, one on each side relative to the axis or centre point, or where there is an equal distribution of weight and forces relative to the axis. ${ }^{41}$

Although it is true that symmetry supports balance, it is not true that balance requires symmetry. ${ }^{42}$ Arnheim is keen to point out that one can have an experience of visual balance without observing symmetry in the image. ${ }^{43}$ Asymmetrical formal relations may well be capable of expressing order and balance as long as the "forces" within the work counterbalance each other. To illustrate this, let us compare two images as taken from Barry Lyndon (see figure 3.8). $A$ is an example of symmetry of the sort that one often encounters in the work of Kubrick. If you would split the image in two at the height of the mountain in the background of the image, you could see that whatever is on the left of the vertical axis seems to be mirrored in size and relative position on the right also. By contrast, composition $B$ does not evoke this symmetry. We do see some symmetry between the characters, but this does not apply to the whole of the image. Yet, we do experience the right image as balanced. How does this come about? A part of the explanation lies precisely in the factors listed by Arnheim. The darker area on the right half of the image is counterbalanced by the brighter area on the left half of the image. Moreover, the isolated and smaller object of the fallen chair on the left, an unconcealed reference to William Hogarth's second satirical painting The Tête à Tête from his Marriage à-la-mode series, poses a counterweight to the visual weight of the larger group of people on the right. The result is a balanced composition in which all factors are mutually determined in such a way that, to quote Arnheim, "no change seems possible, and the whole assumes the character of 'necessity' in all its parts." ${ }^{4}$
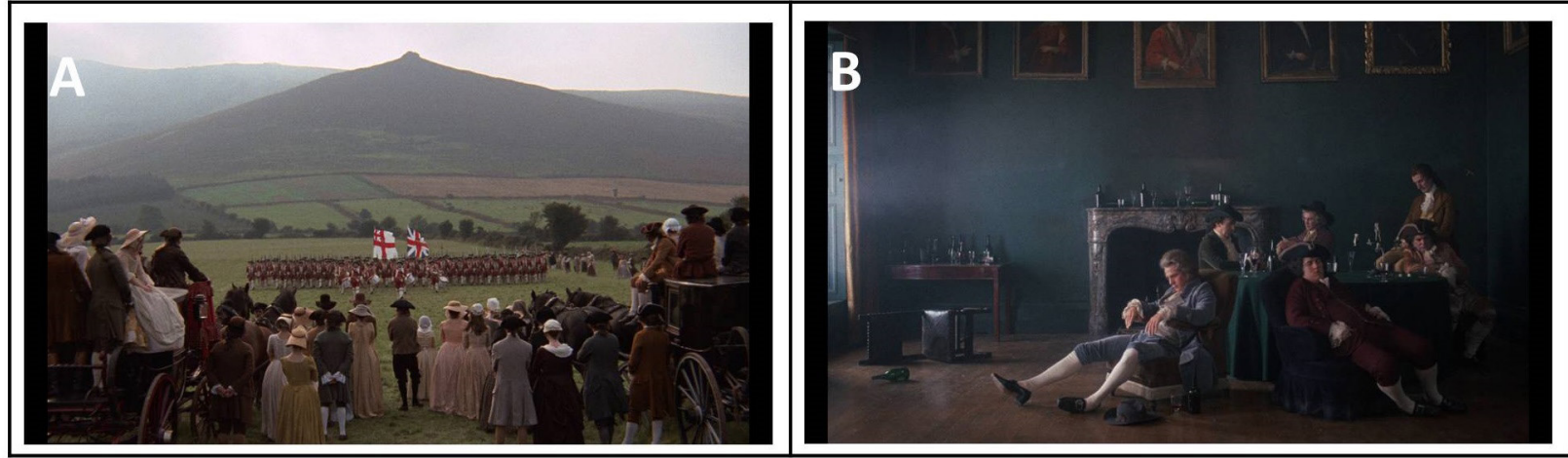

Figure 3.8. Visual balance in Barry Lyndon: $A$, symmetry versus $B$, asymmetry.

As a viewer, we are able to infer these aesthetic thoughts because the duration of the shot allows for a kind of artful contemplation that is normally more associated with the experience of watching a static work of art such as a painting. Contemplative static shots, however, if present at all, usually occupy only a small fraction of the total amount of images of an entire film. What distinguishes our experience of watching a film from our experience of 
watching a still picture, is precisely the observation of motion. In other words, what underlies film is not a static, but a dynamic conception of the CONTAINER schema that comes into being once we attribute motion to either both or one of the two central entities, that is, once the frame and/or the visual object become(s), to use a term from the previous chapter, a trajector. This gives rise to a number of patterns which, as we have seen in the previous chapter, may be identified as "dynamic patterns of containment." Depending on the moving entity, we may distinguish between two subgroups of dynamic patterns: one subgroup in which the container is the relatively moving figure and another subgroup in which the contained object is the relatively mobile entity. Following film terminology, both subgroups may be referred to as the "dynamic patterns of fixed-frame movement" and the "dynamic patterns of mobile framing or camera movement," respectively. In what follows, we address each subgroup separately before turning toward their interaction.

\subsection{The dynamic shot}

\subsubsection{Dynamic patterns of fixed-frame movement}

How many ways are there for an object, either motivated by an internal force or an external force, to go into or to go out of a fixed frame? Again, the answer to this question lies in the nature of the film image. Given the three axes of the film image, as discussed above, fixed-frame movement can take three forms: (1) lateral (left-right or top-down movement), (2) in-depth (movement toward or away from the camera), or (3) diagonal (a combination of lateral and in-depth movement). As Boggs points out, "purely lateral movement creates the impression of movement on a flat surface (which the screen is) and therefore calls attention to one of the medium's limitations: its two-dimensionality." ${ }^{45}$ Consequently, if the cinematographer wants to create the illusion of three-dimensionality, he has to choose in-depth movement and diagonal movement over purely lateral movement. Combined with Burch's six zones of off-screen space, then, an object may enter or exit a frame in the following ways: (1) from the left edge of the frame, (2) from the right edge of the frame, (3) from the top edge of the frame, (4) from the bottom edge of the frame, (5) from the space beyond the set or (6) from the space behind and near the camera. The direction of the movement has a major influence on the force dynamics of a shot or any other visual representation. According to Arnheim this is a logical consequence of the force of gravity which makes us live in "anisotropic space, that is, space in which dynamics varies with direction." ${ }^{46}$ This is how, for instance, we come to experience upward movement differently than downward movement. As Arnheim observes, "to rise upward means to overcome resistance-it is always a victory. To descend or fall, is to surrender to the pull from below, and therefore is experienced as passive compliance." ${ }^{47}$ Similarly, the art historian Heinrich Wölfflin has observed that the diagonal running from left to top right is commonly perceived as ascending, while the other is seen as descending. ${ }^{48}$ Notwithstanding the direction of the movement, each instance of entry or exit can be seen as a concrete manifestation of one of the two dynamic patterns as diagrammed in figure 3.9A-B. 
A

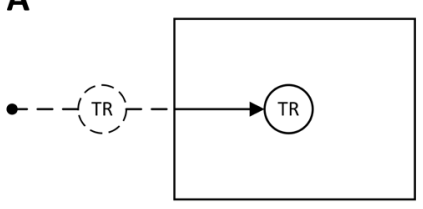

C

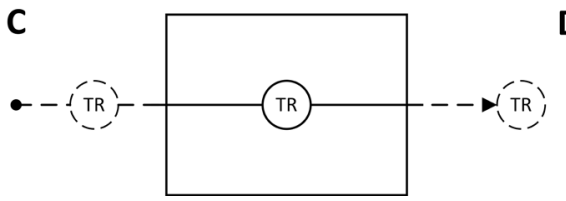

B

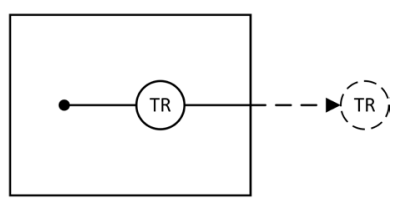

D

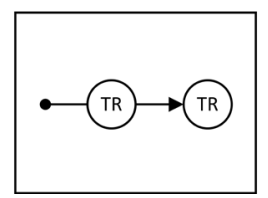

Figure 3.9. $A$, ENTRY, $B$, EXIT, $C$, ENTRY and EXIT, and $D$, no ENTRY nor EXIT.

Both patterns have opposing source-goal locations. In figure 3.9A the source of the TR is located outside the container and the goal is located inside the container, whereas in figure $3.9 \mathrm{~B}$ the source is located inside and the goal is located outside. We may also combine both patterns. In that case both source and goal are located outside (figure 3.9C). If both entities are located inside, then the notions of entry and exit do not apply (figure 3.9D).

As Dewell remarks, pictorial representations such as in figure 3.9 are deceptive in several ways though, making the images appear less schematic and less dynamic than they really are. ${ }^{49}$ For instance, figure $3.9 A-B$ gives the impression of representing a single entry or exit event while they actually give expression to the whole range of image schema transformations. The container may be instantiated in the frame or it may be instantiated in the set (e.g., a room) or any other bounded region within the set (e.g. a mirror). Moreover, both images are schematic with respect to the path arrows. Although they run horizontal, they can be freely rotated so that the entry and the exit could be through any side of the container.

Within these diagrams we might also discern the workings of two other patterns of sensory-motor experience, namely that of VISUAL BLOCKAGE and THE REMOVAL OF VISUAL RESTRAINT (see figure 3.10). The logic of both patterns can be connected to the force image schemas of BLOCKAGE and REMOVAL OF RESTRAINT, respectively. ${ }^{50}$ The former pertains to our everyday encounter of obstacles that block or resist physical force, the latter to our everyday experience of the removal of a barrier or the absence of some potential restraint. This schema thus suggests an open way or path. Here, however, we are not speaking of physical blockage, but of visual blockage, just as Arnheim was not referring to physical balance when discussing balance in visual works of art. VISUAL BLOCKAGE occurs when a visual object is "blocked" from our vision (see figure 3.10A). REMOVAL OF VISUAL RESTRAINT accounts for the removal of this blockage (see figure $3.10 B$ ). The arrows in both figures do not represent a trajectory of an entity, but an entity's transition from a state of invisibility to a state of visibility (and vice versa). Depending on which entity is charged with movement, there are two means to achieve the latter. Either the visual object that is blocked from our vision seeks an alternative pathway of motion so as to enable visualization. This is what happens with ENTRY. 
The object moves from a location blocked from our vision (i.e., the space off-screen) to a location visible to us (i.e., the space on-screen). The opposite occurs with ExIT. Alternatively, visualization can be achieved not by moving the object, but by moving the obstacle itself. In our case, this would entail the movement of the boundary of the container (i.e., the frame). By moving the camera (and thus achieving the effect of the mobile frame) one would be able to include the object into the perceiver's visual field. This discussion, however, will be reserved for the next section of this chapter.

A

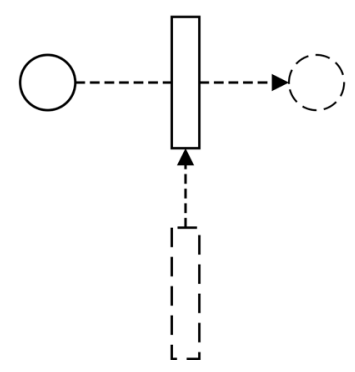

B

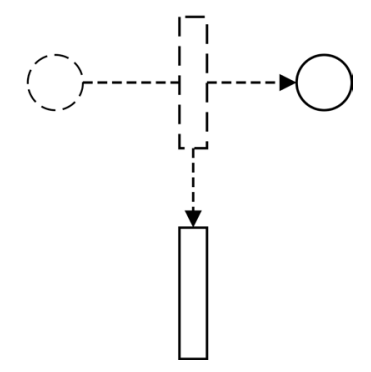

Figure 3.10. $A$, visual BLOCKAGE versus $B$, REMOVAL OF VISUAL RESTRAINT.

Together with the structural elements of the CONTAINER schema, this leads us to map the space outside the container (i.e., off-screen) onto the invisible and the space inside the container (i.e., on-screen) onto the visible. As figure 3.9 above already suggests, this may be processed diagrammatically by using a dashed line for the invisible space and a straight full line for the visible space. Thus, it follows that the dynamic pattern of ENTRY marks the transitional pattern of APPEARING whereas EXIT marks the transitional pattern of DISAPPEARING.

As a way of illustrating the patterns of ENTRY and EXIT, let us consider some examples as selected from Kubrick's films. For instance, figure 3.11 shows a cinematic manifestation of figure 3.9C in which both patterns are elicited by lateral fixed-frame movement. The space pod, operated by Bowman inside of it, enters from the left edge (figure 3.11A). It carries the lifeless body of Frank Poole into the frame. Inside the frame, the pod sets the body free (figure $3.11 B$ ). Due to the loss of gravity in space, Poole now floats inside the frame, to exit it again from its right edge (figure $3.11 C$ ).

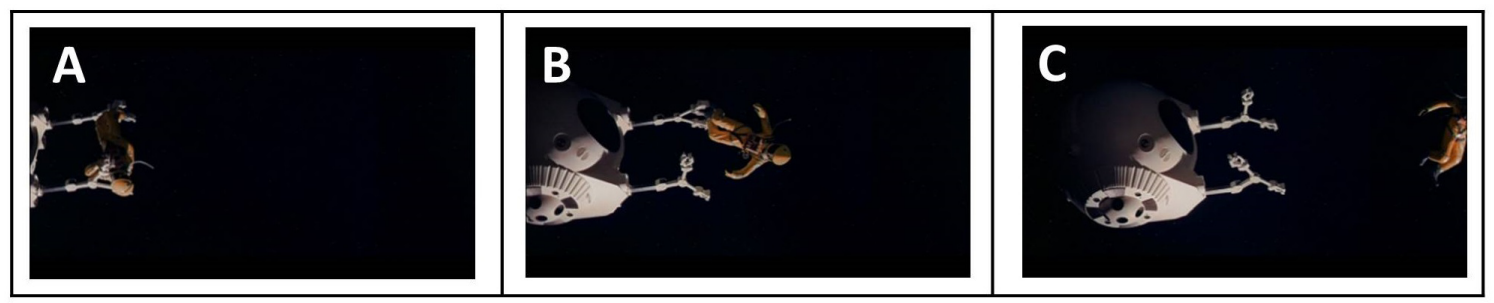

Figure 3.11. ENTRY and EXIT elicited by lateral fixed-frame movement in 2001. 
In this example, Poole's body enters and leaves the frame, not on his own accord, but by an external force imposed upon him by another entity. Let us now consider two variations on the same theme, one in which the character enters the frame by using his intention as an internal force and another in which the other entity, imposing the external force, is blocked from our vision. Figure 3.12 shows an instance of the first variation and a cinematic manifestation of figure 3.9A. It shows the character of Jack Torrance as he rises triumphantly upward into the frame after just having axed his opponent Dick Hallorann to death, a gesture which is mirrored at the musical level by Penderecki's excerpt of Utrenja which articulates a similar "ascending motion."

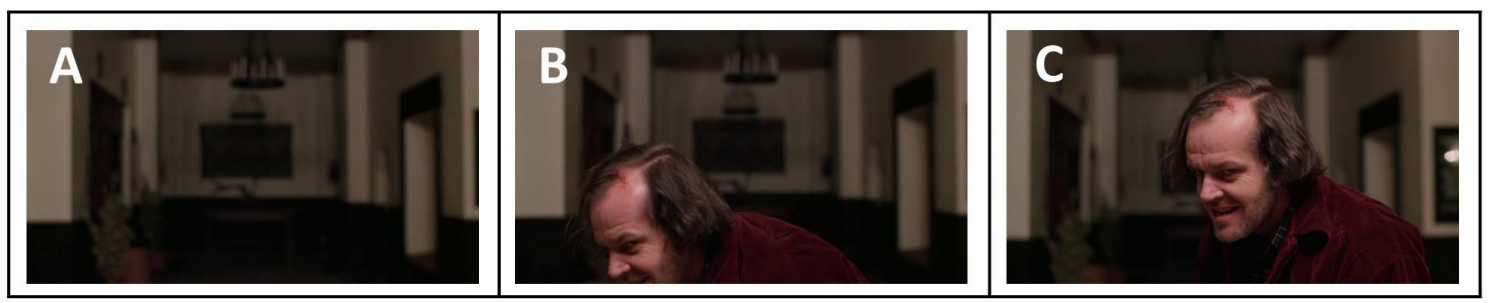

Figure 3.12. ENTRY by upward fixed-frame movement in The Shining (visible origin of force).

The second variation is exemplified in figure 3.13. It shows a high-angle shot of a tennis ball rolling into the frame from its below edge until it halts in the centre of the image where little Danny is residing (figure 3.13A-B). However, the shot, being a high-angle shot, prevents the spectator from seeing (and thus knowing) the origin of the force that sets the ball in motion. This, in turn, raises the question as to where the ball is coming from? The next semi-subjective shot, taken from behind the boy, attempts to answer this question by showing the space in front of his eyes (figure 3.12C). Alas, the only thing we see is an empty corridor. As such the film succeeds in keeping the mystery and suspense intact. ${ }^{51}$
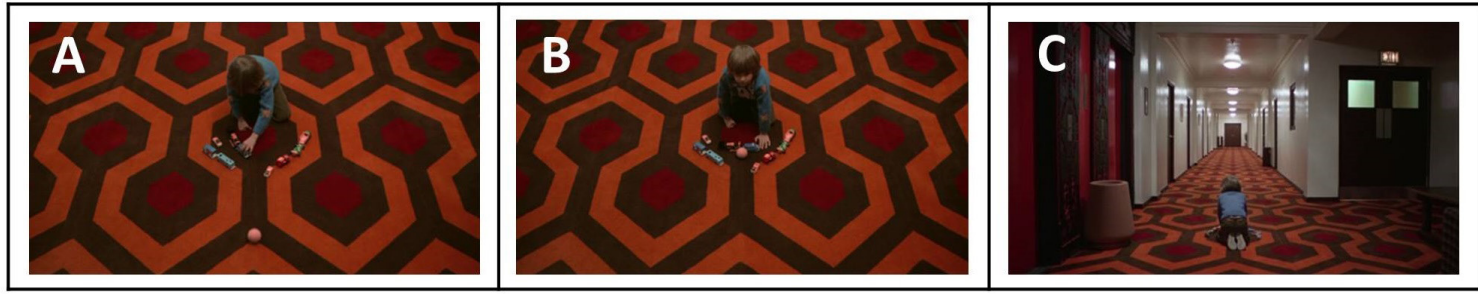

Figure 3.13. ENTRY by upward fixed-frame movement in The Shining (invisible origin of force).

In the examples discussed so far at least one or more of the four edges of the frame are being crossed by the actual movement of the object. By contrast, the fifth way, entry through the set, does not necessarily involve this intersection of the boundary of the frame. For instance, a character may enter or exit the inside of the frame from behind the set 
without intersecting one of its edges. The former occurs, for example, when a character enters the frame by coming in through a door in the back of the image. A good manifestation of this can be found, for instance, in the scene from A Clockwork Orange when Alex frightens the Cat Lady by entering her room uninvited (see figure 3.14). What we see here is a manifestation of figure 3.9A in figure 3.5, whereby the pattern of entry is not related to container A (the frame), as was the case in the previous examples, but to container $\mathrm{C}$ (a bounded region within the set).

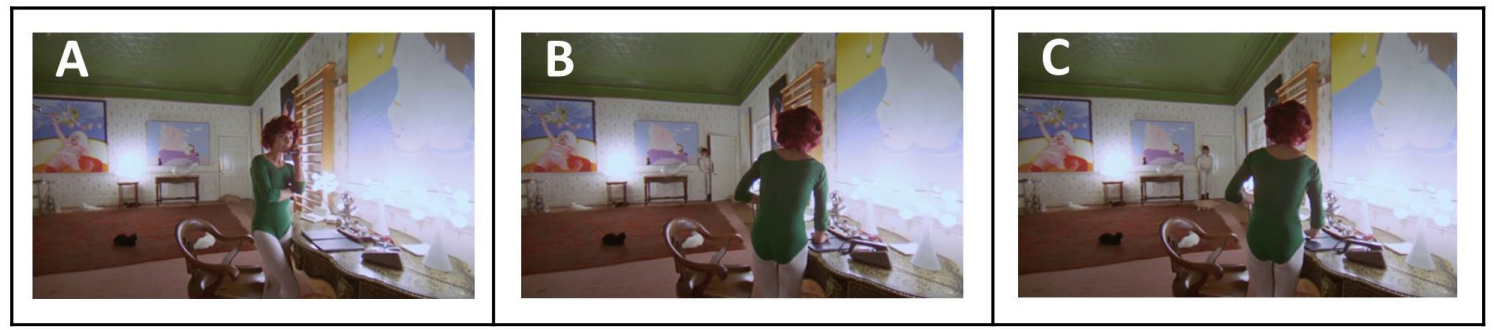

Figure 3.14. ENTRY through a bounded region in the set in A Clockwork Orange.

Moreover, visual objects may also appear in a static frame or disappear from its inside without actually entering or exiting it. This is the case when the patterns of VISUAL BLOCKAGE and REMOVAL OF VISUAL RESTRAINT are manifested inside the visual content of the frame itself. A vivid example of appearing without entry through the removal of visual restraint can be found in the scene from Spartacus where a group of gladiators (including Spartacus himself) are awaiting their duel until death inside a wooden cabin (see figure 3.15). As the door of the cabin slides open, two new parties are revealed into the frame: in the top background, the Roman audience sitting on a balcony waiting for the gladiators to enter the arena, in the center middle, the arena itself taken in by their brutal trainer Marcellus. ${ }^{52}$

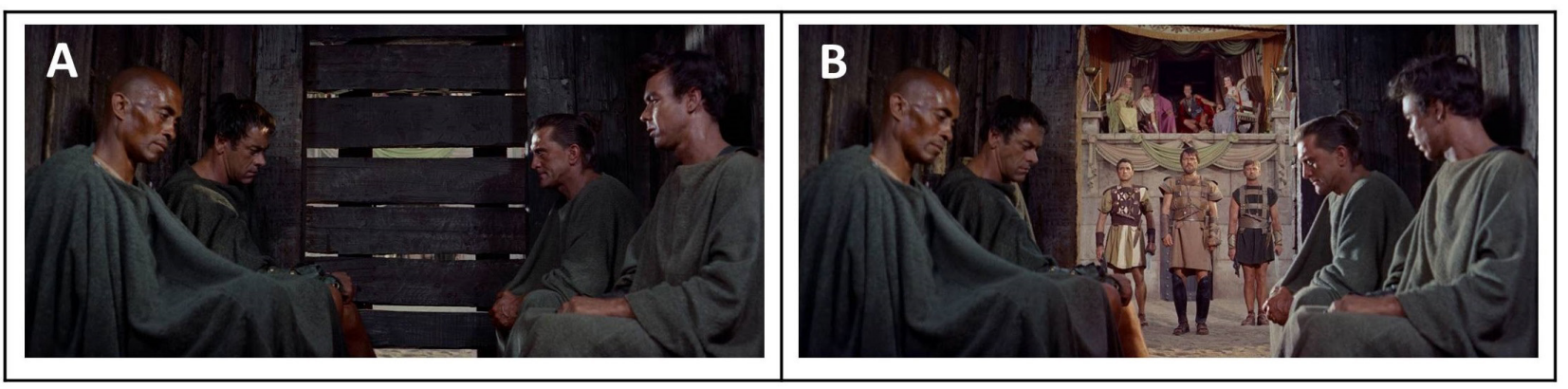

Figure 3.15. Appearing without ENTRY in Spartacus.

From the examples of ENTRY and EXIT (via the frame) we may also draw another finding, namely that the amount of intersection points of the TR with the boundary of the frame depends on the distance of framing. As a general 
rule one can say that the greater this distance, the fewer the amount of intersection points with the frame, and vice versa, the smaller this distance, the higher this amount. For instance, if the TR would exit the fixed frame by moving, along the depth axis, forward to the space near the camera (i.e., the sixth zone of off-screen space), all edges of the frame will be crossed.

The distance does not only influence the amount of intersection points, but also the amount of space inside of the frame that is being occupied by the TR. The framed TR may be far from the camera, but moving in the camera's direction. In that case the amount of space occupied by the TR will gradually increase. By contrast, the TR may also be close to the camera, but moving away from the camera's location. In that case the amount of space occupied by the TR decreases. Two dynamic patterns that we can naturally capture as an APPROACHING schema and a DISTANCING schema, respectively. ${ }^{53}$ The greater the distance, the smaller the TR and the "emptier" the frame, and vice versa, the smaller the distance, the larger the TR and the "fuller" the frame. Both patterns might be diagrammed as in figure 3.16. The dashed circle represents the TR's starting location whereas the full lined circle represents the TR's ending location.
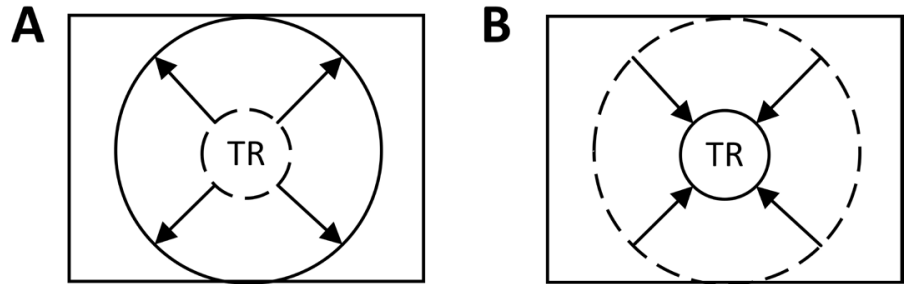

Figure 3.16. $A$, APPROACHING versus $B$, DISTANCING.

We already encountered two cinematic manifestations of the first pattern in figure 3.6. Another example can be found, for instance, in 2001 when the space pod rapidly approaches Frank Poole, whose lifeless body resides offscreen in the area behind the camera (see figure 3.17). The pod gradually evolves from a little, almost unnoticeable dot in the centre of the frame $(A)$ to a full blown-up figure occupying almost one third of the image $(B)$.

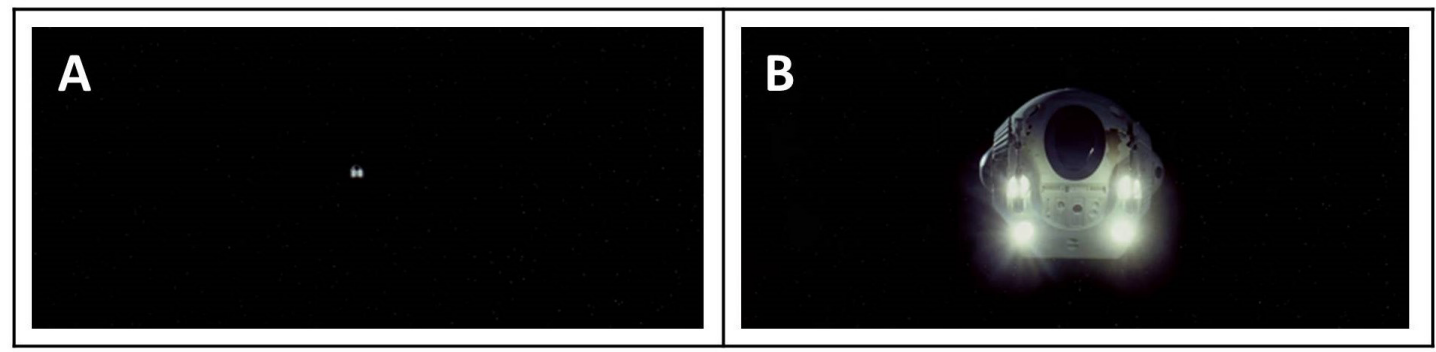

Figure 3.17. Approaching in 2001. 
The shot from Fear and Desire, as shown in figure 3.18, illustrates a striking example of the second pattern. It starts with a close-up of the face of Sidney $(A)$, the private who was left behind to guard the young peasant girl whom the soldiers have apprehended. As he turns around and walks away from the camera, the girl is revealed inside the frame, as she is bound to a tree $(B-C)$. As with figure 3.15 this shot exemplifies a case of appearing through the removal of a visual restraint, albeit this time the revealing is instantiated by a pattern of DISTANCING elicited by the blocking entity (i.e., Sydney).

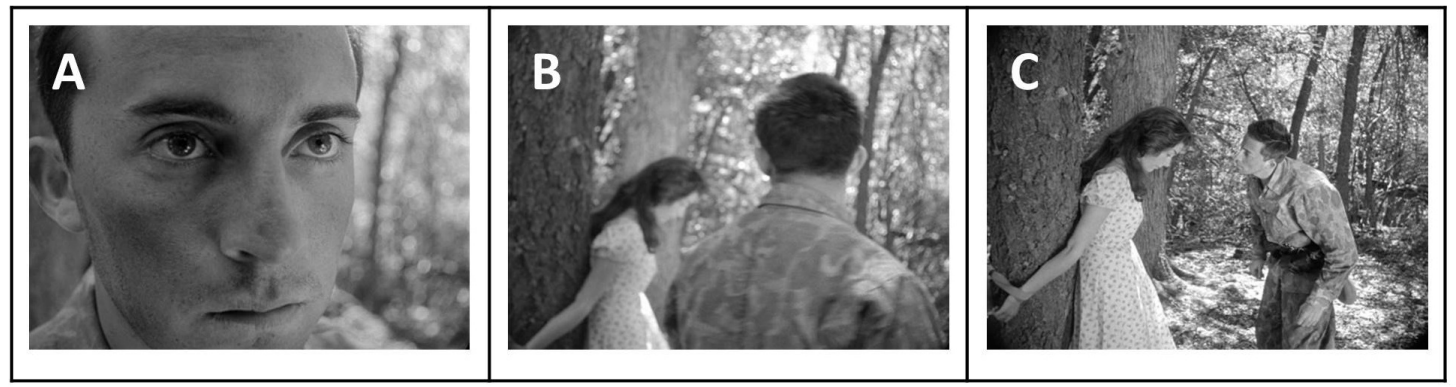

Figure 3.18. Appearing by distancing in Fear and Desire.

\subsubsection{Dynamic patterns of mobile framing}

Having addressed some of the dynamic patterns of containment that are inherent to fixed-frame movement, let us now shift our attention to the frame as trajector as captured by the concept of "mobile frame." This concept may be defined as the effect on the space inside the frame as a result of actual or apparent camera movement caused by external forces exerted on the camera. As a starting point, let us first define what we mean by the term "actual or apparent camera movement"? It refers to a distinction within the general category of camera movement between two types of movement.

We speak of "actual" camera movement when we can attribute literal movement to the physical entity of the camera. One may further divide this type into two subtypes, that is, the effect of the mobile frame may be elicited either (1) by a camera that has its body moving from a fixed physical location, or (2) by a camera that has its body moving from one physical location to another. The first subtype of camera movement is reminiscent of the head and eye movements of a stationary human body and further designates two camera techniques: panning in which the camera's line of sight moves in a horizontal plane to the left and right and tilting in which the camera's line of sight moves in a vertical plane, up and down. ${ }^{54}$ The second subtype of camera movement has the camera travelling along a pathway (either predetermined or not). If the camera moves alongside the photographed object(s) it is called a tracking shot. By definition, this movement allows for numerous possibilities including in-and-out movement (i.e., closer/further away from the subject) as well as side-to-side movement.

In addition, the effect of the mobile frame might be created without requiring any literal movement of the camera. Hence, the term "apparent" camera movement. This type commonly coincides with the use of zoom lenses. 
Consisting of a series of lenses that keep the image in constant focus, the zoom lens allows a stationary camera to glide fluidly toward or away from the subject. ${ }^{55}$

Notwithstanding these distinctions, camera movement can only occur insofar there is an external force that causes the camera to move (either literally or apparently). This brings us to the second part of the definition. As the term "external" suggests, this part excludes the possibility of any internal force. This marks a fundamental difference with lively subjects such as actors to which both forces may apply. An actor may move itself into the frame by using its intention as internal force or he may be moved into the frame by an external force (e.g., he can be pushed into the frame by another entity). In the case of camera movement, however, the force is always external, meaning that a camera, being a lifeless mechanical device, cannot move on its own. In other words, the camera has an intrinsic force tendency toward rest. As such it can only be moved by means of the application of an external force. This external force is the concept by virtue of which we understand the cause of camera movement. Inferential evidence for this metaphorical mapping can be found in the systemic relationship between the logic of forced camera movement and the logic of causation (see table 3.4). As the reader may notice, this table is identical to table 2.9 from the previous chapter except for now the moving entity is specified as the camera.

Table 3.4. The inferential correspondences between forced camera movement and causation.

\begin{tabular}{|c|c|}
\hline Inferences true of forced camera movement & Inferences true of causation \\
\hline $\begin{array}{l}\text { The application of the external force precedes or } \\
\text { accompanies the camera movement. }\end{array}$ & $\begin{array}{l}\text { The occurrence of the cause precedes or accompanies } \\
\text { the effect. }\end{array}$ \\
\hline $\begin{array}{l}\text { The camera movement would not have occurred } \\
\text { without the application of an external force. }\end{array}$ & $\begin{array}{l}\text { The change of state would not have occurred without a } \\
\text { cause. }\end{array}$ \\
\hline The external force impinges on the camera. & The cause impinges on the entity that changes state. \\
\hline
\end{tabular}

It is in locating the origin of this external force that the role of the camera operator or cameraman comes into prominence as he or she is the person responsible for exerting a force onto the camera (i.e., the target to which the force is directed) causing it to move, literally or apparently, so as to achieve the effect of the mobile frame. Schematically, this causal relationship might be put as follows (where the double arrow denotes "leads to"):

Force acting upon camera $=>$ Camera movement $=>$ Effect of the mobile frame

The application of the force onto the camera might take several forms of which its variety might best be understood in terms of verbs of forced movement such as "moving," "pushing" or even "throwing." A vibrant application of the latter verb can be found in A Clockwork Orange. When Kubrick in an interview with Sight \& Sound was asked how he managed to create the subjective shot of Alex jumping out of the window, the director answered (italics mine):

We bought an old Newman Sinclair clockwork mechanism camera (no pun intended) for $£ 50$. It’s a beautiful camera and it's built like a battleship. We made a number of polystyrene boxes which gave about 18 inches of protection around the camera, and cut out a slice for the lens. We then threw the camera off a roof. In order to get it to land lens first, we had to do this six times and the camera survived all six drops. On the final one it landed right on the lens, and smashed it, but it 
didn't do a bit of harm to the camera. This, despite the fact that the polystyrene was literally blasted away from it each time by the impact. The next day we shot a steady test on the camera and found there wasn't a thing wrong with it. On this basis, I would say that the Newman Sinclair must be the most indestructible camera ever made. ${ }^{56}$

As Lakoff and Johnson have pointed out, it is interesting to see how various verbs seem to specify different kinds of forced movement. ${ }^{57}$ The verb "throw" describes a situation in which the camera operator applies a force instantaneously or for a very short time, and the movement of the camera occurs after the removal. As the example above already suggests, throwing is a rather unorthodox way for a camera operator to move a camera from one location to another. In the majority of times, the camera operator will simply move the camera by moving its position. As a verb of forced motion, "move" describes a situation in which a force is applied constantly rather than temporally. The application of this verb may be illustrated through the workings of three cinematic techniques which all occupy a significant place in the work of Kubrick: the Steadicam, the dolly and the hand-held camera.

The Steadicam is a portable, one-person camera with a build-in gyroscope device that prevents or compensates for rough camera movements (i.e., camera shake). The result is a smooth shot, even when the person carrying the camera is running over an irregular surface. In order to achieve this weightless effect, the camera is mounted on to a spring-loaded arm, which is attached to a frame, which is in turn strapped to the operator's shoulders, chest and hips. Kubrick used the Steadicam technique ever since The Shining, when he hired Garrett Brown, its inventor, to shoot the fast, flowing camera movements in the maze (see figure 3.19).

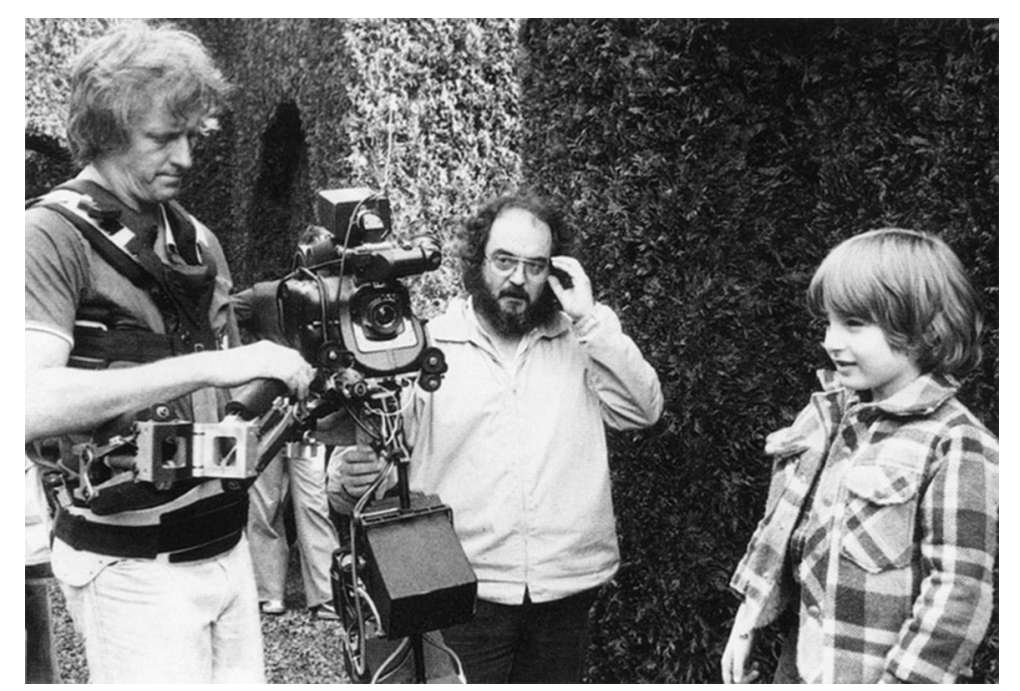

Figure 3.19. Garrett Brown with his Steadicam on the set of The Shining. Courtesy of Garrett Brown.

In an interview with French film critic Michel Ciment about the making of this film, the director commented on the technique as follows (an excerpt from it): 
The Steadicam allows one man to move the camera any place he can walk -- into small spaces where a dolly won't fit, and up and down staircases. We used an Arriflex BL camera, which is silent and allows you to shoot sound. You can walk or run with the camera, and the Steadicam smooths out any unsteadiness. It's like a magic carpet. ... The only problem with the Steadicam is that it requires training, skill and a certain amount of fitness on the part of the operator. You can't just pick it up and use it. But any good camera operator can do useful work even after a few days' training. He won't be an ace but he'll still be able to do much more than he could without it. I used Garrett Brown as the Steadicam operator. He probably has more experience than anyone with the Steadicam because he also happened to invent it. ${ }^{58}$

Before the introduction of the Steadicam, a director had two choices for moving the camera from one location to another. One time-consuming and less practical way was to mount the camera on a wheeled cart, the so-called dolly. The person who operates the dolly is called a dolly grip. Likewise, the position of dolly grip can be considered a highly skilful one as he or she has to push and pull the cart and usually a camera operator and camera assistant as riders. So here we have the interaction of two forces causing the camera to move: the force exerted on the dolly by the dolly grip and the force exerted on the camera by the camera operator. Examples of tracking shots using in-out dolly movement can be spotted in the early work of Kubrick. Notable in this regard are the dolly shots in the trenches from Paths of Glory (see figure 3.20).

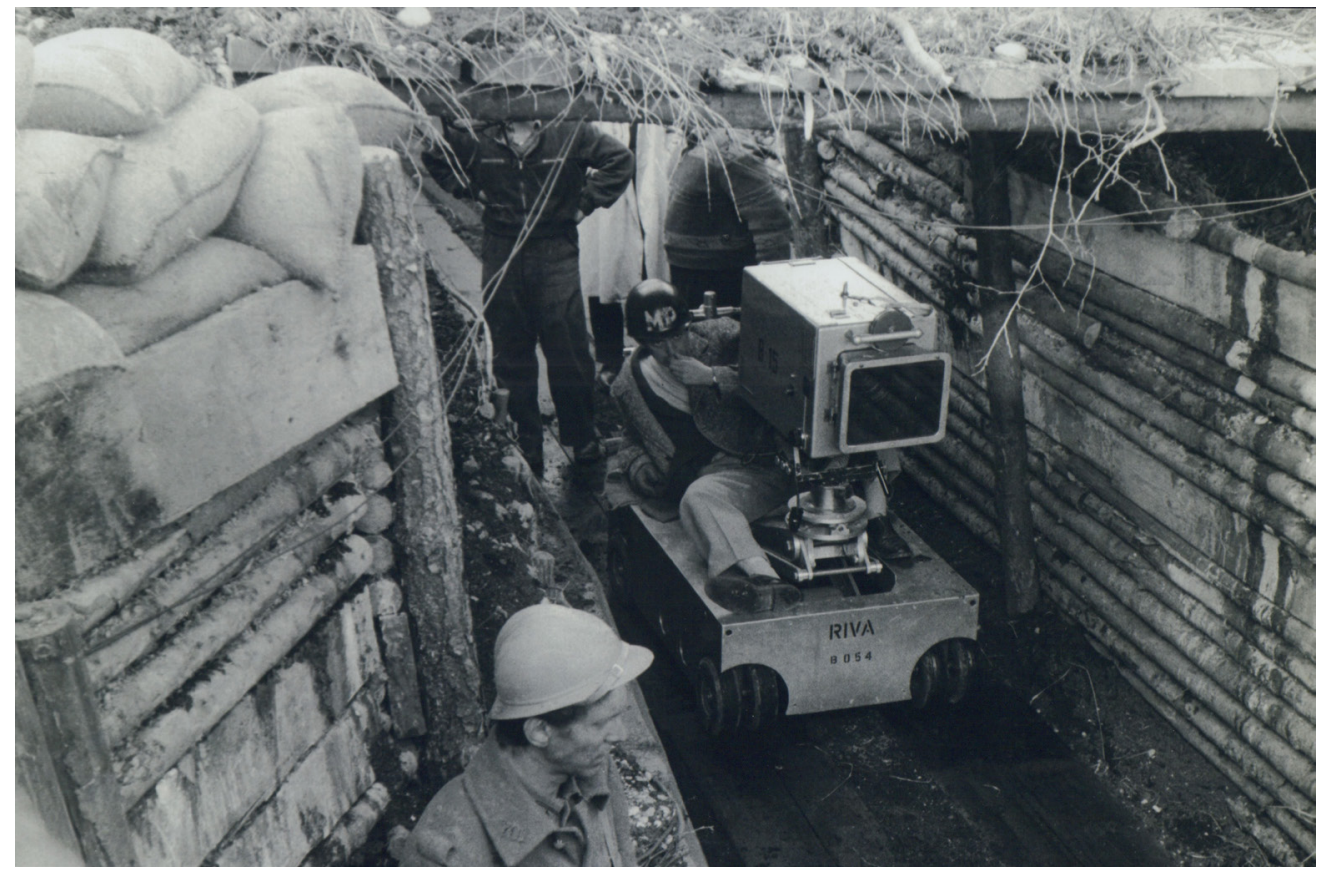

Figure 3.20. A young Stanley Kubrick surveilling the trenches scene from atop a dolly during the filming of Paths of Glory. Photograph presumably taken by Lars Looschen. Courtesy of Bryna Productions, United Artists. 
The other way, less impractical and less time consuming, but even more sensitive for camera shakes, would be simply holding the camera in your hands while moving from one location to another (i.e., hand-held shooting). Likewise, the camera operator has to exert a force continually on the camera in order to prevent it from falling. Interestingly, in locating the origin of the hand-held camera work in his films, one may point to the director himself as many, if not all of the hand-held shots are his. In the same interview with Sight \& Sound as above, he motivated this choice as follows: "In addition to the fun of doing the shooting myself, I find it is virtually impossible to explain what you want in a hand-held shot to even the most talented and sensitive camera operator." ${ }^{59}$ Given its tendency toward shaking, hand-held camera footage has been traditionally used for the shooting of documentaries, news, reportage, live action, or the evocation of authentic immediacy or cinéma vérité during dramatic sequences. This is not any different in Kubrick's work where the hand-held camera has been used to shoot, among others, the U.S. army's attack of Burpelson Air Force Base in Dr. Strangelove, the astronauts' approach of the monolith in 2001, Alex's brutal beating and rape of Mr. Alexander and his wife as well as his fight with the Cat Lady in A Clockwork Orange, and, as can be seen in figure 3.21, Redmond's bare-knuckle fight scene with troublemaker Toole in Barry Lyndon.

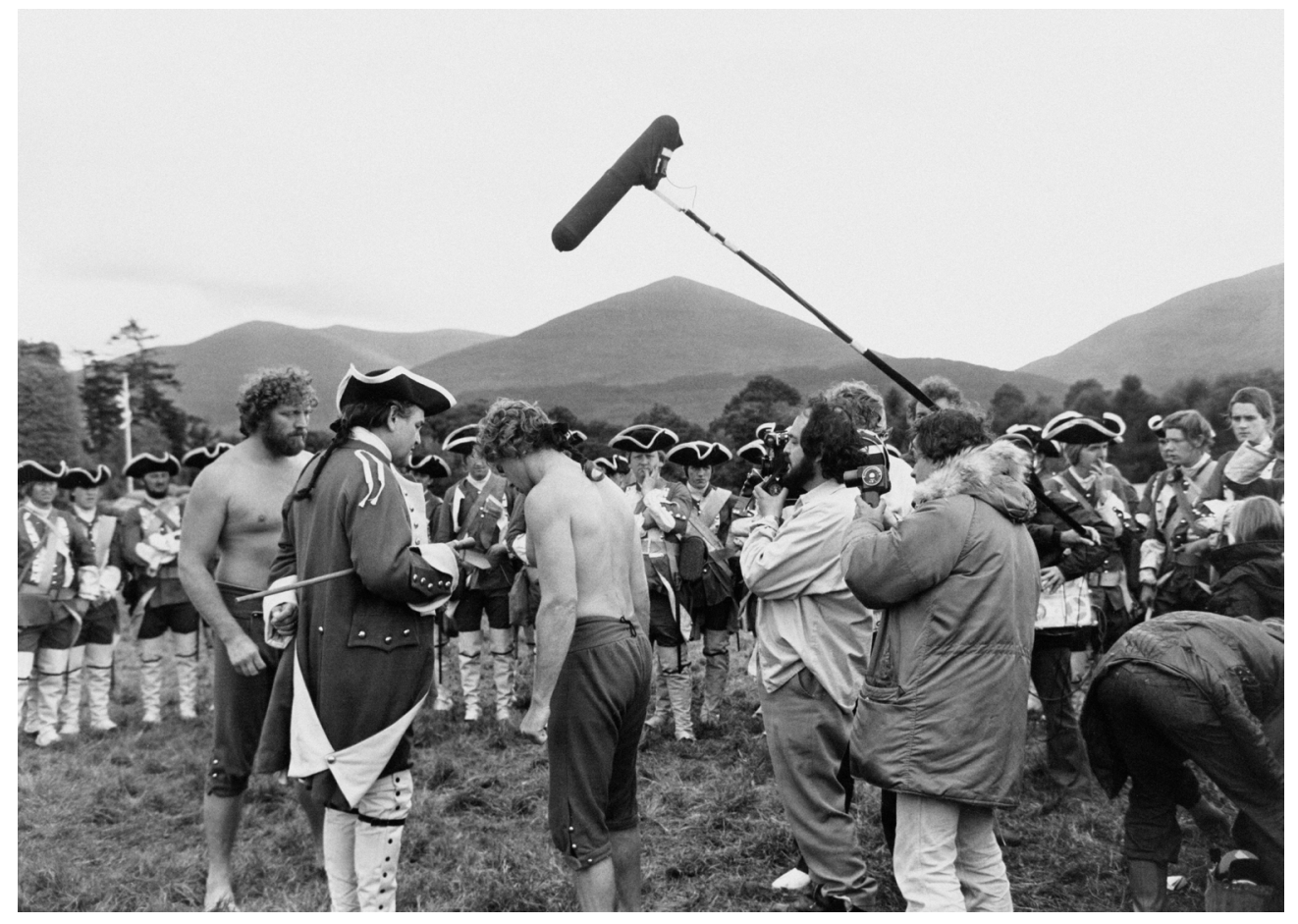

Figure 3.21. Stanley Kubrick while hand-held filming Redmond's bare-knuckle brawl with troublemaker Toole at the army encampment. Courtesy of Alamy Stock Photo. 
It is only when an external force acts upon the camera that camera movement (i.e., the effect of the force) comes into being and the camera seems to acquire an existence detached from the force that triggered it. This is evidenced in our language about camera movement which considers such expressions as "the camera zooms in," "the camera moves" or "the camera dollies in." Each of these expressions takes the camera as an independent entity that, much like a human being, is capable of moving on its own by using its intention as an internal force.

With the effect of the camera movement comes also the effect of the mobile frame. As the definition of the mobile frame above already suggests, this effect is measured in terms of the relationship between the movement of the camera and the change of space inside the frame that results from it. Likewise, we might discuss this effect by distinguishing between several dynamic patterns of containment. Here, we will discuss four of them as they can be referred to as (1) INCLUSION, (2) EXCLUSION, (3) ENCLOSURE and (4) EXPOSURE, respectively. They correspond to the four patterns of fixed-framed movement (ENTRY, EXIT, APPROACHING and DISTANCING) with this crucial difference that now the container is the trajector and the visual object is the relatively stationary entity.

INCLUSION occurs when the container includes a new visual object into the frame. Disregarding the force that instantiates the camera movement, this may be represented as in figure $3.22 \mathrm{~A}$ whereby the dashed-lined rectangle represents the initial starting point of the container's movement and the full-lined rectangle represents its ending point. By contrast, EXCLUsion, as diagrammed in figure 3.22B occurs when the container excludes a visual object from its inside content.

A

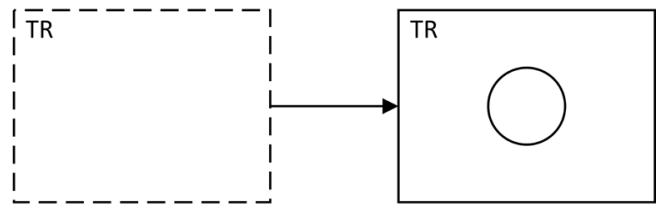

B

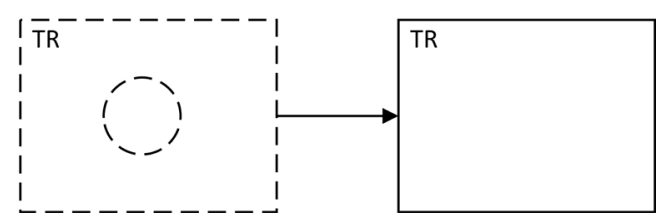

Figure 3.22. $A$, INCLUSION and $B$, EXCLUSION.

Again, it must be stressed that these diagrams are representations of dynamic image schematic structures. As such they can be instantiated in various camera movements, including not only the lateral horizontal movement, as suggested by the diagrams, but also the lateral vertical and the diagonal camera movement.

Despite the fact that both patterns are clearly distinguishable from one another, they are nevertheless constantly and simultaneously at work meaning that the inclusion of one visual object always entails the 
exclusion of another visual object and vice versa. As a way of illustrating this, consider the following lateral camera movement from Barry Lyndon, as shown in figure 3.23. The shot starts with the camera already in motion showing us a group of three people $(\mathrm{O} 1)(A)$. As they approach the balcony, the camera slowly pans to the right, thus gradually relocating the group to the off-screen space. Simultaneously, as they disappear, a sleeping man appears $(\mathrm{O} 2)(B)$. As with the previous group, this screen appearance, however, is short-lived as the camera does not halt, but continues his path along the horizontal line of the balustrade until it includes its two leading characters (O3), Redmond Barry and the Chevalier du Balibari, into the frame (C).

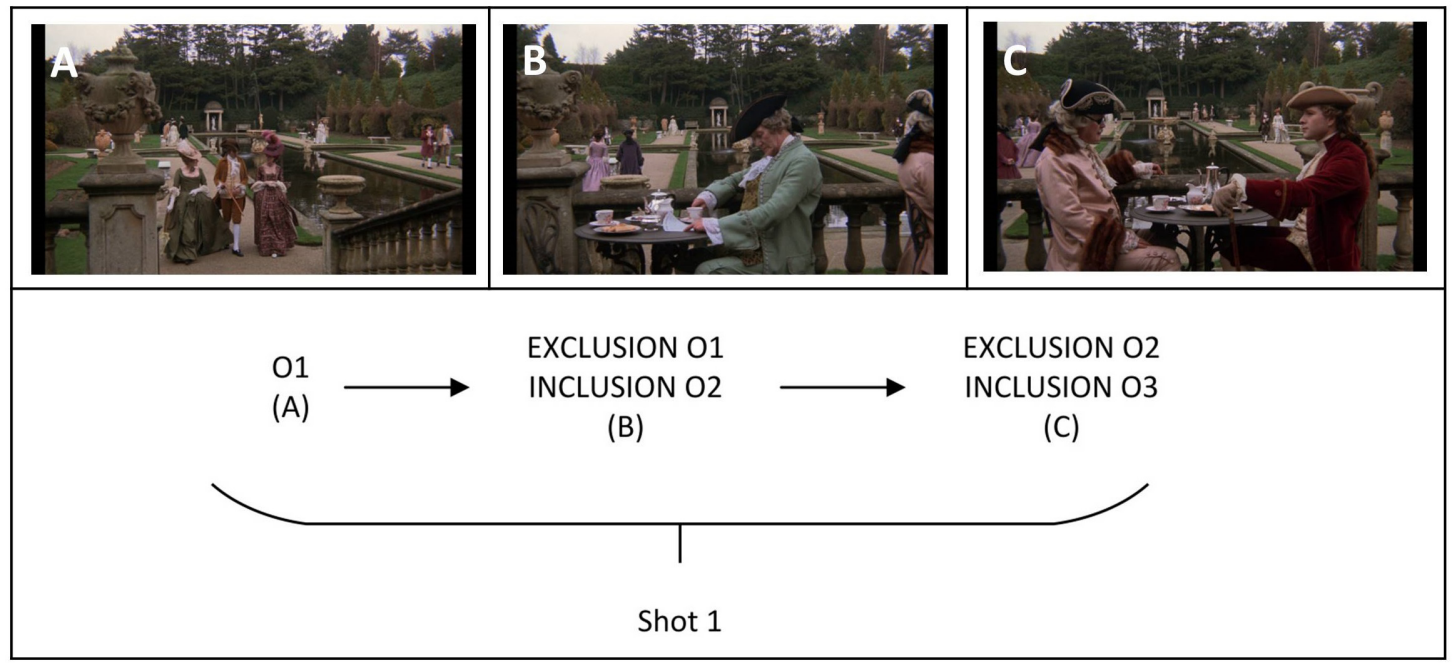

Figure 3.23. INCLUSION and EXCLUSION by lateral camera movement in Barry Lyndon.

The patterns of INCLUSION and EXCLUSION, as diagrammed in figure 3.23, are given expression through lateral camera movement. Figure 3.24, taken from Eyes Wide Shut, shows us an example in which the same effect is achieved, but this time through a semi-circular camera movement. The camera shows the front of Alice (O1) as she is standing stationary and without her husband Bill at the Ziegler's Christmas party $(A)$. The camera then slowly and graciously moves around her left side thus gradually excluding her face (O1) and including her back $(\mathrm{O} 2)(B)$. Simultaneously, as the semi-circular camera movement has come to an end, the increasing distance between the camera and Alice allows for the inclusion of a new character, the flirtatious Hungarian Sandor Szavost (O3) who, in the events that follow, will attempt to hit on her $(C)$. Here, one already may anticipate the goal of the next chapter as this camera movement might be extended metaphorically through the PERSON IS A CONTAINER metaphor. Annoyed by her husband's absence and giddy on champagne, which weakens the boundary of marriage, she lays herself more "open" toward other men. 


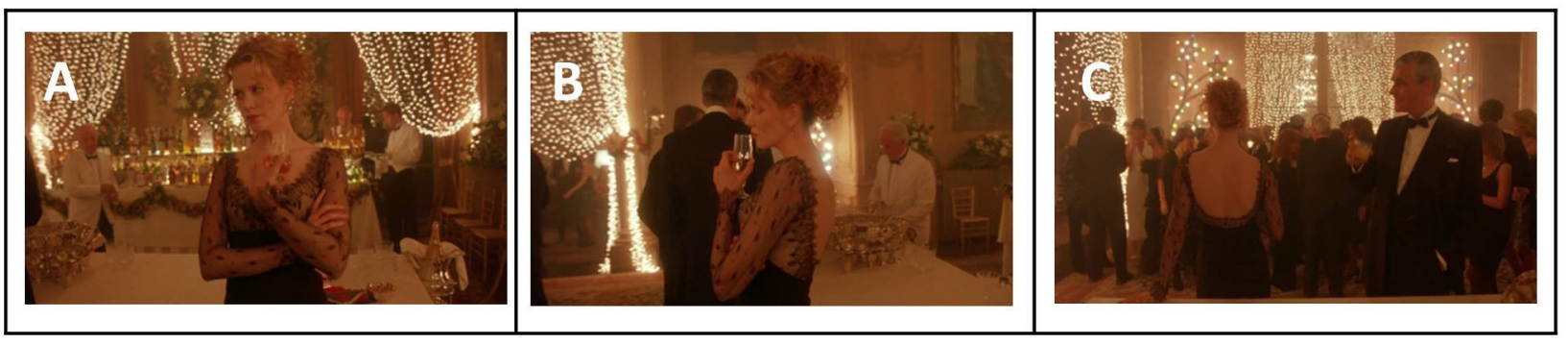

Figure 3.24. EXCLUSION and INCLUSION by semi-circular camera movement in Eyes Wide Shut.

A visual object $\mathrm{X}$ will not be included nor excluded when the frame shifts to keep that object $\mathrm{X}$ on-screen. This is the case, as other examples will show us later on, with a following shot.

ENCLOSURE occurs when the container closes in on the visual object so as to exclude the free space that resides between the boundary of the container and the object inside of it. This can be diagrammed as in figure 3.25A. Naturally, this pattern is inherent to in-depth camera movement in which the camera moves, apparently or literally, toward the object. By contrast, EXPOSURE occurs when the distance between the boundary of the container and the object increases so as to permit the inclusion of more space inside of it. Consequently, the arrows are pointing outward rather than inward (figure 3.25B). Likewise, this pattern is inherent to in-depth camera movement in which the camera moves, apparently or literally, away from the object.
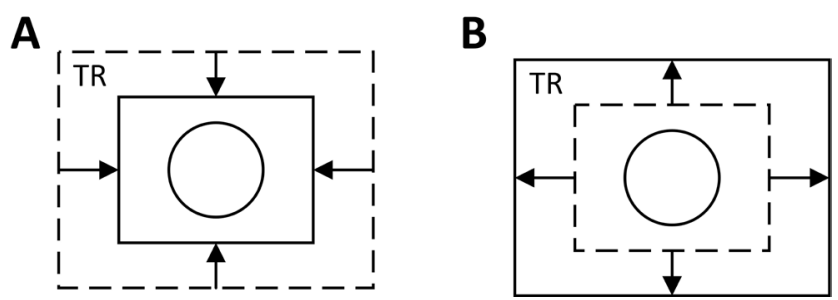

Figure 3.25. $A$, ENCLOSURE and $B$, EXPOSURE.

Both patterns are expressed through what is perhaps one of the trademarks of Kubrick's stylistic system, namely the use of the zoom lens. As already stated, movement elicited by this device can be seen as a rather unusual type of camera movement in that the camera does not physically move from one location to another. Yet, as with literal camera movement the camera has to be forcefully controlled in order for it to achieve the effect of the mobile frame. This is also expressed by the English cinematographer John Alcott who collaborated four times with Kubrick (2001, A Clockwork Orange, Barry Lyndon and The Shining). When, in an interview with the journal American Cinematographer, he was asked about the use of the zoom lens in Barry Lyndon, he answered: 
Oh, yes-we used it a great deal. The Angenieux 10-to-1 zoom was used on the Arriflex 35BL, in conjunction with Ed DiGiolio's Cinema Products "Joy Stick" zoom control, which is an excellent one. It starts and stops without a sudden jar, which is very important, and you can manipulate it so slowly that it almost feels like nothing is happening. This is very difficult with some of the motorized zoom controls. I find that this one really works. ${ }^{60}$

Shots that result from the forceful use of this "joy stick" zoom control are abundant and can be found in almost each of Kubrick's films. Figures 3.26 and 3.27 compile a selection of two zoom movements (one for each pattern) as they were gathered from The Shining and Barry Lyndon, respectively. As shall become clear in the next chapter, the speed in which these patterns unfold should be seen in function of the subject matter (e.g., slow movement for contemplation and fast movement for abrupt and suspenseful perceptions).
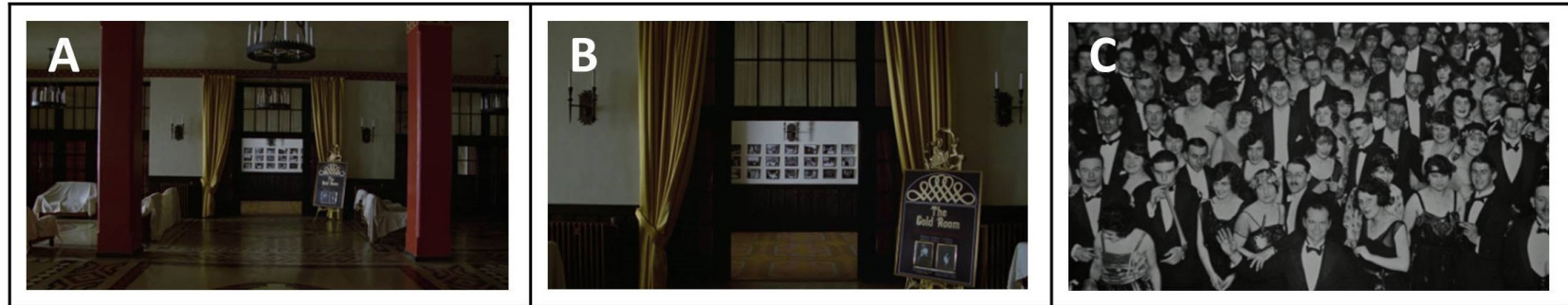

Figure 3.26. ENCLOSURE as elicited through the use of the zoom-in lens in The Shining.

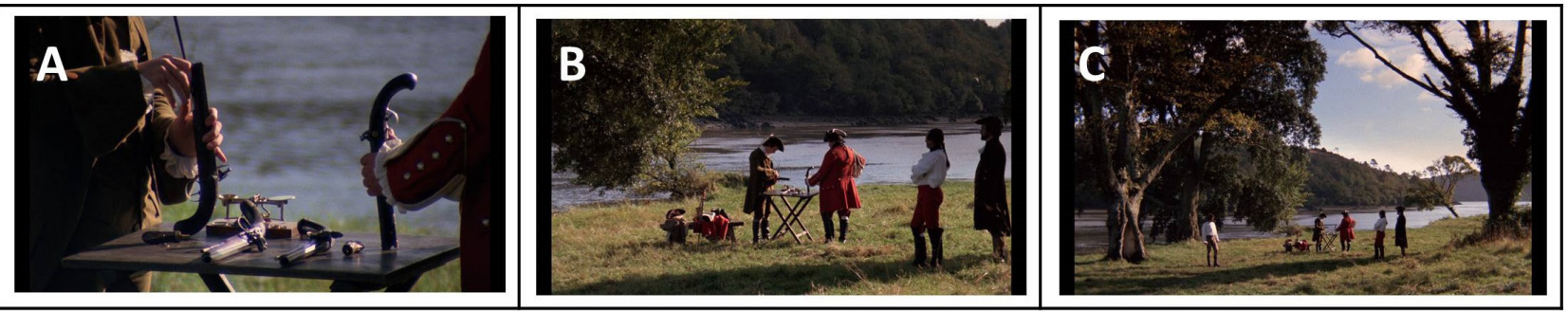

Figure 3.27. EXPOSURE as elicited through the use of the zoom-out lens in Barry Lyndon.

In the manifestations of both patterns we may also observe the workings of another image schema, that of PARTWHOLE. ${ }^{61}$ As with the CONTAINER image schema, this schema is grounded in the experience of our bodies (i.e., as wholes with parts). Consisting of the structural elements of a whole, parts, and a configuration, we may follow Lakoff and articulate its basic logic according to the following postulates: "If A is a part of B, then B is not a part of A. ... If the parts exist in the configuration, then and only then does the whole exist." ${ }^{62}$ From this it follows that "if the parts are destroyed, then the whole is destroyed." Given this brief description, then, one may define ENCLOSURE as a specific case of ExCLUsion where its starting point delineates the whole and its ending point a part of that 
whole. By contrast, EXPOSURE can be defined alternatively as a specific case of INCLUSION where its starting point conjoins with a part of the whole and its ending point with the whole. Again, we might turn to the logic of CONTAINMENT to draw these inferences. Figure 3.28 diagrams this logic as applied to figures 3.26 and 3.27, respectively.

A

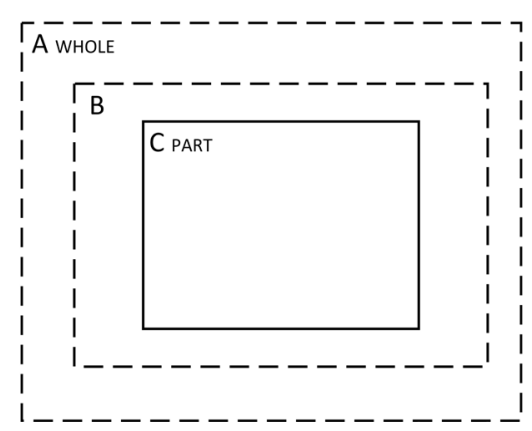

B

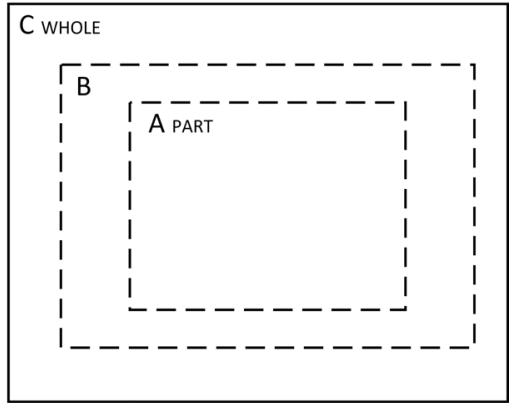

Figure 3.28. The inferential logic of CONTAINMENT as inherent to the dynamic patterns of $A$, ENCLOSURE and $B$, EXPOSURE.

It is here that we may discern a fundamental difference with the example as illustrated in figure 3.23. The image that serves as the ending point of the camera movement in this figure does not constitute a part of the image that serves as the starting point of that same movement (and vice versa).

\subsubsection{Linking dynamic patterns in one shot: The long take}

Having discussed and illustrated both groups of dynamic patterns in isolation, let us now turn toward the question of their interaction. Which dynamics arise from the pairing of dynamic patterns in a single shot? Since film unfolds in time and space, the filmmaker has the possibility of structuring the visible world in such a way as to create a complex and structured whole in which two or more dynamic patterns are bonded together in temporal succession through a LINK schema. As we already saw in the previous chapter, a LINK schema is an image schema that consists of two or more entities, connected physically or metaphorically, and the bond between them. Naturally, the unfolding of such links of dynamic patterns in one and the same shot depends on the duration of the shot. The longer the shot lasts, the more likely that more than one dynamic pattern will unfold in the shot. This brings us to the technique of the long take. ${ }^{63}$ The long take is a shot that lasts much longer than the conventional editing pace either of the film itself or of films in general. As such, it has the potential for eliciting a series of dynamic patterns. Again, Kubrick's work is highly illuminating in showing how this might unfold cinematically. To illustrate this, let us consider the underlying image schematic structures of two long takes taken from The Killing.

The first long take occurs just before Johnny Clay, the leader of the gang, enters the back office to steal $\$ 2$ million from the money-counting room. The second long take occurs afterward when the conspirators are gathered at an apartment where they are to meet Johnny and divide the money. In both long takes Kubrick manages to connect various group members by eliciting a series of dynamic patterns. To structure the analysis somehow, we first provide a 
schematic and formal outline of the linkage of dynamic patterns underlying the long take. In this overview the various dynamic patterns are grouped by an underbrace representing the single shot. Moreover, each dynamic pattern will be illustrated by one still image of the film. For practical reasons we will show the reader only a snapshot of the moment that accords with the ending point of the SOURCE-PATH-GOAL image schema as embedded in the movement of either the character or the camera. For example, if the pattern is INCLUSION, the letter associated with it, will correspond with a screenshot showing the included visual object (as opposed to a screenshot of the empty frame).

Having said this, the underlying structure of the first long take might be represented as in figure 3.29.

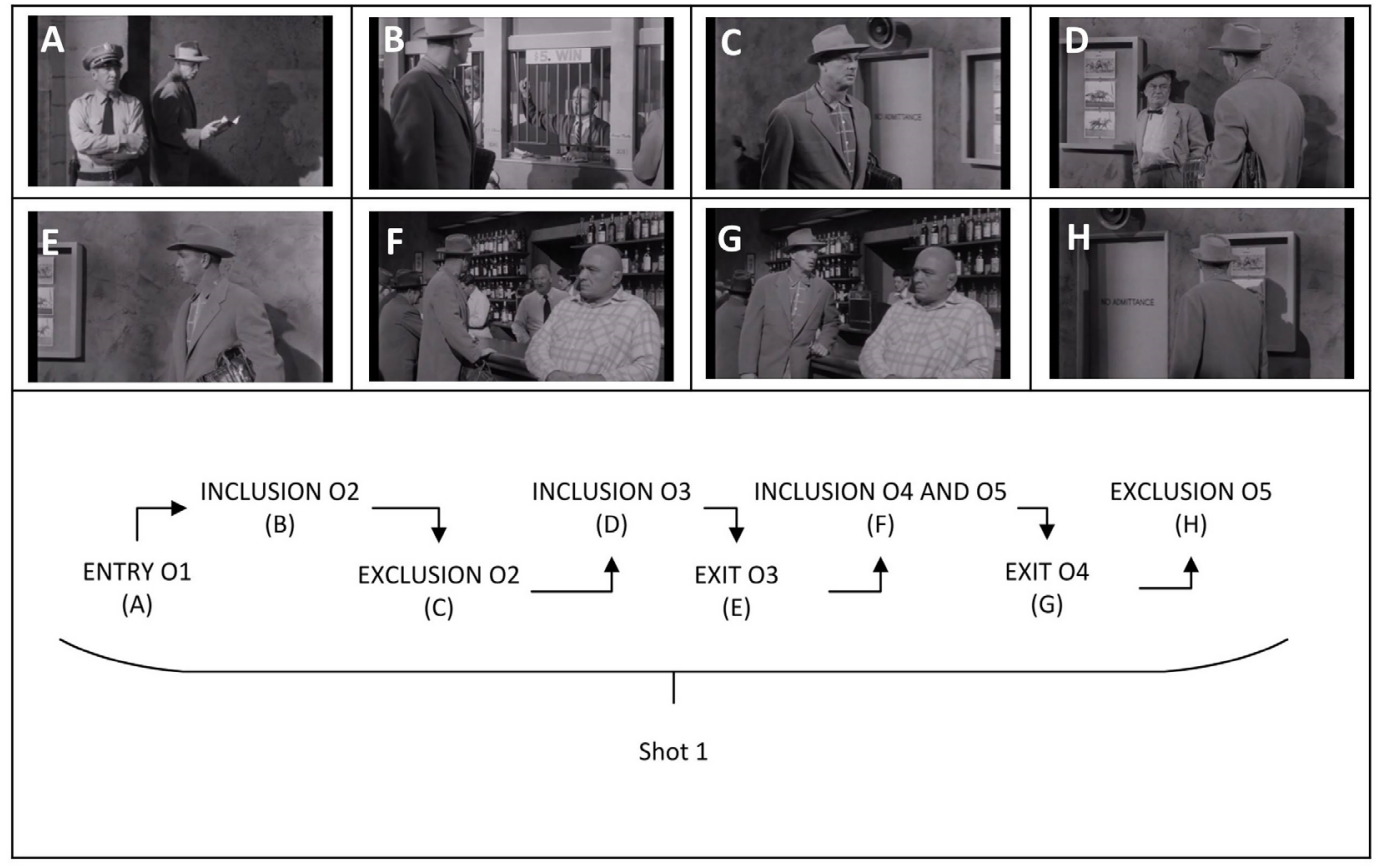

Figure 3.29. Linking various dynamic patterns of containment via the long take in The Killing (case one).

The schema reads as follows: Johnny Clay $(\mathrm{O} 1)$ enters the frame from behind the set $(A)$. The camera follows him as he walks toward the clerk George Petty (O2) who is now included as a stationary entity by the movement of the camera $(B)$. The camera excludes him again as soon as Johnny continues his walk figure $(C)$. He then makes a turn as he recognizes Marvin Unger (O3), the bookkeeper of the group $(D)$. Again, the character is included by the movement of the camera. However, this time the character himself exits the frame rather than the camera excluding him $(E)$. Johnny continues his walk, this time toward the bar where Mike O'Reilly (O4), the track bartender, and Maurice Oboukhoff (O5), the wrestler, are awaiting his signal to start off the distraction scene $(F)$. Mike leaves the frame by exiting it from the right side of the frame $(G)$. Maurice is excluded as Johnny now walks toward the door that gives entrance to the back office where the race track money is hidden $(H)$. The label "no admittance" 
clearly signals that entry here is strictly forbidden. Later in the film, when Maurice has caused a quarrel thus attracting the cops, George will open the door for Johnny to come in and rob the place.

After the successful robbery the group members are gathered at the apartment where they are anxiously awaiting the arrival of Johnny. Similarly, the scene is rendered in one single take in which various characters are introduced by the camera following one character, in this case, the nervous clerk George Petty. Likewise, the dynamic structure underlying this long take might be represented as in figure 3.30.

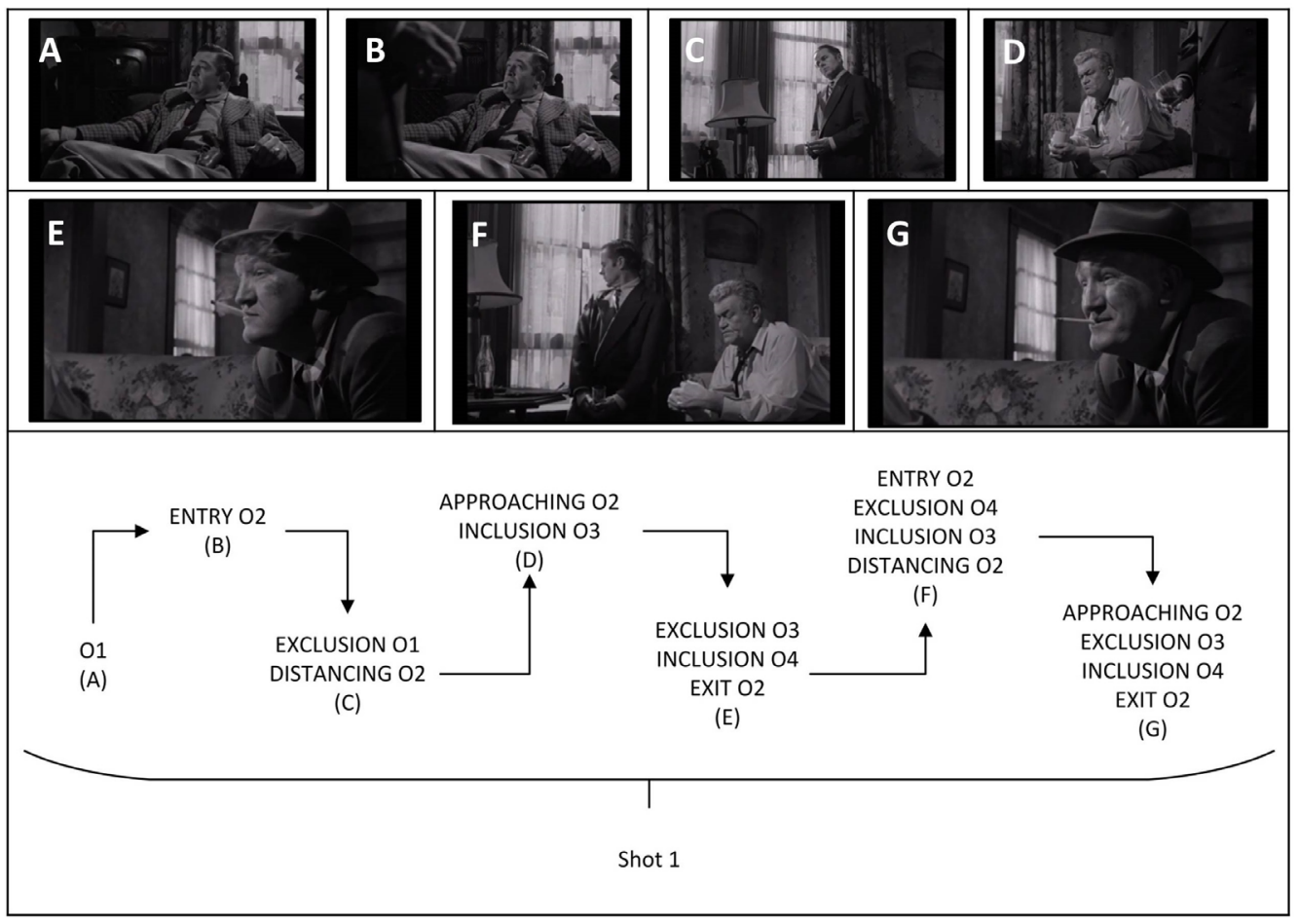

Figure 3.30. Linking various dynamic patterns of containment via the long take in The Killing (case two).

The chain of dynamic patterns starts off with a shot of the corrupt policeman Randy Kennan (O1) sitting in a sofa smoking his cigarette $(A)$. As his eyes move up, George $(\mathrm{O} 2)$ enters the scene from the left side of the frame $(B)$. Because he is close to the camera, we can only see a part of him. Randy is again excluded from the frame as George distances himself from the camera by walking toward the window $(C)$. He holds still for a few seconds, only to move again this time diagonally in forward direction. As he approaches the camera, Marvin (O3) is revealed $(D)$. From the right side of the frame George then turns away from Marvin, thus excluding him and revealing the face of Mike (O4) while he himself exits the frame from the right side of the frame $(E)$. George then enters the frame once more to position himself again near the window next to Marvin $(F)$. The long take ends by repeating the same pattern of figure $3.30 E(G)$. 


\subsection{The relation among shots}

\subsubsection{Linking dynamic patterns through editing}

The long take connects the dynamic patterns of containment together in one shot that is continuous along the dimensions of time and space. Another way of linking these patterns would be by means of connecting the individual shots together. In other words, through the technique that is unique to film, namely editing. Because we are dealing with relations among individual shots, those links may well be temporally and/or spatially discontinuous. There is probably no better way to illustrate this distinction than with what is perhaps the most iconic film cut in film history, the bone to satellite transition from 2001. Before starting, let us first mark our territory of analysis. The film cut may be considered a part of a series of four shots starting with the image of the ape-man throwing the bone in the air and ending with the image of a satellite in space whose orbit appears to continue the bone's downward trajectory. ${ }^{64}$ How brief the moment may be in the film, the total duration only lasting 120 seconds, a look at its underlying conceptual structure betrays the workings of a number of dynamic patterns of containment of which its schematic structure may be summarized as in figure 3.31 .

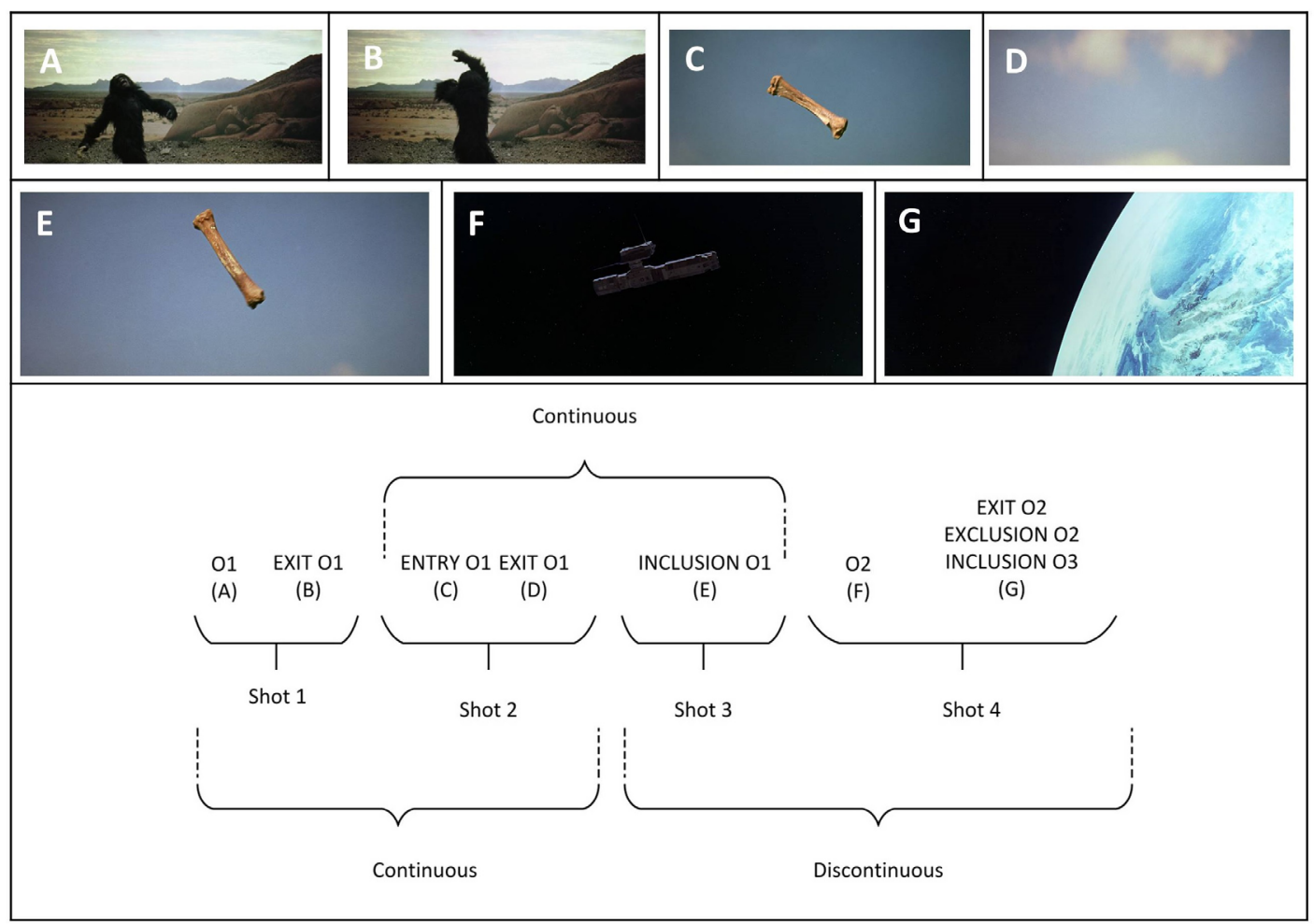

Figure 3.31. Linking dynamic patterns of containment through editing: the bone-satellite match-cut in 2001 . 


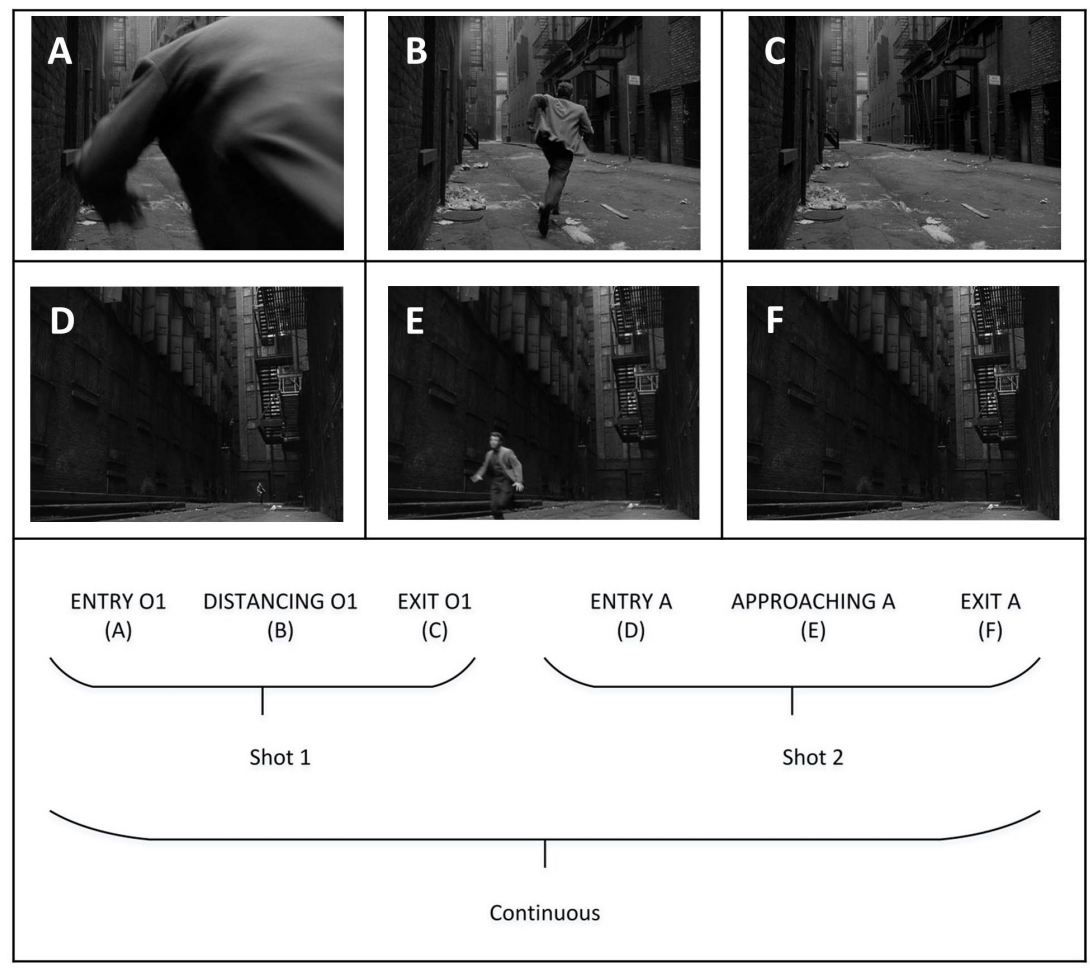

Figure 3.32. Linking dynamic patterns of containment through editing (example taken from Killer's Kiss) (part one).

In the first shot $(A)$, the ape-man throws the bone (O1) up in the air causing it to exit the frame from the top side $(B)$. The film, then, cuts to the second shot which shows the same bone now whirling into the frame from the bottom side $(C)$. For a couple of seconds the camera follows the bone (hence, no inclusion or exclusion). However, because the bone moves faster than the camera following it, the bone exits the frame from the top side for a second time $(D)$. The film, then, cuts almost unnoticeable to the third shot. No entry this time, as it is the camera now (i.e., the frame) that picks up again what it has left in the previous shot $(E)$. The camera continues to follow it as the bone falls downwards. It is in the course of this downward movement, then, that the film breaks its continuity by cutting to a shot of a new object, a satellite in space (O2), that is both spatially (earth versus space) and temporally (million years ago versus modern times) detached from the previous shots $(F)$. These discontinuities, however, are counterbalanced by a graphical and formal resemblance between the two objects $(\mathrm{O} 1=\mathrm{O} 2)$ which, in turn, prompts the viewer to see the bone and the satellite both as part of "the same, human history of domestication and exploitation of the physical world." ${ }^{65}$ From the perspective of cognitive linguistics, we might term this match-cut an example of what Lakoff has coined an image metaphor. ${ }^{66}$ Image metaphors differ from the type of conceptual metaphors most commonly theorized in the literature 
(see also previous chapter) in that they do not map complex conceptual structures in a source domain onto conceptual structure in a target domain (e.g., EVENT-STRUCTURE metaphor, MIND Is A BODY), but instead "map conventional mental images onto other conventional mental images by virtue of their internal structure." ${ }^{17}$ As Lakoff and Turner write, they are "one-shot metaphors, relating one rich image with one other rich image." ${ }^{68}$ Likewise, then, we might understand the match-cut as an image mapping in which one concrete object is linked to another concrete object, with the elongated shape of the bone corresponding to the elongated shape of the space vessel. ${ }^{69}$ What we then perceive is a combination of both ExIT and ExcLusion: due to the loss of gravity in space, the object slowly moves to the bottom left corner of the frame while at the same time, the camera moves to the right. As a result the satellite is no longer visible and a new visual object of the planet Earth appears on-screen $(\mathrm{O} 3)(G)$.

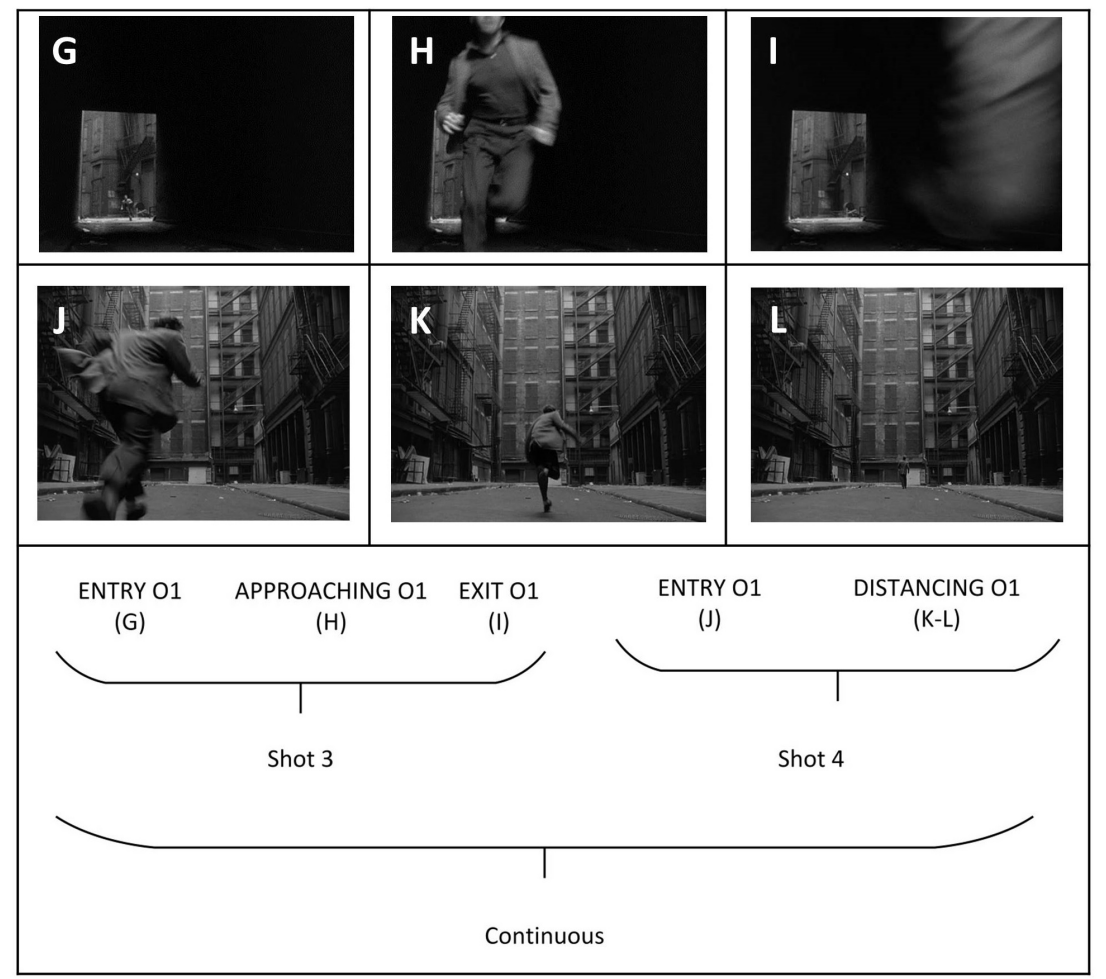

Figure 3.33. Linking dynamic patterns of containment through editing (example taken from Killer's Kiss) (part two).

A vigorous montage involving the dynamic patterns of DISTANCING and APPROACHING can be found in the chase scene near the end of Killer's Kiss when the lead character Davey Gordon tries to outrun his pursuers. The scene consists, among others, of a series of four static shots whereby each shot gives expression to a pattern of DISTANCING 
Or APPROACHING, whether or not preceded and or followed by a pattern of ENTRY and EXIT, respectively. In the first shot (figure 3.32A-C) Davey runs into the frame from the right edge of the frame, from a place behind and near the camera, thus crossing three edges of the frame and filling almost the total amount of empty space inside the frame (A). Empty space takes over again as Davey runs toward the back of the image, thus distancing himself from the camera $(B)$. He exits the frame by disappearing behind the corner of the building (i.e., not by crossing any edges of the frame) (C). By contrast, the second shot (figure 3.32D-F) maintains the opposite structure as Davey now appears from behind the corner of the same (?) building $(D)$. He then runs forward in a diagonal way (E) across the camera's field of vision, exiting the frame from its left edge $(F)$.

The same structure is repeated in the following shot $(3.33 G-I)$, albeit now the movement runs from left to right and more straight to the camera. The movement continues in the next shot (figure 3.33J-L) as Davey enters the frame from the left side $(J)$. He distances himself by running away from the camera toward the background of the image figure $(K)$, where he halts and contemplates a way out by spotting the fire escape figure (figure $3.33 L$ ). The shot thus ends with no exit. Without moving the camera and with the help of continuity editing the film thus creates a highly dynamic structure, a ballet of physical movement, elicited by the repetitious juxtaposition of the patterns of APPROACHING and DISTANCING.

\subsubsection{Eliciting dynamic patterns by means of editing}

Until now the shot was treated as a container for at least one or more dynamic pattern(s). However, an impression of a dynamic pattern may also be created after a juxtaposition of shots. In this case, the dynamic pattern is holding the shots together rather than the shot holding the dynamic patterns together. Schematically, this difference between two distinctive organizational templates might be represented as in figure 3.34.

A

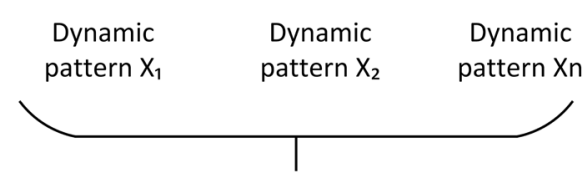

Shot $\mathrm{X}_{1}$
B

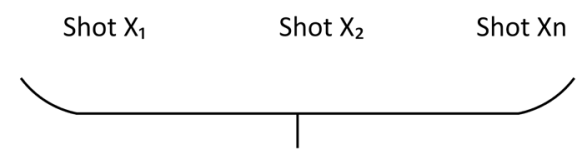

Dynamic Pattern $X_{1}$

Figure 3.34. $A$, the shot as organizational principle, versus $B$, the dynamic pattern as organizational principle.

One prototypical example of a dynamic pattern that might be provoked by way of editing is the WHOLE-TO-PARTS transition, as we already encountered in relation to the pattern of ENCLOSURE. In film this spatial change might be evoked by one of the most common techniques of the continuity editing system, namely the technique of cutting from an establishing shot, which delineates the overall space of a location, to a shot of a part of this space. ${ }^{70}$ Consider, for example, figure 3.35 which shows a series of shots as taken from The Shining. The first shot, $A$, establishes the spatial whole of the men's restroom and the positions of Jack and Grady inside of it. This shot is followed 
by a second one, $B$, which is part of that space, albeit taken from across the centre line or the $180^{\circ}$ line, thus turning the second shot into a mirror image of the previous one. Jack now occupies the place in the image that Grady occupied in the previous shot (and vice versa). Also here we may already precede the next chapter as this alteration might be metaphorically linked to the subject matter of the conversation which suggests an identity between Jack, the current caretaker of the Overlook Hotel, and Grady, its previous caretaker. Once the whole is laid out for us, the space is analytically broken down into its components. Shot $B$ is followed by two medium shots, $C$ and $D$, which are both spatially continuous with the two previous shots. Here again we may see the logic of containment unfolding itself. Given that shot $B$ is part of shot $A$ and shots $C$ and $D$ are part of shot $B$, it follows that shots $C$ and $D$ are also part of shot $A$. Once the $180^{\circ}$ line has been established by shot $B$, Kubrick relies on the technique of the shot/ reverse shot to join shots $C$ and $D$ and to cut back and forth from Jack to Grady.

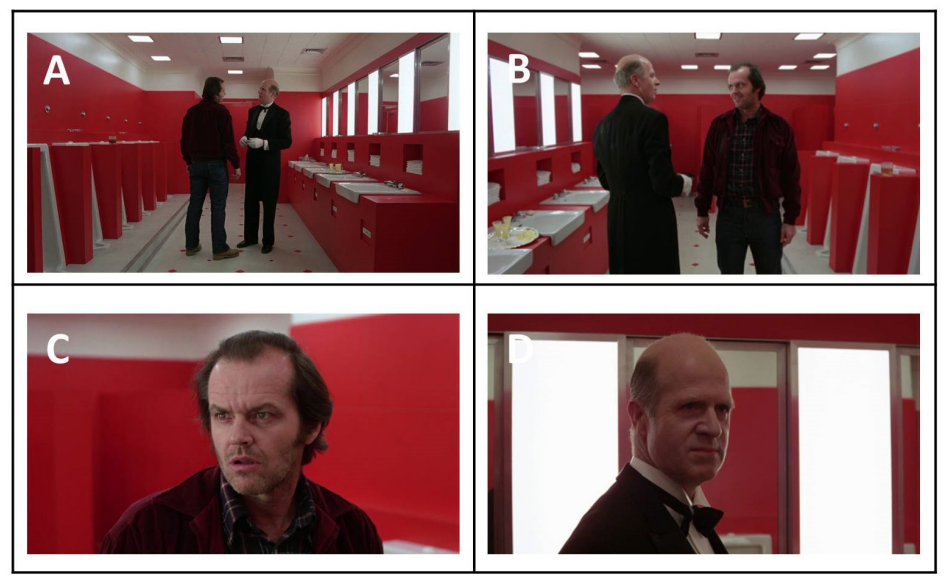

Figure 3.35. The WHOLE-TO-PARTS transition as elicited by editing (example taken from The Shining).

As the reader may notice, the pattern that results from this editing technique is quite similar to the pattern of ENCLOSURE, as discussed earlier, except for now the pattern is elicited by editing as opposed to camera movement. The fundamental difference here is that the viewer does not see all of the intermediary locations between the starting point and the ending point of the camera movement. In other words, the pattern is created through a process of elimination rather than through a process of showing. In this particular case, however, it would have been practically difficult to provoke the same effect by means of camera movement given that the camera angle differs in each shot. For instance, in order to arrive at the same image of shot $B$, starting from shot $A$, it is not only sufficient that the camera moves closer to the actors, but also that it makes a circle of $180^{\circ}$. If the angle would stay unchanged in each of the separate shots, the effect would be quite similar to the pattern of ENCLOSURE that results from forward and perpendicular camera movement (e.g., zoom-in). Such an example can be found in 2001 as illustrated in figure 3.36. 


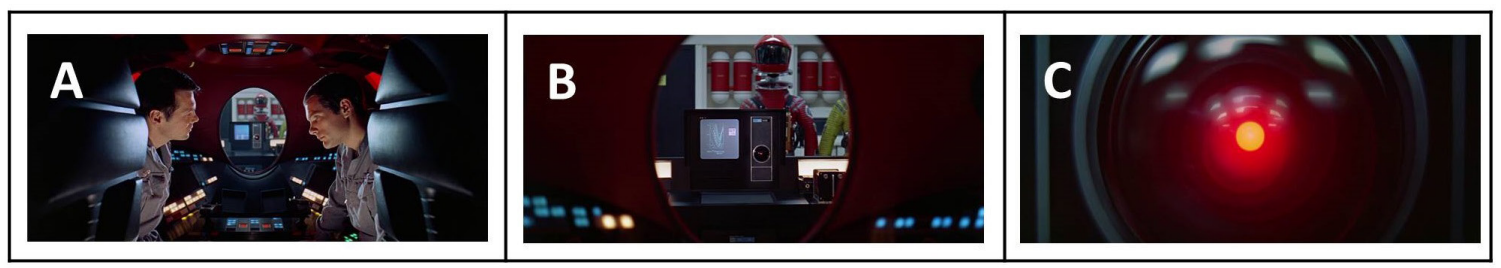

Figure 3.36. ENCLOSURE as elicited by editing (example taken from 2001).

In the two examples above, the rhythm of the editing is significantly held slow, that is, the shots that designate the parts and the wholes are left on-screen deliberately lengthily with the duration of the "whole" shots being somewhat longer than the duration of the "part" shots. However, the director might, for instance, speed up the tempo by adjusting the length of the shots in such a way as to evoke a more dynamic and impressionistic effect. A good example of this can be found, for example, in A Clockwork Orange in the fast editing pattern that is shown near the beginning of the film when Alex, in his bedroom, is listening to a cassette of Beethoven's $9^{\text {th }}$. Figure 3.37 shows the first eight shots of this pattern of a total amount of twenty shots, the whole only lasting fifteen seconds. As with our previous example, the editing alternates between the whole, here composed of four Christ figures who have their arms intertwined like a chorus line, and parts of this whole. Yet, here the cutting is so fast that the effect is excitement rather than slowness. Again, we might relate this stylistic choice to the filmmaker's desire to express the content of the story which, in this particular case, overlaps with Alex' arousal when hearing Beethoven's music. Or as our male hero puts is: "O bliss, bliss and heaven, oh it was gorgeousness and georgeosity made flesh."

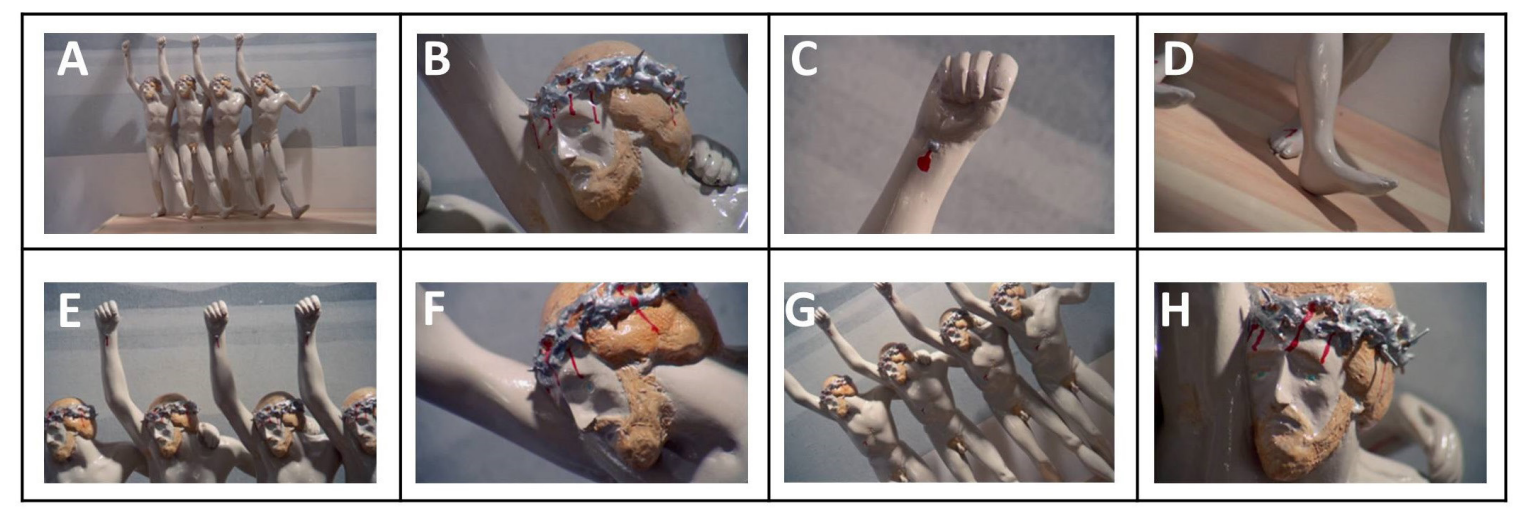

Figure 3.37. Rhythmic editing in A Clockwork Orange.

In all of the three examples discussed so far the structural element of the whole is clearly visible on-screen. Alternatively, the filmmaker could elicit the PART-WHOLE schema without even showing the whole. This assumption of spatial coexistence of parts in the absence of a whole (i.e., an establishing shot) is known among film 
scholars as the Kuleshov effect. ${ }^{71}$ According to this effect, viewers infer a spatial whole on the basis of seeing only the component parts. A good example of this technique can be found, for example, at the end of Fear and Desire, in the scene where Corby finishes off the General who looks just like him. Throughout the whole scene both opponents are never shown together. Yet, through editing and the organization of the visual elements on-screen, the viewer infers a spatial and causal relationship among the individual shots. As shown in figure 3.38A, we first see Corby approaching the scene in long shot. Next, we see a medium shot of the face of the wounded General as he shouts, "I surrender," immediately followed by a close-up of Corby while he shoots the General $(B-C)$. We do not see the gun, but only hear the gunshot. The General's head falls down to the ground $(D)$. This juxtaposition of faces is repeated a couple of times, as partially exemplified in figure 3.38E-F-G, in order to stress the bodily likeness between the two men and Corby's own recognition of this resemblance. The scene ends as they leave the area again $(H)$.

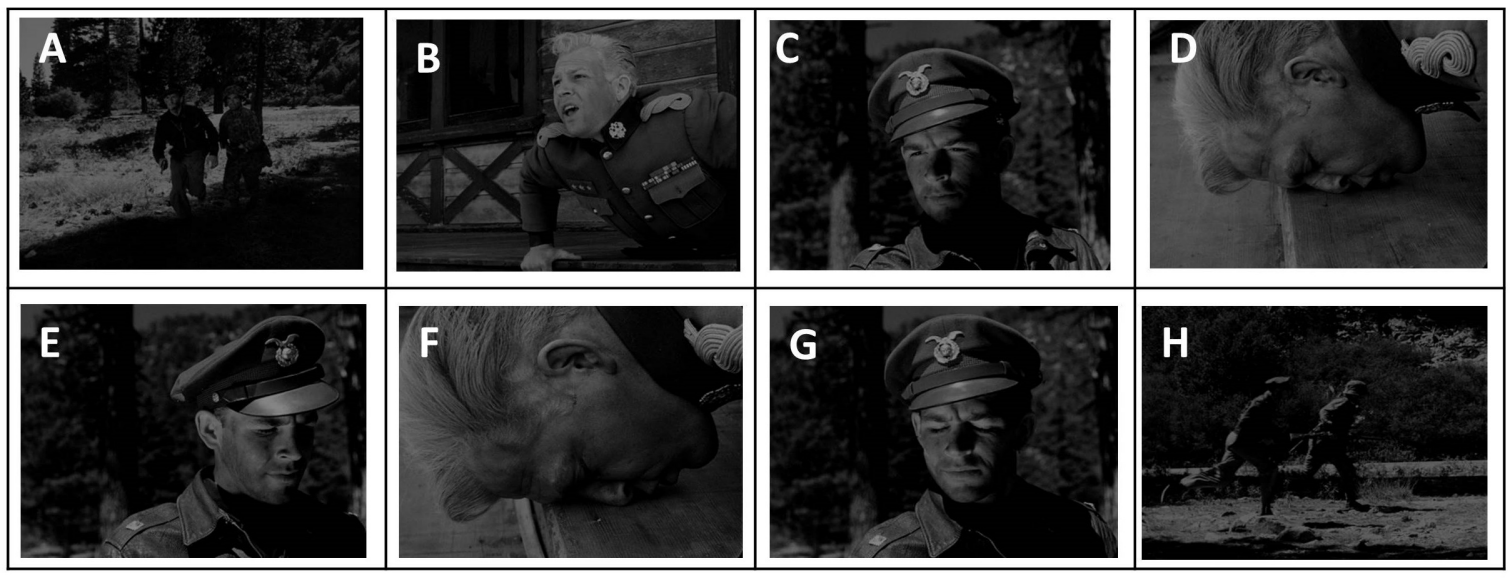

Figure 3.38. Inferring a spatial whole on the basis of seeing only its parts (example taken from Fear and Desire).

\section{Target domains and acting}

We now have discussed and illustrated some of the principle ways in which cinematic resources may arouse the same kind of image-schematic patterns as they were identified by cognitive linguists in our prototypical mode of communication, language. In the next chapter we will see, through a visual analysis of Kubrick's work, how the inferential logic of these patterns may, in turn, be retrieved metaphorically in order to flesh out the inferential logic of the target domains that make up the conceptual structure of mental causation (e.g., perception, cognition, emotion). Before starting this discussion, however, we first have to consider the question as to how these target domains may be elicited non-verbally in film. Addressing this question is of fundamental importance for if there is no target domain, there is no narrative object of meaning for which the image schemas may be appropriated. In the beginning of this chapter, we already put forward the assumption that these target domains may be elicited 
wordlessly through the metonymical resource of acting, especially given the close association between performance and non-verbal behavior. In this section we would like to elaborate this relationship more in detail, starting with a brief description of an epistemological problem which lies at the heart of the relationship between acting and the identification of others' mental states. It is only once we have a clear notion of this problem, which in the literature is referred to as the "other minds problem," that we can adequately characterize the rhetorical role of acting in classical narrative cinema (and Kubrick's position within it). In the second section, then, we will illustrate more concretely through a discussion of some examples of Kubrick's work, how actors' bodies can be employed to intend the concepts of mental causation. This clear conveyance of mental concepts through the actor's physical behavior, however, can also be undermined and complicated by the filmmaker. Kubrick's work in this regard can be seen as an excellent exemplar of this point. Illustrating this will be the subject matter of the remaining section.

\subsection{The other minds problem, performance, and Active Analysis}

In chapter 2 of this book we already saw how people have a natural tendency to attribute mental states to physical behavior and perceptual organs. This formed the basis of such conceptual metonymies as FACIAL EXPRESSIONS FOR EMOTIONS, EYES FOR SEEING and HEAD FOR THINKING. In this sense, one might say that these metonymies presuppose the capacity of observing another's mind without having direct perceptual access to it. In other words, they take for granted the ability to overcome a problem which in the philosophy of mind is known as "the other minds problem." ${ }^{72}$ Following Thomas Nagel we might roughly distinguish between two philosophical versions of this problem. ${ }^{73}$ The first is epistemological and asks how we can know for certain that others have a mind. The second is conceptual and deals with the question as to how we know if the minds of others are like our own. As stated, both problems follow naturally from the ontological distinction between visible behavior and inaccessible experience, that is, "one's direct observation of the former does not presuppose one has or can have direct knowledge of the latter." ${ }^{\prime 4}$ As with the paradox of cinematic meaning, we are thus challenged to overcome a logical inconsistency which leads again to a questioning of our capability of attributing mental states to others. This paradox, let us coin this the paradox of mental attribution, may be articulated more formally as follows:

(1) People have a natural cognitive tendency to attribute mental states to others.

(2) It is an ontological truth that we cannot have direct access to the mind of others.

(3) How, then, can we attribute mental states to others?

If we, however, want to further assert that the actor's body forms a vital means for expressing the target domains of mental causation, we must first cope with this problem to some extent. Where then lies the solution to this dilemma? In what sense, could we attribute inner, mental experience to others? As the metonymies of mental causation, as discussed in the previous chapter, already suggest, the answer to this question has to be found in the relationship between mental experience and bodily behavior. It is true that we cannot observe other minds directly, but from this observation it does not follow, as the other minds problem assumes, that inner experience and bodily 
behavior are distinct and that bodily changes are separate from feelings. Aaron Taylor, a film theorist specialized in screen acting, sums up two important reasons why this latter assumption is mistaken. ${ }^{75}$ The first reason is that the relationship between bodily changes and feeling is not random. As he writes, "experience of these changes belongs both to the subject who feels it and the object in which the feeling is experienced (i.e., the body)."76 Here, we may point again toward some of the stories of mental causation as exemplified in chapter 1. Recall, for instance, the Ludovico technique from A Clockwork Orange. In a way, this technique represents the strong interdependency of body and mind as Alex' retching and his physical struggling against his straight jacket cannot be detached from his experience of seeing the violence. Taylor himself gives the example of the various training sequences in Full Metal Jacket which the author considers to represent the absurdity of trying to "produce robotic behavior that is autonomous from the experience of feeling." 77

Secondly, the other minds problem does not take into account the important fact that we make use of our bodies to communicate our mental states to others. As the author argues, "you intentionally direct a sense of your experience to another via bodily signals, and others are able to intuit your state of mind through observation even if 'another cannot have your bodily feeling or experience' directly." 78 There are good evolutionary and functional reasons for this. Inferences such as these allow us to understand and predict the behavior of others in order to adjust and update our own (social) behavior. In the concluding chapter of this book, we will see, how embodied simulation processes allow for such inference processes to occur on a neurological level, but for now let us take such faculties for granted.

This brings us to the essence of our argument, namely that the other minds problem is no so much of a problem for those living in the practical world-we are capable of making inferences about others mental states quite easily—as it is an intriguing, albeit abstract and theoretical puzzle for philosophers. Therefore, the "real" problem, as Taylor dubs it, is not so much a question of plausibility (can we attribute mental states to others?), but a question of pragmatics (to what degree can we accurately identify others' mental states?). ${ }^{79}$

It is at this point in our inquiry that we can make the link to acting, and in particular to its function within the rhetorical system of classical narrative cinema, as it is said that one of the main characteristics of performance in this category of cinema is to provide the viewer with a performance that allows him or her to identify the character's interiority in a way that is "comprehensible and unambiguous." ${ }^{80}$ In other words, the function of performance in classical cinema is primarily to inform, that is, to reinforce "the narration's aim to provide optimal narrative clarity for viewers." ${ }^{81}$

If the actor's body is one of the chief expressive means to achieve the goal of "transparent signification," which, then, is the technique of acting to be best employed? ${ }^{82}$ Academic inquiries into performance usually align classical cinema's urge toward clarity with a type of acting technique that is "realistic" and "natural." Scholars usually line up these features with Stanislavskian modes of acting as opposed to the Brechtian techniques of modernist or postmodern narratives which are characterized by elements such as "estrangement and episodic structures that lack of motivation and causal relationships." ${ }^{83}$ Although this distinction does give us some broad theoretical insight, it is unavoidably too oversimplified in several respects. Firstly, classifying an actor's work as belonging to either one of the two categories fails to capture the complexity of an actor's work. As Carnicke points out: "The final performance on screen tells you virtually nothing about the acting technique used during filming. What reads as realistic might 
arise from any variety of acting techniques, including those of Stanislavski, Brecht, Delsarte, Suzuki, and so on." ${ }^{84}$ The author sees the actor more as a flexible performer who is capable of adapting him-or herself to the needs of the director, to give him, as Jack Nicholson once put it, "what he wants ultimately, no matter what it is." ${ }^{85}$ Secondly, the distinction overlooks the complexity of the two theoretical systems of acting themselves. For instance, Carnicke is eager to point out that Stanislavski did not only direct realistic plays, but also plays that resisted coherent development and thus are more in tune with the Brechtian system of acting. ${ }^{86}$

Having said this, where does the cinema of Kubrick fit into this distinction? Categorizing the performances of his films as either realistic or non-realistic would be equally over-simplifying things. Broadly speaking, it is safe to say that the director saw performances chiefly in function of the demands of the narrative. Here, we may turn, as we already did in chapter 1, toward the significant influence of Stanislavski on the filmmaker's approach to performance. The director himself has repeatedly stressed in interviews that Gorchakov's Stanislavsky Directs has guided him in his thinking about how to work with actors. ${ }^{87}$ As Carnicke writes: "Emulating late Stanislavskian technique, Kubrick developed a clear focus on the link between actor and narrative." 88 The same observation has also been made by Falsetto who considers the creation of character in Stanley Kubrick's films as "complex and intimately linked to the various thematic and stylistic operations at play." ${ }^{89}$ This link between narrative and acting is best captured by Stanislavski's method of "Active Analysis" which forms the subtext of Gorchakov's book. A close analysis of this method falls beyond the scope of this book, but generally speaking Active Analysis "makes the actor aware of the play's narrative structure through repeated improvisations that function as drafts of the final performance." 90 The embodied notion underlying this method is that actors are able to leak information about the inner world of the human being (i.e., the conceptual demand of the narrative) through gesture, body language and facial expression; all of which can be seen and interpreted by others, on the outside. ${ }^{91}$ As various theorists of acting have pointed out, the Active Analysis Method thus bears a close resemblance to the thesis of embodiment as advocated by second-generation cognitive science. ${ }^{92}$ Clare, for instance, sees in the principles of Stanislavski's actor training an implementation of the central proposition of Lakoff and Johnson that our concepts are formed through the body. As she writes: "Their view literally and figuratively incorporates the subjective; Stanislavsky shows how to do this in practice for the purpose of acting." 93

It is in the light of this method, then, that we should understand and justify Kubrick's legendary emphasis on performative repetition. ${ }^{94}$ The director did not let his actors repeat a scene merely for the sake of repetition. He wanted his actors to reach the conceptual and emotional core of the narrative structure, or "scheme of the play," as Stanislavski called it, and repetition was one means to achieve this aesthetic goal. ${ }^{95}$ That is, through repetition actors become familiar with their dialogue to the extent that they do not have to be concerned anymore about the words they have to say when performing the scene. Repetition thus neutralizes the actor's focus on "knowing the lines" that otherwise would distract from the emotional essence of a scene. In his own words, Kubrick has stated this as follows:

You cannot act without knowing dialogue. If actors have to think about the words, they can't work on the emotion. So you end up doing thirty takes of something. And still you can see the concentration in their eyes; they don't know their lines. So you just shoot it and shoot it and hope you can get something out of it in pieces. ${ }^{96}$ 
It is also interesting to note here how repetition also resonates throughout the actors' dialogues. As Pezzotta convincingly has demonstrated through a discussion of various examples, many spoken lines in Kubrick's films, notably The Shining, are full of repetition with actors often repeating in their responses sentences and words that were already uttered by the speech of others. ${ }^{97}$ This repetition should not only be regarded as a way for actors to easily memorize their dialogue - and thus reach the conceptual essence more effortlessly-but also as a symptom of Kubrick's aesthetic resistance against the propositional and linguistic view of meaning, as elaborated in the introduction. By including these verbal reiterations, Kubrick manages to stress the materiality of the speech. As such, words are deprived of their semantic content and the attention is drawn away from their linguistic meaning and toward the purely bodily and acoustic aspects of the performance, precisely those aspects through which meaning is communicated non-verbally. That this may result to the extent that the effect is even comical, can be illustrated, for example, with the dialogue that accompanies the scene where Jack finds out that Wendy is reading his manuscript: ${ }^{98}$

JACK: How do you like it? How do you like it? What are you doing down here?

WENDY: I just wanted to talk to you.

JACK: Okay. Let's talk. What do you want to talk about?

WENDY: I can't remember.

JACK: You can't remember.

WENDY: No, I can't.

JACK: Maybe it was about Danny?

WENDY: Maybe it was about him. I think we should discuss Danny. I think we should discuss what should be done with him.

JACK: What should be done with him?

WENDY: I don't know.

JACK: I don't think that's true. I think you have some very definite ideas about what should be done with Danny. And I'd like to know what they are.

WENDY: Well I, I think maybe he should be taken to a doctor.

JACK: You think maybe he should be taken to a doctor? When do you think maybe he should be taken to a doctor?

WENDY: As soon as possible?

JACK: As soon as possible?

WENDY: Please.

JACK: You believe his health might be at stake.

WENDY: Yes.

JACK: And you are concerned about him. And are you concerned about me?

WENDY: Of course I am.

JACK: Of course you are! Have you ever thought about my responsibilities?

WENDY: What are you talking about?

JACK: Have you ever had a single moment's thought about my responsibilities? Have you ever thought for a single moment about my responsibilities to my employers? 
Kubrick's work reveals yet another strategy for undermining the meaning of linguistic expressions, one that is not so much defined by repetition, but by a gap between the utterance and the situational context. This argument is central to Kolker's account of Dr. Strangelove. "What Kubrick, Terry Southern, and Peter George do in their script and what Kubrick does in his direction," he argues, "is create a series of linguistic and visual reductions, giving the characters utterances that defeat meaning." ${ }^{99}$ He illustrates the workings of this process of "linguistic subversion," as he coins it, by analysing various fragments of character speech, including an excerpt from the dialogue of Major Kong (Slim Pickens). ${ }^{100} \mathrm{He}$ is the commander of the aircraft that is ordered to drop a nuclear bomb on Russia. When he prepares for "nuclear combat, toe to toe with the Russkies," he pulls out a cowboy hat, and tells his men:

I reckon you wouldn't even be human beings if you didn't have some pretty strong personal feelings about nuclear combat.... If this thing turns out to be half as important as I figure it just might be, I'd say that you're all in line for some important promotions and personal citations when this thing's over with. And that goes for every last one of you, regardless of your race, color, and your creed.

It is precisely this clash between the seriousness of the situation, on the one hand, and the banality of the cowboy image, on the other hand, that makes the scene so surprisingly funny and frightening at the same time. As Kolker argues: "The serious is made light of and the ridiculous is made serious. The language circles upon itself; it has no subject or object, no detachable meaning. The meaning is the utterance itself and its own perfectly logical irrelevance and banality." 101

Turning back again to Kubrick's relation to Stanislavski, there is, however, one crucial difference that separates the two artists. This has to do with the way they worked with actors. Where the Russian stage director, in the stage of rehearsals, allowed for typical actor-director discussions about character psychology and a shared understanding of the play's goals and intentions, Kubrick did not encourage such explanatory collaborations. ${ }^{102}$ Taylor coins this the technique of "strategic improvisation," that is, "the actors' limited and calculated creative additions to or deviations from scripted dialogue or action." ${ }^{103}$ Such a tactic allows actors an uncommon creative and collaborative freedom, yet at the same time it leaves the actors deliberately ignorant and bewildered about the characters' motivations.

If we assume, on the basis of this brief characterization of Kubrick's unique approach to acting, that performance should reflect the needs of the conceptual structure of the narrative, in what sense, then, do the performances in his films accurately reflect the concepts as inherent to the structure of mental causation? Considering his work, we may respond to this question in a twofold manner. On the one hand, we may discern various examples of acting, especially in his earlier work, of which it can be stated with a degree of certainty, that they are intended to communicate minded characters. On the other hand, it would be a categorical mistake to treat all of the acting in Kubrick's work as merely an illustration of transparent signification. Following Taylor, we may also argue that a significant number of examples seem to resist the presumed communicative function of classical cinema. Acting thus becomes a symptom of what the author calls "sceptical classicism," "a mode of narration in which our natural ability to conceptualize and engage with character's mental states is impeded." ${ }^{104}$ Let us consider each part of the answer more in detail. 


\subsection{Mental causation, performance and film style}

How are viewers able to interpret the bodily performance of an actor as standing for the content of the narrative or, as in our case, the content of mental causation? As a starting point for investigating this question, let us consider Daniel Richter's wordless performance as Moon-Watcher in the epiphany scene from 2001, as verbally described in chapter 1. At the beginning of the scene, as shown in figure 3.39A, Moon-Watcher's physical behavior signals to us an animal in search of food. He is surrounded by many devoured bones of an antelope skeleton, but he does not seem to care much about them as he is too occupied digging the ground for food, his visual field being fully occupied by the dry soil upon which he stands. The emphasis of the performance is clearly on the action. Then, suddenly, as if in a burst of bright light, something happens. He suspends his instinctive need and lifts up his head $(B)$. The performance turns into a static appearance. His eyes are no longer directed toward the soil that he was so eagerly inspecting. It is as if the film, through this gestural change, wants to suggest that the object of his perception lies somewhere else. The next shot seems to confirm this hypothesis as a quick, almost subliminal image appears that is spatially discontinuous with the previous shot. It reveals the celestial alignment with the monolith that has been shown before in relation to an earlier experience of Moon-Watcher $(C)$. Through the image schema of LINKAGE, elicited by editing, the film thus suggests a relationship between Moon-Watcher's facial gesture and the appearance of the monolith (is MoonWatcher remembering this image?).

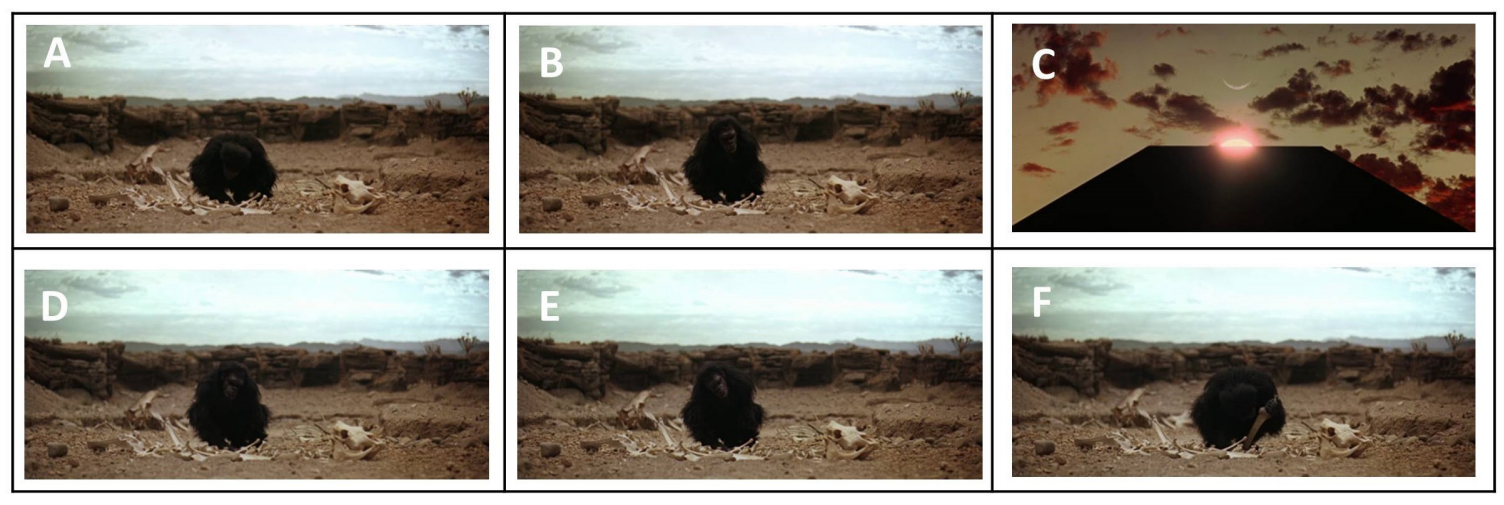

Figure 3.39. HEAD FOR THINKING in 2001 (part one).

The film, then, turns back again to Moon-Watcher as he now directs his gaze toward the bones in front of him $(D)$. He moves his head a couple of times from left to right, thus suggesting the metonymy HEAD FOR THINKING $(E)$. The mental image of the alignment seems to have conveyed an idea to his mind. Soon after, this idea is materialized into action as Moon-Watcher picks up one of the bones and starts to play with it $(F)$. Thinking gives rise to behavior. Slowly realizing that he can use the bone as a weapon, he crashes the bone down repeatedly on the skeletal remains at his feet, first hesitantly and then more forcefully. He raises the bone high and mighty in the air, an act which is 
captured on-screen as an ENTRY path into a static frame filled with blue sky (figure 3.40G). As he forcefully crashes the bone down onto the head of the skeleton $(H)$, another subliminal image appears, this time of a live tapir taking a dive (I). Is it a future image of what will be the logical consequence of his cognitive progression? As to visually emphasize the importance of this discovery, the physical act as a whole is analytically broken down to its essential parts in very fast and repeated succession (e.g., $J-K-L$ ), thus forming a formal and aesthetic contrast with the previous "thinking" images. From now on the man-ape will be able to hunt for food. The primate has evolved from a vegetarian to a tool-using carnivore.

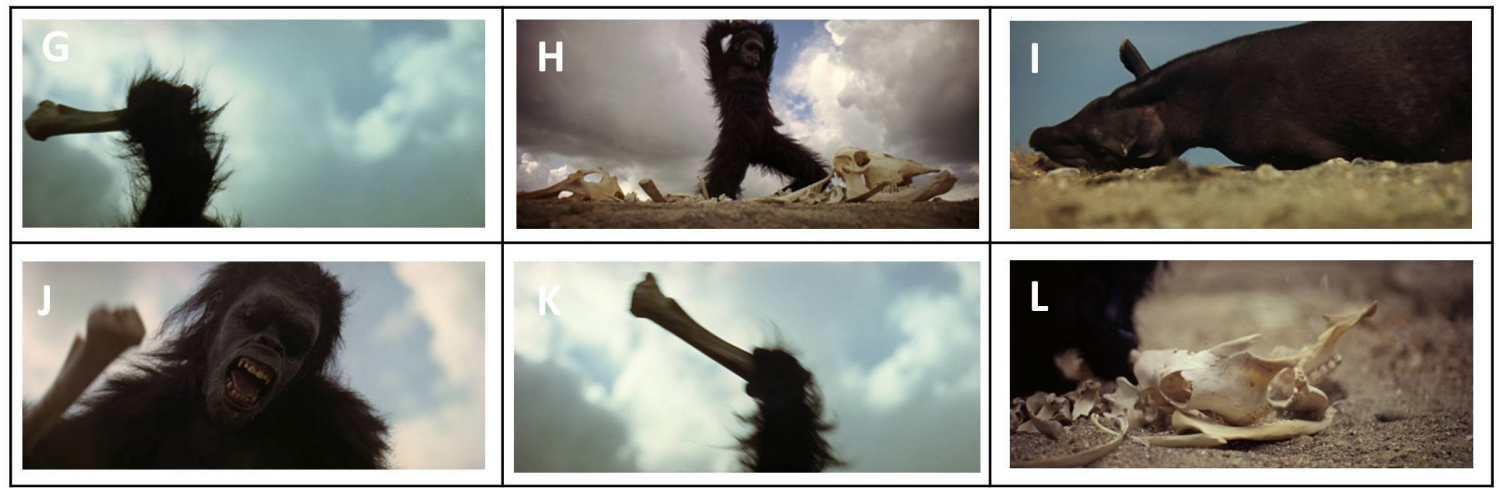

Figure 3.40. Mental-to-physical causation in 2001 (part two).

Notice also the way this cognitive leap-forward, as expressed through Richter's bodily performance, is not only accentuated stylistically through the musical accompaniment of Strauss' Also sprach Zarathustra, which now reaches its monumental heights, and, as in our example from A Clockwork Orange, through a radical acceleration of the editing pace, but also through the change of the angle of framing. At the beginning of the scene, the angle is straight-on, thus emphasizing Moon-Watcher's downward relationship with the earth surface. At the highpoint of Moon-Watcher's moment of insight, however, this common angle has changed into a low-angle which positions us as looking up at Moon-Watcher who is now no longer framed against a background of earthly landscape, but against a wall of bright light (the natural light of the mind?). Here, again, we may already anticipate the next chapter, as the properties of the image schema of UP-DOWN are extended metaphorically in order to meet, in a purely visual manner, the demands of the narrative content, which were already made clear for us through Richter's bodily performance.

So what does this example tell us? Above all, it informs us that there is a high degree of (metonymical) correlation between the actor's performance and the narrative structure of mental causation. Just by watching MoonWatcher's body language we can infer a line of causation that runs from the mental to the physical.

To support this claim with one more example, consider Ryan O' Neal's performance in Barry Lyndon, as illustrated in figure 3.41. It shows Redmond as he "sees" an opportunity to escape his six-year commitment to the British army by stealing the clothes and steed from an officer who is embracing another man in a lake. 
As with our example from 2001, an image lies at the cause of the protagonist's mental act of thinking, but this time the image is not attributable to the character's memory, but to the character's actual perception. This is illustrated in figure 3.41A in which Barry notices the uniforms hanging on a branch of a tree. He, then, turns his head back toward the viewer after which he looks around a couple of times $(B-E)$. This series of left to right movements of the head gestures to us something along the lines of "Barry is checking out whether or not the coast is clear to steal the clothes." When he reaches the positive answer to this question, he stops his head and much like Moon-Watcher, he gazes fixedly in front of his eyes. Barry thus "turns his attention to his own consciousness," as Wittgenstein would call it. ${ }^{105}$ This mental act is also given form visually through camera movement as the camera slowly zooms in on the subject's head, thus entirely ENCLOSING it $(F)$. As a result, the space surrounding Barry's head is EXCLUDED and the HEAD FOR THINKING metonymy is once more prompted to us. Millions of years separate Barry from Moon-Watcher, but in essence they are the same minded subjects whose actions are outer tokens of inner processes.
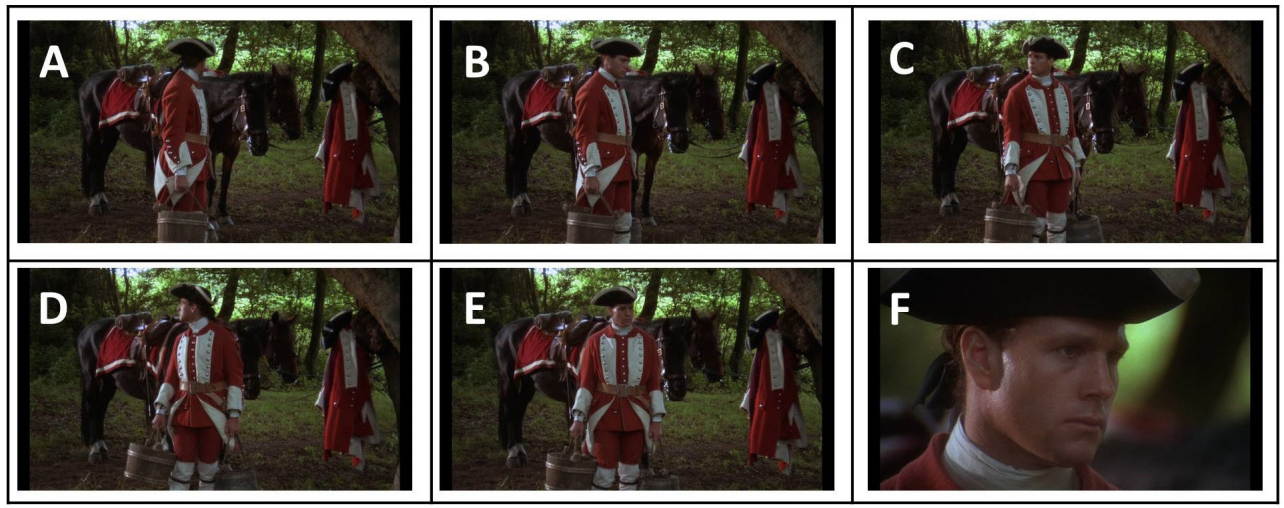

Figure 3.41. HEAD FOR THINKING in Barry Lyndon.

If performance can signal cognitive processes, what, then, about emotions? What does an actor's performance reveal us about the emotional states of a character? As we already alluded to in chapter 2, one may draw here upon the work of Paul Ekman whose studies have systematically explored the relationship between facial expressions and emotion concepts, a connection that we saw captured through Kövecses' metonymy FACIAL EXPRESSION FOR EMOTION. ${ }^{106}$ For instance, Ekman and Friesen have identified six basic emotions (happiness, sadness, anger, fear, disgust and surprise) and their corresponding descriptions of the facial muscles involved in the formation of them. ${ }^{107}$ They are often called "universal emotions" as they are believed to be recognized across different cultures. ${ }^{108}$ These descriptions often read as instructions for actors to communicate emotions via eye movements and complex patterns of expression. For instance, happiness is characteristically described by tense lower eyelids, raised cheeks and lip corners pulled up, whereas sadness is described by inner eyebrows raised and drawn together and lip corners pulled down. It is not difficult to find exemplars of these descriptions in each of Kubrick's films. 
Figure 3.42 shows three of them, as they are expressed in Paths of Glory (sadness), A Clockwork Orange (disgust) and The Shining (fear). By this, however, we do not wish to imply that emotions in Kubrick's films are always that clearly readable from the actors' facial expressions, on the contrary. We will see in the next section how some of the performative techniques applied in his films exactly seem to complicate this human ability to conceptualize and engage with characters' emotions.

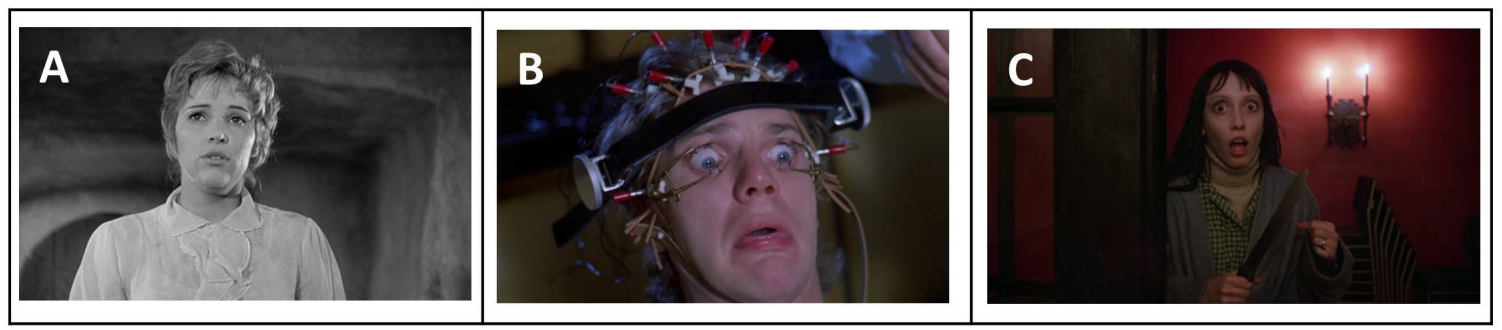

Figure 3.42. Basic emotions: A, sadness in Paths of Glory, B, disgust in A Clockwork Orange, and C, fear in The Shining.

Looking solely at the bare physical behavior of an actor, tells us much about the kind of mental activity that the character is engaged in (e.g., perceiving, thinking, feeling), but it does not tell us much, however, about its content. Toward which object is the perception directed? Which image or idea in the character's mind triggered the physical behavior? Why is a character feeling sad or disgusted? Raising these questions, brings us to the second important observation, namely that for a viewer to be able to answer these questions, and thus infer stories of mental causation, he or she has to be able to relate the performance to an object or event that is either located inside or outside the character's mind. If this object is located outside the character's mind, as with perception, this object can be easily visualized. If, however, the object is located inside the character's mind (e.g., memory, fantasy, thought), other means of expression have to be sought.

As our example of 2001 already suggests, one solution would be to treat the internal object as an external object that can be perceived by the viewer. By placing the memory of the monolith outside the protagonist's mind (thus making it observable), and linking it to the outer performance, through editing, we quite effortlessly establish a causal relation between the mental and the physical. The application of the same tactic can also be found, for example, in Eyes Wide Shut as when Bill sits in the cab thinking about what Alice has told him (see figure 3.43A-B). Later in the film, the same fantasy image returns to haunt Bill as he, aimlessly walking along the street, sees a young couple up against a shop front kissing passionately, oblivious of all around them $(C-E)$. As he continues walking, he beats his fists in anger over his fantasy $(F)$. From this chronological juxtaposition of images one can infer, quite effortlessly, a flow of mental causation that runs from the sight of the couple toward the fantasy in his mind and up toward his physical reaction. Consequently, as we shall see in the next section, withholding certain images would impede the ease with which we make such causal inferences. 


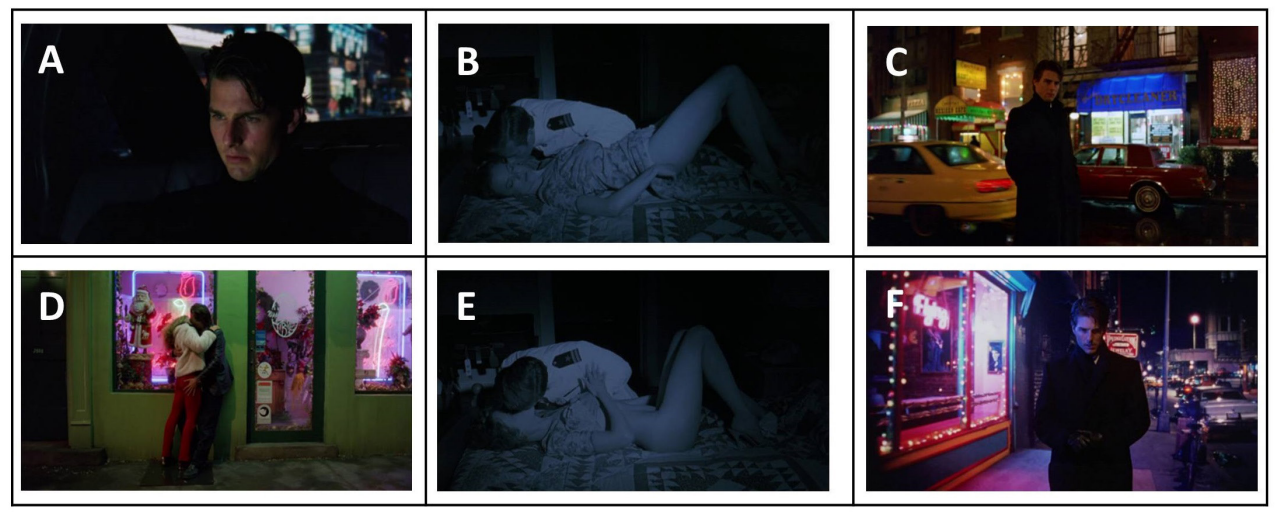

Figure 3.43. Mental-to-physical causation in Eyes Wide Shut.

The choice for editing as a means to establish the connection between performance and the inner object is not incidental, but necessitated by the narrative context. In both 2001 and Eyes Wide Shut, the film images represent mental images of spatial locations that are distinct from the locations where the characters are residing at the moment of them performing the mental act. Moon-Watcher recalls an image of an event that he has seen before and Bill visualizes in his mind a hypothetical sexual experience that was conveyed to him verbally by his wife. Hence, what is required, is a tool such as editing that enables to connect two locations that are spatial discontinuous to each other. Such a connection cannot be achieved simply by moving the camera from a location A to a location B. The tool, however, may change with the context. Take character perception, for example. It is conditional of (normal) visual perception that the object of perception shares the same spatial region as the perceiver, for otherwise, the perceiving character would not be able to see it. Indeed, fictional beings (at least those existing in a realistic context) can only see, much like human beings, what is in his or her visual field. Thus, the filmmaker may opt to instigate the relationship between perceiver and object by simply showing both entities in the same shot, or, as we shall see in the next chapter, by relying on the dynamic patterns of fixed-frame movement and camera movement; all of which are able to connect spatial continuous locations perfectly well.

Another way of establishing the inner object non-verbally would be not by visualizing it, but by evoking the object indirectly in the mind of the viewer on the basis of what the character perceives. Take again our example of Barry Lyndon. On the basis of Barry's visual perception of the uniform, we infer that he is thinking about stealing it for the purpose of deserting the army, but we do not see this idea visualized in the same way as Moon-Watcher's memory or Bill's fantasy were visualized. What we do get to see, is the physical implementation of the idea by the actor soon after its conception (e.g., we see Barry stealing the uniform). The same holds, for example, for the idea of using the bone as a weapon that comes to the mind of Moon-Watcher. We see Moon-Watcher thinking, but we do not see what he is thinking. This becomes only clear to us after he makes use of the bone.

In both 2001 and Barry Lyndon the perceptual relationship between the PR and the OP is captured objectively in a single shot. An even more effective means to render the same effect, however, would be by separating both entities 
over two distinctive shots. This division lies at the centre of what is commonly known in film theory as the pointof-view shot (POV). ${ }^{109}$ It is usually established by being intersected between a shot of the actor's performative act of looking at something, and a shot showing the actor's reaction (i.e., a shot-reverse-shot). Through the image schema of LINKAGE the inside property of the frame (i.e., the container) thus becomes a metaphorical expression of the character's visual field. To illustrate how this technique can be used to facilitate inferences about the thought process of characters, consider, for instance, the visual way in which Davey's escape plan from Killer's Kiss, as described in chapter 1, is induced in the viewer's mind. At first we see a static shot of Davey's face, as it lies on the ground (figure 3.44A). This is followed by a semi-subjective shot, showing the character in relation to the window he is looking at $(B)$. Through static framing both parts are thus blocked as a whole in which the properties of the FRONT-BACK image schema are extended in order to structure the relationship between the PR (front) and the OP (back). From this spatial whole the film cuts to one of its parts as now only the window is shown from the (relative) point-of view of Davey (C). A dynamic pattern, reminiscent of ENCLOSURE, unfolds itself as a result of editing. The film, then, cuts back again to Davey's facial expression $(D)$. He now moves his eyes away from the window and toward one of his opponents whose attention is drawn to the quarrel between Vinnie and the girl $(E)$. Next, we see a medium shot of the other opponent's feet which are standing between those of Davey $(F)$. Likewise, his eyes are directed toward the quarrel $(G)$. The moment has come for Davey to escape. He overmasters the opponent after which he runs toward the window to throw himself out of it (I). Thus, as with 2001 and Barry Lyndon, the film shows the materialization of an idea that the viewer already has inferred on the basis of the prior juxtaposition of images.

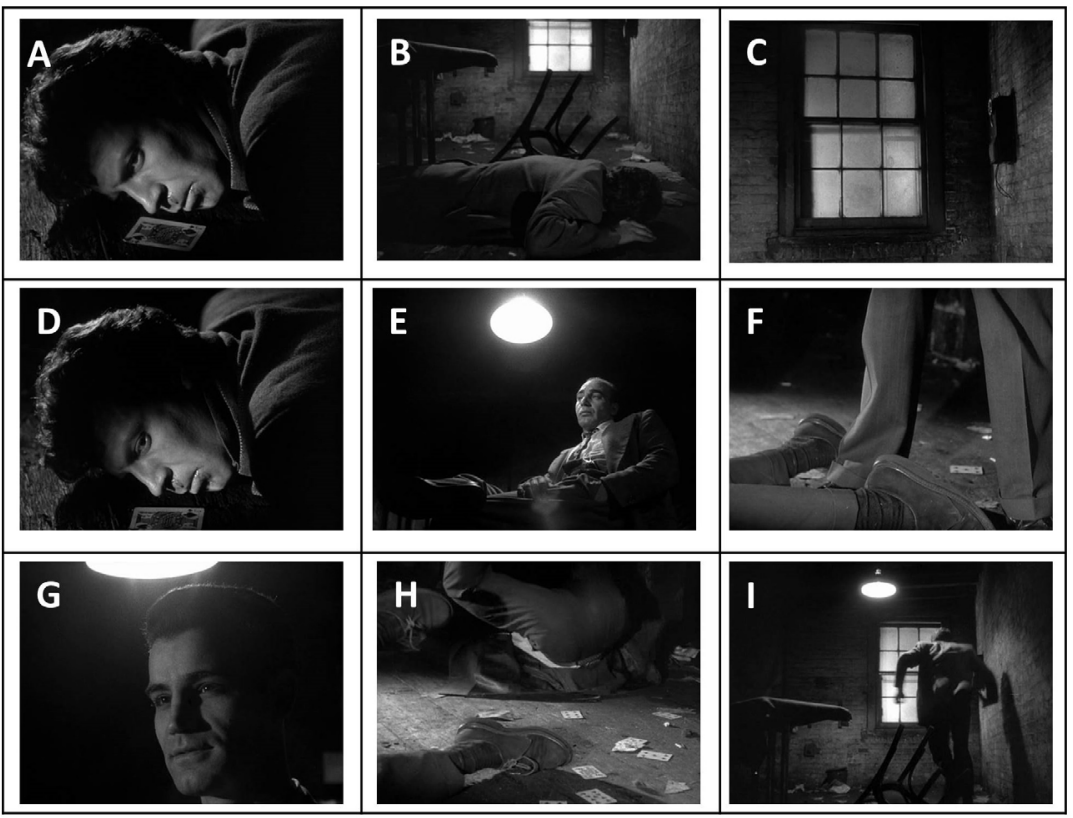

Figure 3.44. Mental-to-physical causation in Killer's Kiss. 
What this example shows, is that a filmmaker does not always have to resort to an act of showing in order to elicit the thoughts of a character. The latter can equally be brought to the viewer's mind by embedding the actor's facial expression in a dynamic image schematic pattern that is intended to structure the perceptual relationship between the PR and the OP.

\subsection{Performative and stylistic impediments to transparent signification}

Having presented some of the performative aspects of conveying stories of mental causation, thereby already anticipating the next chapter by emphasizing the significance of dynamic patterns and film style, let us now turn toward that other question: how may this transparent signification of mental causation be obstructed? From the insights provided above, we can already make a few assumptions.

If it is said that character perception facilitates the construal of stories of mental causation, as discussed above, then one can easily assume that these stories can be obstructed by impeding this perception. As Kubrick's work reveals, one way to achieve this is by showing the face of a perceiving character that does not, however, draw attention to a perceptual object. The result is a facial expression in isolation, an effect without a cause, a perceiver without an object perceived. Taylor, in a similar sense, coins this strategy the strategy of "artificially immobilized expressions." 110 Because the facial expression does not signal any object, the subject becomes itself objectified. Take, for instance, the petrified glare of Alex during the opening zoom-out from A Clockwork Orange (see figure 3.45A-C). The zoom-out evokes a dynamic pattern of containment-what we specified earlier as EXPOSURE-but paradoxically this movement is not intended to reveal the object of Alex' perception. We do get to see his fellow "droogs," but the object of Alex's perception is withheld from the viewers' knowledge during the entire length of the shot. The direction of Alex' gaze contributes a lot to this effect. In Killer's Kiss, the close-up of Davey's facial expression was clearly directed toward one of the edges of the frame, thus suggesting the presence of an object outside the frame, but still inside the diegetic world. Here, Alex' eyes are directed toward us, the viewer who is detached from the story told on-screen. This strategy adds a lot to the feeling of discomfort that accompanies our experience when watching the scene. As Taylor writes: "His expressive paralysis is horrific because it appears to indicate an objectified subject, one who takes in nothing from the subjects around him nor from his immediate environment, remaining unchangeable and impenetrable."111

A similar example, but this time with a zoom-in movement, can be found in The Shining (see figure 3.45D-F). The zoom-in recalls the transition from figure 3.41E to figure $3.41 \mathrm{~F}$ from our example of Barry Lyndon, yet, this time the movement is not embedded in a larger structure that is intended to tell a story of mental causation. For instance, the shot is not preceded by a shot of Jack looking at something that could have motivated the zoom-in, nor the shot is followed by a physical implementation of the idea that arose in his mind. Aided by the metaphor CHANGE OF STATE IS MOVEMENT, here elicited by the dynamic pattern of ENCLOSURE, we assume as a viewer that something is happening in his mind (the turning point from sanity to insanity?), but that is about the only thing we can do. As with A Clockwork Orange, the result is silent and enigmatic communication, the emblematic, impenetrable "Kubrick stare," as so many scholars have dubbed it, "head tilted downward, heavy-browed eyes looking upward." 112 


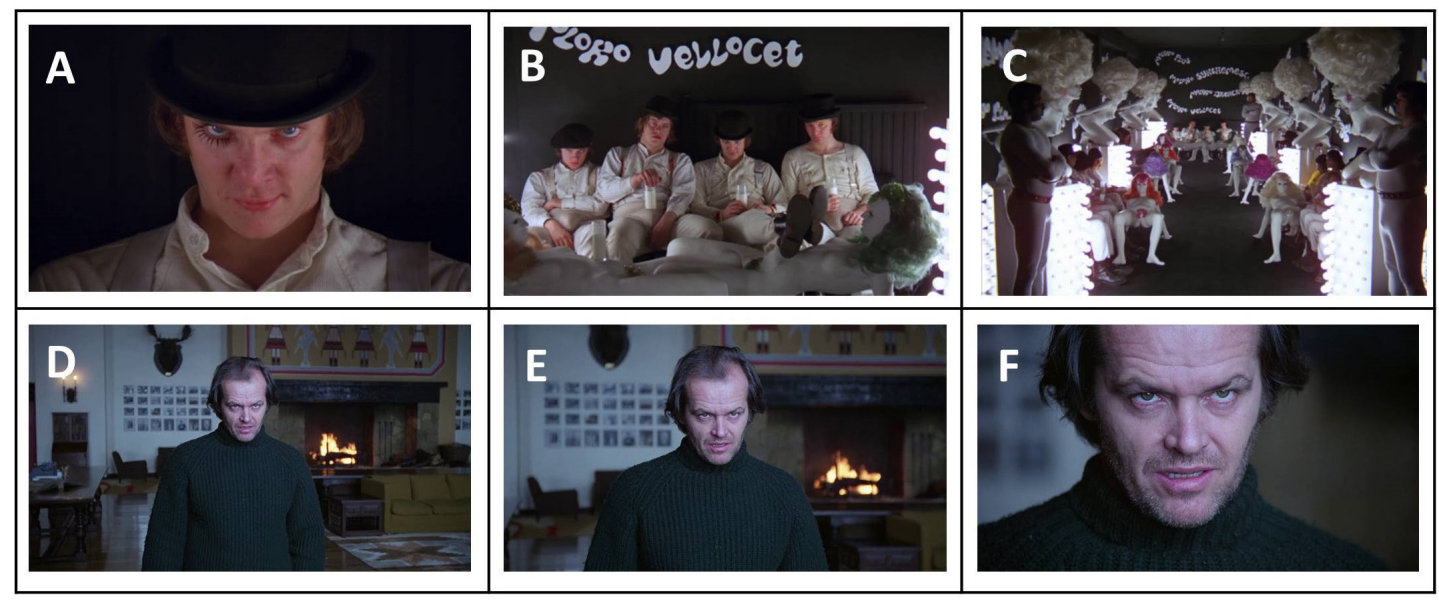

Figure 3.45. The Kubrick Stare in A-C, A Clockwork Orange and D-F, The Shining.

A second way in which a filmmaker may impede the transparent signification of mental causation, is to provide viewers with bodily performances that are expressive, but keep them in the dark about the events that are causally responsible for prompting this physical behavior. To illustrate this, let us consider, for example, the scene at the beginning of The Shining that shows Jack behind the wheel driving his family to the Overlook Hotel. Already from the first image of the scene, we infer on the basis of the intense expression on his face that he is outwardly annoyed about something (see figure 3.46A). When Danny, seemingly unaware of his father's awkward behavior, harmlessly mentions that he is hungry, Jack responds in a way that betrays his inner frustration. When the boy asks about the Donner party and Jack is forced to mention the subject of "cannibalism," "a perverse glee" appears on his face. ${ }^{113}$ When Danny tries to take away his mother's concern by saying, "Don't worry mom, I know all about cannibalism, I saw it on TV," Jack repeats his son's lines while simultaneously rolling his eyes upward and arching his eyebrows $(B)$. What this example shows, is that there is no "arch," as King critically remarked, through which we can understand Jack's behavior. As King stated, "as far as I was concerned, when I saw the movie, Jack was crazy from the first scene." ${ }^{114}$ What King here refers to as the absence of an arch is nothing more than the absence of a story of mental causation. His frustration, as a viewer of the cinematic adaptation of his own book, comes out from the impossibility to make the kind of causal relations involving mental events that he allowed his readers to make when reading his novel. The effect of this strategy is that the attention is drawn toward the presentational facet of Jack's performance. Taylor dubs this the strategy of "excessive ostensiveness." ${ }^{115}$ Because we are hampered to make such connections, "we are unable to conceptualize the represented individual as being 'minded' in a recognizable way." As Taylor writes, "their ostensive display acts as a resistant surface that belies a withheld experience (i.e., they are perceived only as a performing body)."116 


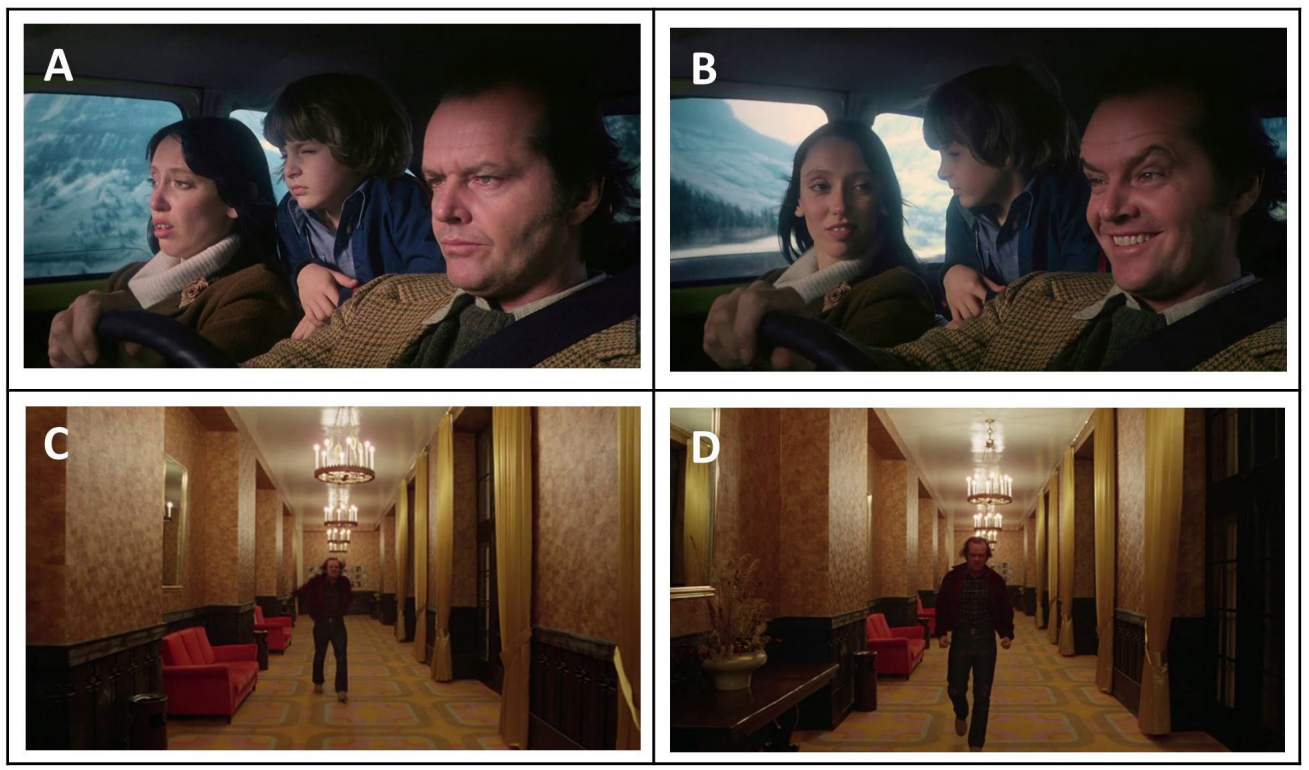

Figure 3.46. Excessive ostensiveness in The Shining.

To illustrate this strategy with another example, let us compare the scene from Eyes Wide Shut, as illustrated in figure 3.43, with the scene where Jack is hysterically and wildly strolling down the corridor that gives entrance to the Gold Room (see figures 3.46C-D). In the former scene there was a clear causal relationship between Bill clapping his hands out of frustration and the fantasy that caused him to express such behavior. In the latter scene, however, we see Jack behaving erratically, punctuating the air with his fists and talking to himself, but we are not allowed to see the inner events that caused him to react as such. As Falsetto describes: "Nicholson communicates the madness and seething anger of the character by the insistent thrusting of his arms down the sides of his body and into the air, as if striking at some unknown assailant." ${ }^{117}$ We can assume on the basis of the previous scene that the devil inside of him must have been prompted by his wife's accusation of harming little Danny, but the certainty by which we infer this causal relation is of a significantly lesser degree when compared to the example of Eyes Wide Shut.

A third and last way of obstructing the viewer's construal of stories of mental causation on the level of acting, would be to suggest exactly the opposite: establish a clear perceptual relationship between perceiver and object, but neutralize the physical expression that comes with the effect that the perception of the object has on the perceiver. In this way the viewer would be denied making the conceptual link between body and mind that lies at the core of the metonymy FACIAL EXPRESSIONS FOR EMOTION. Taylor in similar terms speaks of the strategy of "expressively neutral action." As he writes, "Kubrick's actors frequently adopt affectless facial expressions that are nearly impossible to scan in order to intuit identifiable mental states." 1182001 is perhaps the clearest personification of this strategy. When astronaut Poole (Gary Lockwood) celebrates his birthday with a long-distance video message from his parents, he reacts to it with complete apathy (figure 3.47A). Similarly, Falsetto has compared Ryan O' Neal's performance of Barry to 
that of a "mannequin," one who "lacks interiority" and whose physical movements are "deliberately slow, artificial and stylized." 119 Taylor cites in this regard the climatic pistol dual with his stepson, Lord Bullingdon, as an exemplary case (figure 3.47B), with Barry registering "no discernible reaction whatever to the distress of his nemesis, even as his peers avert their eyes from the vomiting dualist in disgust." ${ }^{120}$ Often this lack of expression in one performance is further enlarged by virtue of the abundance of expression in one's other performance. Here one may cite Carnicke's exquisite analysis of the stylistic distinction between Cruise's and Kidman's performances in Eyes Wide Shut. As a way of illustrating this distinction, she turns to a description of the scene in which Alice confesses her desire for another man:

Cruise maintains an unchanging look and pose [figure 3.47C]. His face has already become the inexpressive mask he will later wear. Cruise accomplishes this feat by doing literally nothing. In contrast, Kidman's face changes rapidly with the story she tells and in reaction to her husband. Her high level of interactivity is naturalistically embedded in the emotional situations and relationships through which her character moves. ${ }^{121}$

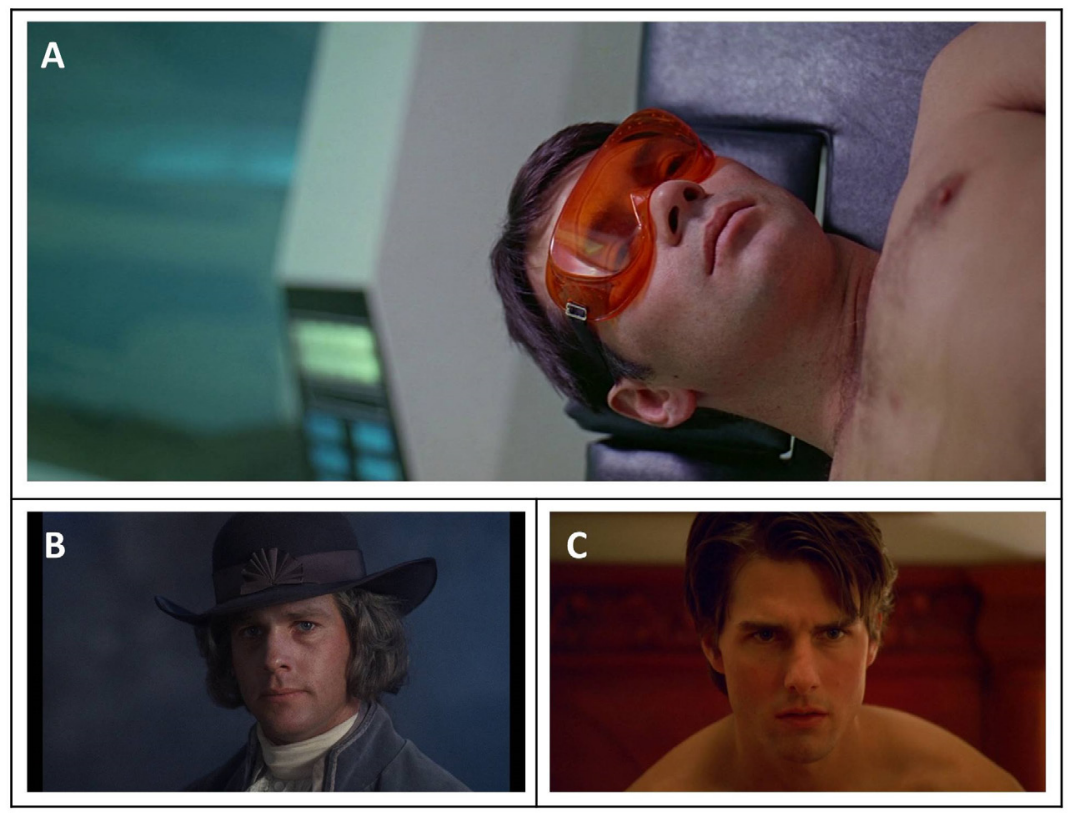

Figure 3.47. Expressively neutral action in A, 2001, B, Barry Lyndon, and C, Eyes Wide Shut.

\section{Conclusion}

The goal of this elaborative chapter was to establish the conditions under which the medium of film can elicit the cognitive tools of embodied meaning-making, as they were elucidated in the previous chapter. This task was divided into two parts. The first part comprised a discussion of how film style can give rise to the same kind of 
dynamic image-schematic structures that were responsible for structuring the concept of mental causation in language. The second part comprised a discussion of the role of bodily performance in eliciting the abstract target domains of mental causation. Consequently, the next logical step is to demonstrate how the films of Kubrick, much in the same way as the linguistic expressions cited in the previous chapter, rely on these image schematic patterns in order to give form to the kind of stories of mental causation as they were identified in the first chapter. Exposing the richness of these metaphorical inferences will be the primary aim of the fourth chapter in which Kubrick, the filmmaker, will be revealed as a genuine artist of embodied and non-verbal meaning-making.

\section{Notes}

1. Arnheim, The Power of the Centre, xi.

2. Two important works in which Arnheim has developed this approach are Art and Visual Perception: A Psychology of the Creative Eye and Visual Thinking.

3. Arnheim, Visual Thinking, 254. See also Arnheim, “A Plea for Visual Thinking," 489-497.

4. Ibid., 254.

5. Arnheim's analysis of Vermeer's painting can be found in Visual Thinking, 270-271. For his analysis of Cézanne's painting, see Art and Visual Perception, 37-41.

6. Arnheim, Visual Thinking, 270.

7. Arnheim, Art and Visual Perception, 39.

8. Johnson, The Body in the Mind, 76-80.

9. Two works in which Arnheim's reservation toward cinema is manifested are Film as Art and The Power of the Center.

10. Arnheim, The Power of the Center, 214.

11. Arnheim, Film as Art, 7.

12. Higgins, "Deft Trajectories For the Eye," 113. See also the other contributions in this excellent volume.

13. Ibid., 113.

14. Bordwell and Thompson, Film Art.

15. Ibid., 49.

16. Ibid., 175.

17. Ibid., 175 .

18. Branigan, Projecting a Camera, 101. Polysemy stands in contrast to another type of ambiguity which is called homonymy. In this case "two words spelled in the same way possess unrelated, or at least very distant, meanings (thus, separate lexical entries)."

19. Ibid., 103-115.

20. Ibid., 103 .

21. Branigan suggests something similar when he writes: "Container schemata variously structure our thinking within the 15 domains of framing in film. Although every frame encloses like a 'container,' what is 'inside' (the contents) and the nature of the 'enclosure' (the criteria for the containing thing) are different for each of the 15 domains. The manner in which a container schema is applied to a domain will determine how inferences are drawn and conjectures made about what is framed." Ibid., 121-122.

22. Burch, Theory of Film Practice, 17.

23. Bordwell and Thompson, Film Art, 504.

24. Through its edges the frame thus actively defines what is visible for the viewer. For this reason, the frame is not a neutral border. As Bordwell and Thompson observe, "the frame imposes a certain vantage point onto the material within the image. ... From an implicitly continuous world, the frame selects a slice to show us, leaving the rest of the space off-screen." Ibid., 252, 258. 
25. Bordwell and Thompson, Film Art, 253-258.

26. For a good discussion of the aspect ratios of Kubrick's films, see also Appelt, “The Craft of Seeing”, 255-256.

27. This has erupted considerable consternation and controversy among the online DVD community. For a discussion, see also Bill Hunt's interview with Kubrick's long-time assistant Leon Vitali who supervised the high definition DVD transfers (Hunt, "Vintage Bits Interview").

28. The Making of The Shining, directed by Vivian Kubrick (1980; Burbank, CA: Warner Home Video, 2007), Blu-ray.

29. Johnson, The Body in the Mind, 80 .

30. Arnheim, Art and Visual Perception, Chap. 1.

31. Ibid., 13.

32. Ibid., 13-14.

33. Johnson, The Body in the Mind, 79-80.

34. Ibid., 79.

35. Arnheim, Art and Visual Perception, 6.

36. Johnson, The Body in the Mind, 80.

37. Arnheim, Art and Visual Perception, 23-26.

38. Bordwell and Thompson, Film Art, 262-263. Three other important aspects of framing that are here excluded, but that are equally important in influencing the balance of a visual scene are: (1) the angle of framing, (3) the level of framing, and (4) the height of framing. Following Bordwell and Thompson they may be defined as follows: The angle of framing is the position that the frame takes in relation to the object $\mathrm{X}$ inside the frame. The camera can look down at the object (a high-angle), be on the same level as the object (a straight-on angle), or can look up at the object (a low angle). The level of framing pertains to the gravitational forces governing the filmed material and the frame. If the framing is level, the horizon inside the frame will be parallel to the horizontal edges of the frame and perpendicular to the vertical edges of the frame. If the horizon is a diagonal line, the frame is canted. The height of framing relates to the distance of the camera above the ground. The material inside the frame is filmed at low (high) height when the camera is positioned close to (far from) the ground. Note that the height of framing does not necessarily coincide with the angle of framing. For instance, the camera can be at low height while the angle is straight-on.

39. These image schemas are included in Hampe, From Perception to Meaning, 2.

40. For a discussion of symmetrical compositions in Kubrick's photographic and filmic work, see Mather, Stanley Kubrick at Look Magazine, 237-241. As Lakoff has pointed out, the concept of symmetry can also be connected to the logic of the LINK image schema: "If A is linked to B, then B is linked to A." For his discussion, see Women, 274.

41. Johnson, The Body in the Mind, 81.

42. As Kolker has pointed out, the balance so naturally implied by a symmetrical composition may, in turn, be challenged by the type of lens that is used to shoot the composition. The author refers especially to Kubrick's use of a wide-angle lens that "tends to confound center and periphery in a way that unbalances the composition." He also connects this use to the narrative level: "Rather than balance, these compositions suggest a collapse; they signify not order but a fall into the abyss that awaits all his characters, a stasis in which the uncanny perfection of the image promises ultimate undoing, along with the characters caught within it." For a further discussion, see Kolker, A Cinema of Loneliness, 119.

43. Arnheim, Art and Visual Perception, 21-22.

44. Ibid., p. 20.

45. Boggs, The Art of Watching Films, 90.

46. Arnheim, Art and Visual Perception, 30.

47. Ibid., p. 30.

48. Wölfflin, "Ueber das Rechts und Links im Bilde," 82-96. See also Arnheim, Art and Visual Perception, 33-36.

49. Dewell, "Dynamic Patterns," 374. 
50. Johnson, The Body in the Mind, 46-47. Gibbs and Colston in similar terms speak of the BLOCKAGE-REMOVAL image schema transformation. For their discussion, see "Image Schema," 252.

51. Earlier in the film, however, we do see Jack, Danny's father, throwing around a tennis ball in the lobby of the Overlook Hotel. Could he, then, be the external source that sets the ball in motion?

52. For a discussion of the composition of this shot and the way it relates to the narrative content of the film, see also Mather, Stanley Kubrick at Look Magazine, 240 and Appelt, “The Craft of Seeing," 256-257.

53. Both schemas are dynamic extensions of the static NEAR-FAR schema. For a discussion of APPROACHING, see also St. Amant et al., "An Image Schema Language."

54. For a discussion of these techniques, see also Boggs, The Art of Watching Films, 90-91.

55. Ibid., 92.

56. Strick and Houston, "Interview with Stanley Kubrick," 64-65. See also Philips, Stanley Kubrick Interviews, 133.

57. Lakoff and Johnson, Philosophy in the Flesh, 185.

58. Ciment, Kubrick, 189-190.

59. Strick and Houston, "Interview with Stanley Kubrick," 64.

60. Lightman, "Photographing Stanley Kubrick's Barry Lyndon," 321.

61. For a discussion of this schema, see Lakoff, Women, 273-274.

62. Ibid., 273.

63. For a discussion of this technique, see also Bordwell and Thompson, Film Art, 284-289.

64. For a discussion of this match-cut from the perspective of embodiment and metaphor, see also Caracciolo, "Bones in Outer Space."

65. Ibid., 78.

66. Lakoff, "Image Metaphors," 219. For two more recent discussions, see Gleason, “The Visual Experience of Image Metaphor”; and El Refaie, "Reconsidering 'Image Metaphor"'

67. One linguistic example which Lakoff cites as a typical illustration of an image metaphor is the following expression of André Breton: "My ... wife whose waist is an hourglass." Ibid., 219.

68. Lakoff and Turner, More Than Cool Reason, 99.

69. Here, one may also observe the influence of what the Soviet filmmaker Sergei Eisenstein termed the "montage of attractions." Often used for expressive and conceptual purposes, this technique relates two separate images to one another on the basis of visual and contextual similarities.

70. Bordwell and Thompson, Film as Art, 313.

71. Ibid., 305. Named after the Sovjet filmmaker Lev Kuleshov whose experiments in cutting during the 1920's famously showed that when people viewed the same neutral face of an actor in juxtaposition with various other shots, they assumed not only that the actor's expression changed depending on what he was viewing, but also that the actor was reacting to things present in the same space as himself.

72. For a good summary of this problem, see Hyslop, "Other Minds."

73. Nagel, The View from Nowhere, 19-22.

74. Taylor, "Blind Spots and Mind Games," 9.

75. Ibid., 9-10.

76. Ibid., 10.

77. Ibid., 10 .

78. Ibid., 10.

79. Ibid., 10.

80. Bordwell, Staiger and Thompson, The Classical Hollywood Cinema, 3.

81. Taylor, "Blind Spots and Mind Games," 5.

82. Ibid., 6 .

83. Carnicke, "Screen Performance," 46. 
84. Ibid., 46.

85. Sherman, ed., Directing the Film, 191.

86. Carnicke, "Screen Performance," 46.

87. Gelmis, "The Film Director as Superstar," 103.

88. Carnicke, "Screen Performance," 53.

89. Falsetto, Stanley Kubrick, 149.

90. Carnicke, "Screen Performance," 53.

91. Clare, "Stanislavsky's System," 48.

92. The number of studies that use the (embodied) cognitive sciences to inform scholarly and practical explorations in theatre and performance studies is rapidly growing and include, among others, Blair, The Actor, Image, and Action; Blair and Cook, Theatre, Performance and Cognition; Clare, "Stanislavsky's System"; and Kemp, Embodied Acting.

93. Clare, "Stanislavsky's System," 52.

94. Anecdotes abound in this regard. For instance, it is rumoured that Shelley Duvall had to perform the baseball bat scene from The Shining 127 times. It still stands as a record for the most retakes of a single movie scene with spoken dialogue.

95. Gorchakov, Stanislavsky Directs, 353.

96. Cahill, "The Rolling Stone Interview," 201.

97. Pezzotta, Stanley Kubrick, 104-107.

98. Ibid., 105-106.

99. Kolker, A Cinema of Loneliness, 134.

100. Ibid., 135.

101. Ibid., 135 .

102. See also Carnicke, "Screen Performance," 53; Taylor, "Blind Spots and Mind Games," 17.

103. Ibid., 17.

104. Ibid., 5 .

105. Wittgenstein, Philosophical Investigations, 131.

106. Ekman's work can be situated within a research history that began with the publication of Darwin's book The Expression of the Emotions in Man and Animals (1872/1998). For a good discussion of the history of facial expression research, see Frank, "Facial expressions," 5230-5234.

107. Ekman and Friesen, Unmasking the Face.

108. For a good discussion, see also Kohler et al., "Differences in Facial Expressions," 235-244.

109. Bordwell and Thompson, Film Art, 264. For a good conceptual description of the elements of the POV shot, see Branigan, "Formal Permutations of the Point-of-View Shot," 54-64.

110. Taylor, "Blind Spots," 23.

111. Ibid., 23 .

112. Ibid., 23. See also, for example, Nolan, "Seeing is Digesting," 192.

113. Falsetto, Stanley Kubrick, 161.

114. Greene, "Stephen King."

115. Taylor, "Blind Spots and Mind Games," 19.

116. Ibid., 19.

117. Falsetto, Stanley Kubrick, 163.

118. Taylor, "Blind Spots and Mind Games," 22.

119. Falsetto, Stanley Kubrick, 154-157.

120. Taylor, "Blind Spots and Mind Games," 22.

121. Carnicke, "Screen Performance," 60. 